\title{
Microfluidic Gradient Device for Studying the Mesothelial Cells' Migration and Effects of Carbon Nanotubes Chronic Exposure
}

\author{
Hanyuan Zhang
}

Follow this and additional works at: https://researchrepository.wvu.edu/etd

\section{Recommended Citation}

Zhang, Hanyuan, "Microfluidic Gradient Device for Studying the Mesothelial Cells' Migration and Effects of Carbon Nanotubes Chronic Exposure" (2014). Graduate Theses, Dissertations, and Problem Reports.

7360.

https://researchrepository.wvu.edu/etd/7360

This Thesis is protected by copyright and/or related rights. It has been brought to you by the The Research Repository @WVU with permission from the rights-holder(s). You are free to use this Thesis in any way that is permitted by the copyright and related rights legislation that applies to your use. For other uses you must obtain permission from the rights-holder(s) directly, unless additional rights are indicated by a Creative Commons license in the record and/ or on the work itself. This Thesis has been accepted for inclusion in WVU Graduate Theses, Dissertations, and Problem Reports collection by an authorized administrator of The Research Repository @ WVU. For more information, please contact researchrepository@mail.wvu.edu. 
Microfluidic Gradient Device for Studying the Mesothelial Cells' Migration and Effects of Carbon Nanotubes Chronic Exposure

by

Hanyuan Zhang

Thesis submitted to the Benjamin M. Statler College of Engineering and Mineral Resources at West Virginia University in partial fulfillment of the requirements

for the degree of

Master of Science

in

Electrical Engineering

Approved by

Yuxin Liu, Ph.D., Chair

Thirimachos Bourlai, Ph.D.

Xian-An Cao, Ph.D.

Lane Department of Computer Science and Electrical Engineering

\author{
Morgantown, West Virginia
}

2014

Keywords: Microfluidics, gradient device, cell migration, single walled carbon nanotubes, human plural mesothelial cells

Copyright 2014 Hanyuan Zhang 
UMI Number: 1555329

All rights reserved

INFORMATION TO ALL USERS

The quality of this reproduction is dependent upon the quality of the copy submitted.

In the unlikely event that the author did not send a complete manuscript and there are missing pages, these will be noted. Also, if material had to be removed, a note will indicate the deletion.

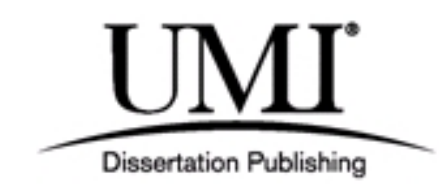

UMI 1555329

Published by ProQuest LLC (2014). Copyright in the Dissertation held by the Author.

Microform Edition () ProQuest LLC.

All rights reserved. This work is protected against unauthorized copying under Title 17, United States Code

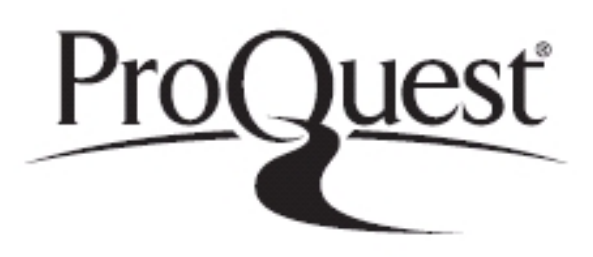

ProQuest LLC.

789 East Eisenhower Parkway

P.O. Box 1346

Ann Arbor, MI 48106 - 1346 


\section{Abstract}

Microfluidic Gradient Device for Studying the Mesothelial Cells' Migration and Effects of

Carbon Nanotubes Chronic Exposure

Hanyuan Zhang

Cell migration is one of the crucial steps in many human physiological events and diseases, including cancers. Recent studies have shown that carbon nanotubes (CNTs), like asbestos, can induce accelerated cell growth and invasiveness that contribute to their mesothelioma pathogenicity. Malignant mesothelioma is a very aggressive tumor that develops from cells of the mesothelium, and is most commonly caused by exposure to asbestos. CNTs have similar structure and mode of exposure to asbestos. This has raised a particular concern regarding the potential carcinogenicity of CNTs, especially in the pleural spaces, which are key target tissues for asbestos-related diseases.

In this thesis, a passive diffusion based microfluidic device that generates stable gradient is developed to study the migration of human lung mesothelial cells upon long-term exposure (4 months) to sub-cytotoxic concentration $\left(0.02 \mu \mathrm{g} / \mathrm{cm}^{2}\right)$ of single walled CNTs (SWCNTs). During the migration, we observed that the cell morphology changed from a flattened shape to a spindleshape prior to the migration after the cell sensed the gradient. The migration of chronic SWCNTs exposed mesothelial cells was conducted under different fetal bovine serum (FBS) concentration gradients, and the velocities of cell migration and number of migrated cells were extracted and compared. Results showed that chronic SWCNT exposed mesothelial cells were more aggressive compared to non-CNTs treated cells with FBS concentration of $5 \%$ and $10 \%$ in terms of migration velocity. The SWCNT exposed cells were less aggressive under the FBS concentration of $15 \%$ and $20 \%$. The method described here allows simultaneous detection of cell morphology and migration under chemoattractant gradient conditions. It also allows for real time monitoring of cell motility that resembles in vivo cell migration. 


\section{Contents}

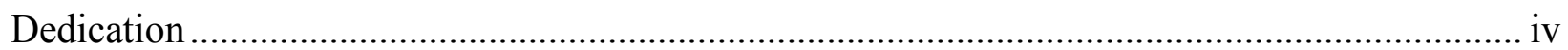

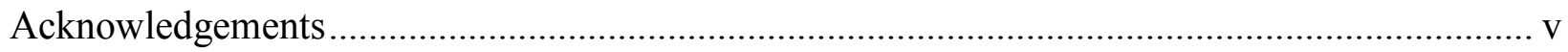

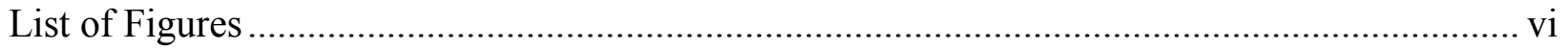

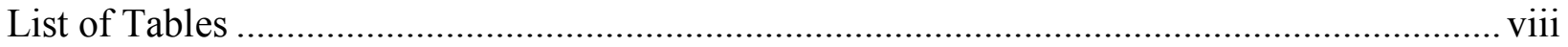

Chapter 1. Cell Migration Review ..................................................................................... 1

1.1 What Are Cell Migration and Chemotaxis............................................................. 1

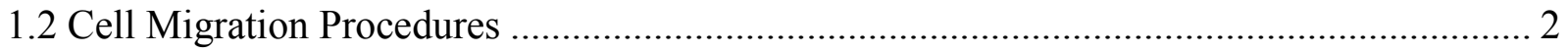

1.3 Conventional Assays for Studying Cell Migration ..................................................... 3

Chapter 2. Microfluidic Gradient Device Based Applications ................................................ 8

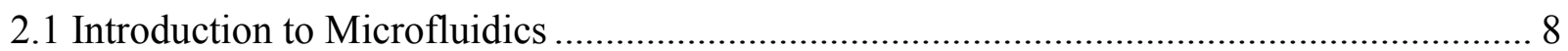

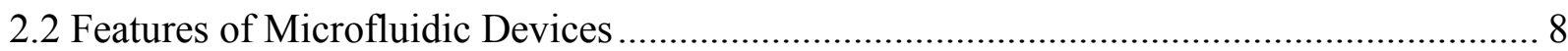

2.3 Principles of Microfluidic Gradient Generators....................................................... 11

2.4 Biological Applications of Microfluidic Gradient Devices ....................................... 12

2.5 Advantages of Studying Cell Migration with Microfluidics........................................ 17

Chapter 3. Microfluidic Device Fabrication ........................................................................ 19

3.1 Polymer Based Soft Lithography ...................................................................... 19

3.2 Chrome Mask Fabrication ................................................................................. 22

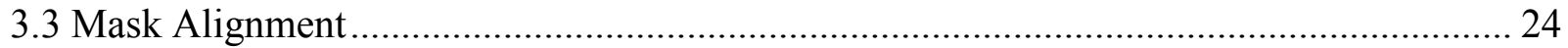


4.1 Why Study Pleural Mesothelial Cells ..................................................................... 27

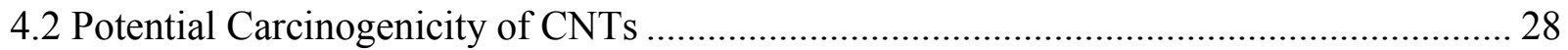

4.3 Studies on Mesothelial Cells Migration ...................................................................... 30

Chapter 5. Microfluidic Device For Gradient Generation and Cell Viability ........................... 32

5.1 Perfusion Based Microfulidic Gradient Device ................................................... 32

5.2 Pseudo-perfusion Based Microfluidic Gradient Device........................................... 34

5.3 Diffusion Based Microfluidic Gradient Device ......................................................... 35

5.4 Functional Device Design and Fabrication ............................................................. 38

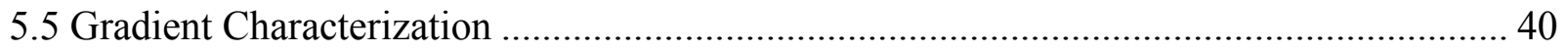

Chapter 6. Experiment Methods ......................................................................................... 42

6.1 Cell Culture and Chronic SWCNTs Exposure ......................................................... 42

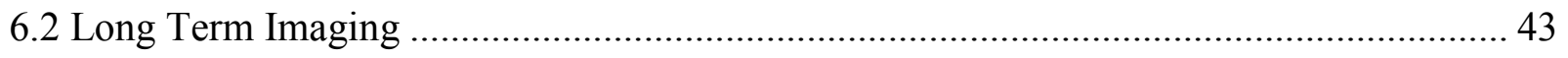

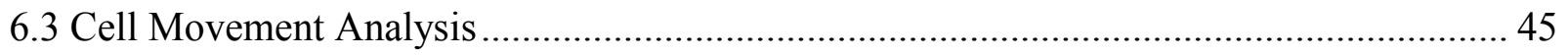

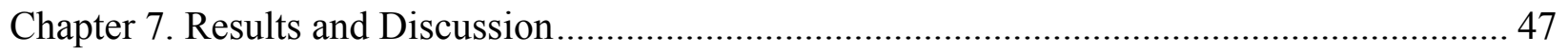

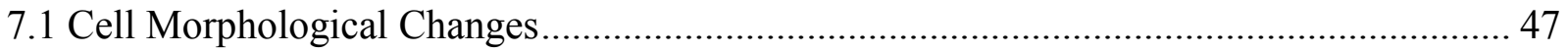

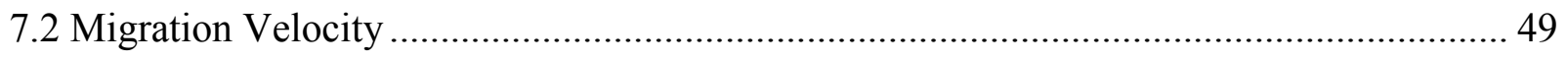

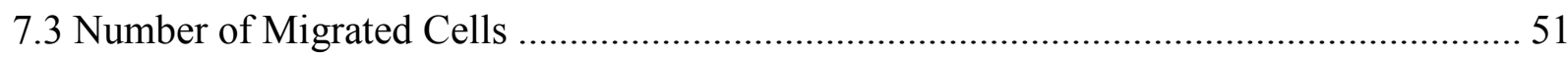

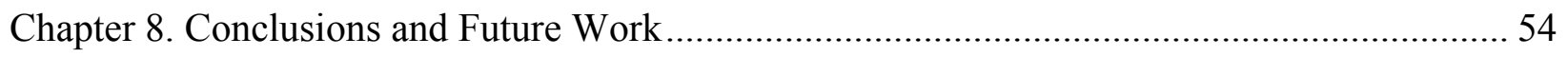

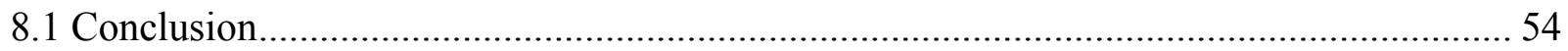




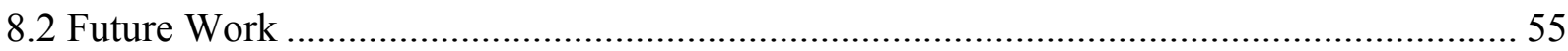

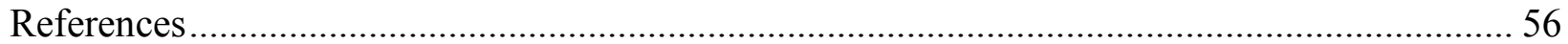




\section{Dedication}

This thesis is dedicated to my parents and my girlfriend. Thank you very much for all your support and encouragement. 


\section{Acknowledgements}

First and foremost I would like to express my sincere gratitude to my advisor Dr. Yuxin Liu for the continuous support and encouragement. Her patience, motivation and immense knowledge helped me all the time during my Master's study and research. One simply could not ask for a better advisor.

My gratitude also goes to the rest of my thesis committee: Dr. Thirimachos Bourlai and Dr. Xian-An Cao, for their guidance and insightful comments in the course work and my thesis.

My gratitude extends to Dr. Warangkana Lohcharoenkal for the information and guidance in cell preparation.

I would like to thank Dr. Kolin Brown, Mr. Harley Hart for their great help in cleanroom training and microfabrication.

I thank all members in the MICRoChip lab: Mr. Xiang Li, Mr. Zhouchun Huang, Mr. Ruizhi Zhong and Miss. Bhargavi Thotakura for their guidance, collaboration and all the fun we had in the past two years. I will always miss the time we spent together.

Last but not least, I would like to thank my parents for all the supports. 


\section{List of Figures}

Figure 1. Schematic view of epithelial to mesenchymal transition (EMT) and metastasis [6]. A tumor has a population of cells that have undergone EMT. These cells are now able to migrate freely, by entering the circulatory system. Upon reaching their final destination, the cells undergo the reverse MET program and form a secondary tumor at a distant site. ............................... 1

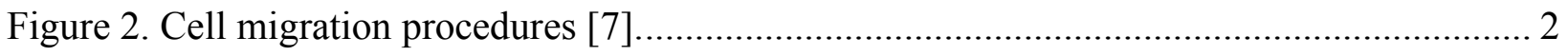

Figure 3. Conventional assays. (A) Schematic view of Boyden chamber. It consists of a chamber with the cell media, a porous membrane and a large chamber with chemoattractant. (B) Dunn chamber [19]. It consists of a glass cover slip and two concentric annular wells on a glass slide. (C) Zigmond chamber [20]. It consists of two parallel channels and a glass bridge that are etched into a glass slide. A cover slip is placed on top of the channels and bridge for cell seeding. (D) Schematic view of wound healing process and adaption to multiple well plates [23]. It involves the creation of a wound through a cell monolayer. The wound is healed by cell migration and proliferation. To get a high throughput result, this method is often integrated with multiple well plates. (a) Cell monolayer. (b) Creation of wound. (c) Cell migration to heal the wound. (d) 8500 well plate. (e) Producing wounds with consistent shape and position within each well with a 96 well pin array. (f) Images with 25 wells stained for filamentous actin. (E) Schematic drawing of Teflon fence used for cell migration studies [15]. Cells are seeded in the center well formed by Teflon fence. The fence is removed when a cell monolayer is formed. Cells are cultured continuously for migration assessment. (F) Schematic view of agarose assay. Cells in small wells or parallel channels can migrate in or under the semi-solidified agarose layer towards the higher concentration of chemoattractant. (a) Agarose assay with small wells cut into agarose layer. (b) Agarose assay with connected parallel channels cut into agarose layer. (G) Microfluidic device 
integrated with cellular impedance sensing [21]. The substrate is electrode that carries weak alternating current. Cell attachment and migration can cause electric impedance change, which is recorded as a function of time. (a) Microfluidic device integrated with electrodes and circuits. (b) Schematic illustration of electrode array. (c) Cross-section view of the sensor chip. (d) A local enlarged photo of the electrode. (H) Micropipette-based assay [22]. Electrophysiology micropipettes mounted in a micro controller that is positioned close to cells in a culture dish. The micropipette is filled with chemoattractant and placed in the cell media. A precisely controlled gradient can be formed by pneumatically ejecting the chemoattractant or letting the chemoattractant passively diffuse from the micropipette tip to the cell media. 4

Figure 4. The optical micrograph that shows the laminar flow. Two different dyed aqueous streams flow in parallel without turbulent mixing [30] 9

Figure 5. Perfusion based microfluidic gradient generator. (A) Design of the chamber, verified by COMSOL modeling. The chamber was used to make counter gradients of two chemokines. (B) Measurements of red fluorescent dyes in the channel. (C) Measurements of green fluorescent dyes in the channel. (D) Comparison between modeled (dashed line) and measured profiles [32].

Figure 6. Schematic view of the diffusion based microfluidic gradient device and its chemical gradient profile. (A) A fluorescein solution with a known concentration was continuously flowed in the chemo-effector channel and similarly the buffer solution was continuously flowed in the buffer channel at a rate of $5 \mu \mathrm{Lmin}^{-1}$. (B) Fluorescent images of the center channel were obtained and analyzed [42]. 12

Figure 7. Perfusion based microfluidic device and gradient profiles [40]. (A) Photograph showing a premixing microchannel network generating gradients of green and red dyes. (B)-(D) 
Gradients of Fluorescein isothiocyanate (FITC) observed at the outlet channel region at flow rates of $1 \mathrm{~mm} / \mathrm{s}, 10 \mathrm{~mm} / \mathrm{s}, 100 \mathrm{~mm} / \mathrm{s}$ respectively with dye delivered only to the center input channel. (E)-(G) Linear and parabolic gradients of FITC generated with different concentrations of three inlet solutions. 13

Figure 8. Universal gradient generator. (A) Scanning electron micrograph that showed 8 levels of flow dividers that controlled lateral transport of chemical species. (B) Fluorescence image that showed the resulting FITC distribution. Scale bar is $500 \mathrm{~mm}$. 14

Figure 9. Perfusion based microfluidic gradient device that switches gradient direction using multiple syringe pumps [46]. (A) Schematic view of a microfabricated switched gradient device with dual two-syringe pumps. (B) Chemokine gradient formed by running Pump I. (C) Switched chemokine gradient formed by stopping Pump I and running Pump II. The white arrows in (B) and $(\mathrm{C})$ indicate the flow direction in the main channel. 15

Figure 10. Gradient generator that uses hydrogel and microfluidic channels [40]. (A) Schematic diagram showing layers of gel and PDMS of the microfluidic device. (B) Various microfluidic channels patterned onto the bottom layer of the device. (C) Calculated (red lines) and empirical concentration profiles with various monotonic and complex shapes. 16

Figure 11. The schematic view of the device showing the open architecture of the cell culture/gradient chamber [48]. 16

Figure 12. Ladder chamber devices and their gradient profiles [50]. (A) Ladder chamber devices with different microchannels. (B) Various gradient profiles are achieved by different microchannels. 17

Figure 13. The fabrication processes for PDMS based microfluidic devices. Negative photoresist (SU-8) is used for the demonstration. (A) The wafer is cleaned with acetone, methanol and 
rinsed with DI water. (B) A layer of photoresist is spun-coated on the wafer. (C) A film mask was brought to an intimate contact to the photoresist layer, then, they are exposed to a UV light to transfer the pattern on the film mask to the photoresist layer. (D) Undesired photoresist is washed off by photoresist developer to get the transferred pattern on the wafer. (E) A layer of PDMS is poured on the wafer mold. The PDMS layer is cured in oven. (F) After punching holes, the cured PDMS slab is bonded onto a glass substrate with oxygen plasma............................... 20 Figure 14. Laurel technologies 400 spinner. It supports substrates from $10 \mathrm{~mm}$ to 6 inches. The maximum speed is $8000 \mathrm{rpm}$. Multiple steps with different speed, acceleration and spinning time can be programmed, saved and retrieved. 21

Figure 15. OAI LS30 UV Flood Exposure System. It provides a uniform beam of UV light (365 $\mathrm{nm})$ in a 5-inch diameter exposure area for photolithography processing. During exposure, the system was set to constant intensity. After exposure, it was set to constant power. 22

Figure 16. The film masks for the two layers wafer mold. For each film mask, only one pattern and four alignment markers were shown in this figure. (A) Patterns on the first layer of the film mask. (B) Patterns on the second layer of the film mask. The red square was the opening. (C) The alignment markers on the two films were precisely aligned. 23

Figure 17. Karl Suss MJB3 mask aligner. It is used for patterning multiple layers of photosensitive polymer with UV light. 24

Figure 18. Intensity meter and holders [53]. (A) Karl Suss 1000 UV intensity meter and probe. (B) Mask holder. (C) Sample holder and mask holder grooves on mask aligner. (D) Put probe on sample holder and measure UV intensity. 25

Figure 19. Types of Mesothelium [61]. Pleural mesothelioma (red area) surrounds lungs and lines chest cavity. Peritoneal mesothelioma (blue area) covers bulk of abdominal organs and 
provides support and allowing movement. Pericardial mesothelioma (green area) lines the heart. Testicular mesothelioma surrounds male internal reproductive organs, mesothelioma of uterine serosa covers female internal reproductive organs.

Figure 20. Carbon nanotube structures structure and scanning electron microscopy (SEM) images [65]. (A) Structure of SWCNT, (B) Structure of MWCNT. (C) SEM micrograph of a bundle of MWCNTs [69]. (D) SEM micrograph of synthetic tremolite asbestos [70]. 29 Figure 21. Perfusion based microfluidic gradient device. (A) Fabricated device. (B) Structure of observation area. Numbers along the observation channel help to mark multiple positions......... 33 Figure 22. Comparison of cell adhesion at the 5th hour between the perfusion based microfluidic gradient device and static microfluidic gradient device. (A) Cells in the perfusion based gradient device at the $5^{\text {th }}$ hour. Most cells failed to adhere to the substrate because of the shear stress caused by the perfusion flow. (B) Cells in a static gradient device at the $5^{\text {th }}$ hour. All cells were alive and healthy. Some cells have turned into spindle-shape. The rest of cells turned into spindle-shape at the $6^{\text {th }}$ hour. 33

Figure 23. Pseudo-perfusion based microfluidic gradient device. (A) Fabricated device. (B) Structure of the observation area. Small barriers between the side channels and middle channels helped to confine cells in the middle channel. 34

Figure 24. The gradient profile of the pseudo-perfusion based microfluidic gradient device. (A) Fluorescence image showing a stepped gradient. (B) The normalized intensity profile. This profile showed that a linear gradient with a narrow width (approximately $100 \mu \mathrm{m}$ ) was formed between the stepped gradient. 35 
Figure 25. The static microfluidic gradient device. (A) Fabricated device. (B) Structure of the observation area. The rectangular barriers along the vertical migration channels confined cells in

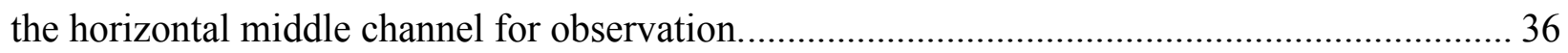
Figure 26. FITC intensity gradient profiles at different $5^{\text {th }}, 7^{\text {th }}, 9^{\text {th }}$ and $11^{\text {th }}$ hour. The profiles showed that the gradient was not stable. 37

Figure 27. Cell distribution in the static gradient device at the $6^{\text {th }}(\mathrm{A})$ and $24^{\text {th }}(\mathrm{B})$ hour. Cells were alive and healthy during the experiment. However, random cell migration was observed because of the non-stable gradient. 37 Figure 28. Microfluidic gradient device. (A) Two devices fabricated and bonded on one glass slide. One is for the control group test, the other is for the CNTs treated group of cells. (B) Image shows the cell receiving chamber, the migration channels, and the cell seeding chamber, respectively. (C) Schematic view of the cross section of the device shows different heights of the cell chambers and migration channels. 38

Figure 29. (A) Fluorescence image shows the gradient across one migration channel. Dashed white lines indicated the boundary of migration channel. Scale bar is $80 \mu \mathrm{m}$. (B) The time course of FITC-albumin gradient across the width of the channel. The normalized fluorescence intensities along the migration channel at different time were compared, showing a stable linear gradient through the migration channel. 40

Figure 30. Real-time imaging system. Devices were placed on the stage in the cage incubation system. The movement of the stage was controlled by the controller equipped with the Nikon NIS Element software. Cells and device structures were shown and recorded in the monitor. ... 43 Figure 31. Devices in a sealed Petri dish. The Petri dish will be fixed on the stage for imaging. 44 
Figure 32. Cell morphologies at adhesion, prior to migration, during migration and after migration. A to D are control cells, E to H are SWCNTs treated cells. Most of the cells are flattened shape after adhesion, then they gradually turn to spindle shape prior to migration. (A) Control cell morphology after the initial adhesion. (B) Control cell morphology prior to their migration ( $\sim 6$ hours after adhesion). (C) Control cell morphology during migration. (D) Control cell morphology after migration. (E) SWCNTs treated cell morphology after initial adhesion. (F) SWCNTs treated cell morphology prior to migration. (G) SWCNTs treated cell during migration.

(H) SWCNTs treated cell after migration. 48

Figure 33. Average velocities of cell migration under different FBS concentration gradient for both control and treated cell groups with standard error bars. P values are marked between same group and different groups 50

Figure 34. Large images showing cell distributions at the beginning and the end of the experiment. (A) At the beginning of the experiment, most cells were in the cell seeding chamber. A small portion of cells were in the migration channels. (B) After 24 hours, more cells were observed in the migration channels. Some cells have migrated through the migration channels to the cell receiving chamber. 52 Figure 35. Average number of migrated cells under different FBS concentration gradients for both control and treated cell groups. 52 


\section{List of Tables}

Table 1. Comparison between perfusion based microfluidic devices and diffusion based

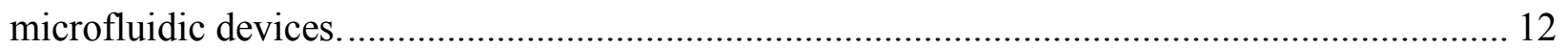

Table 2. Comparisons between microfluidic gradient devices and conventional assays for

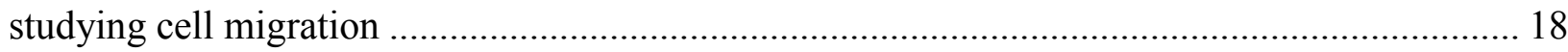




\section{Chapter 1. Cell Migration Review}

\subsection{What Are Cell Migration and Chemotaxis}

Cell migration is a central process in the development and maintenance of multicellular organisms. It refers to the phenomenon that cells will migrate in response to the soluble growth factors in various biological processes such as embryonic morphogenesis, cancer metastasis, tissue remodeling, wound healing, and inflammation $[1,2,3,4]$. Figure 1 shows an example of the cancer metastasis. The migrating cells are highly polarized with complex regulatory pathways that spatially and temporally integrate their component processes [5].

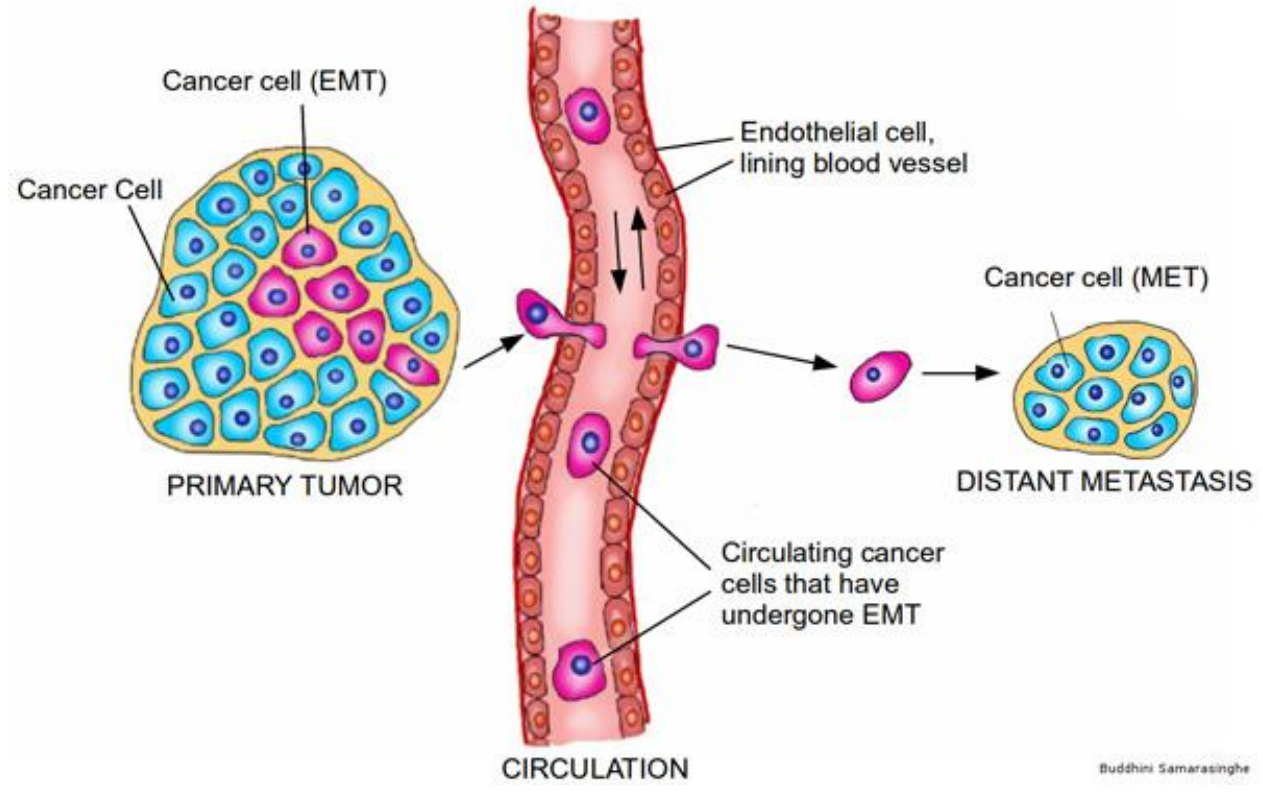

Figure 1. Schematic view of epithelial to mesenchymal transition (EMT) and metastasis [6]. A tumor has a population of cells that have undergone EMT. These cells are now able to migrate freely, by entering the circulatory system. Upon reaching their final destination, the cells undergo the reverse MET program and form a secondary tumor at a distant site. 
Cell migration can be random or directed. The directed cell migration is also referred as chemotaxis. Chemotaxis allows single cell or multicellular organism to find the environment that provides them with greatest supply and flee from poisons.

\subsection{Cell Migration Procedures}

Cell migration involves a coordinated series of molecular and physical events. As shown in Figure 2, generally, cells must acquire spatial asymmetry by polarization prior to their migration. The polarization is trigged by extracellular gradient. The polarization will lead to a series of morphological reactions, including reorganization of cytoskeleton to produce polarization and cellular forces, membrane extension, formation and stabilization of cell attachment, generation of contractile force and rear release. This process repeats as cells keep migrating [5].
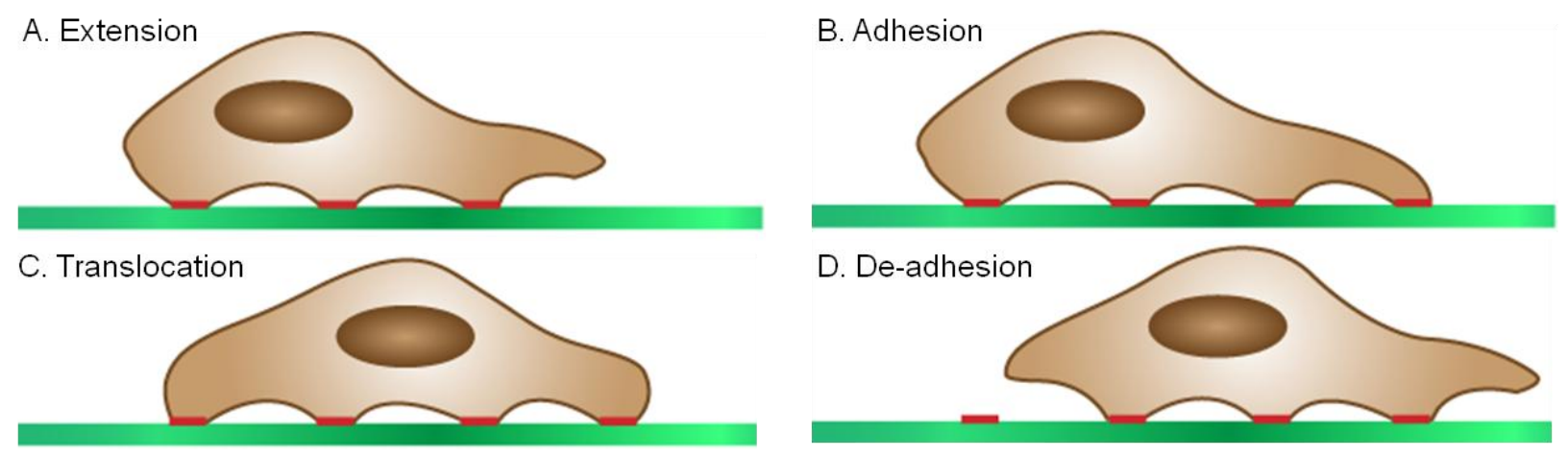

Figure 2. Cell migration procedures [7].

The migration process is driven by the protrusive force and the contractile force. The protrusive force is provided by polymerization of actin filaments and structural organization cross-linked with lattice or bundle $[8,9]$. The contractile force that leads the cell moving forward is generated behind the cell front. The contractile force depends partly on active myosin activity and involves separate mechanisms of force generation [10]. 


\subsection{Conventional Assays for Studying Cell Migration}

Conventional assays and techniques for studying cell migration and chemotaxis include Boyden chamber [11], Dunn chamber [12], Zigmond chamber [13], wound assay [14], Teflon fence assay [15], agarose assay [16], electric cell-substrate impedance sensing migration (ECIS) assay [17] and micropipette-based assay [18], as shown in Figure 3.

In Boyden chamber assay, two chambers are isolated by a porous membrane as a filter, as shown in Figure 3 (A). The chambers are inserted into a single well of multiwall plates. Cells are seeded on the porous membrane in the upper chamber and chemoattractant is loaded in the lower chamber. Because cells will migrate across the membrane, the pore size of the membrane should be properly chosen to enable active transmigration based on the size of cells. This assay is easy to use and has the capability of studying chemotaxis and chemokinesis, screening multiple compounds at different concentration [25].

The Dunn chamber is similar to the Zigmond chamber and it allows the behavior of cells in the linear concentration gradient to be observed with a light microscope directly [12]. As shown in Figure 3 (B), it consists of a glass cover slip with two concentric annular wells on a glass slide. The depth of the annular wells are about half of the thickness of the glass slide. The platform that separates the wells is called bridge. The height difference between the bridge and the surface of the glass slide is about $20 \mu \mathrm{m}$. This gap allows cells to migrate in the space formed by the bridge and the cover slip when a radially directed linear gradient is established by filling the inner well with control media and the outer well with the media of chemoattractant [19]. Dunn chamber can provide good optical properties and a stable gradient. 


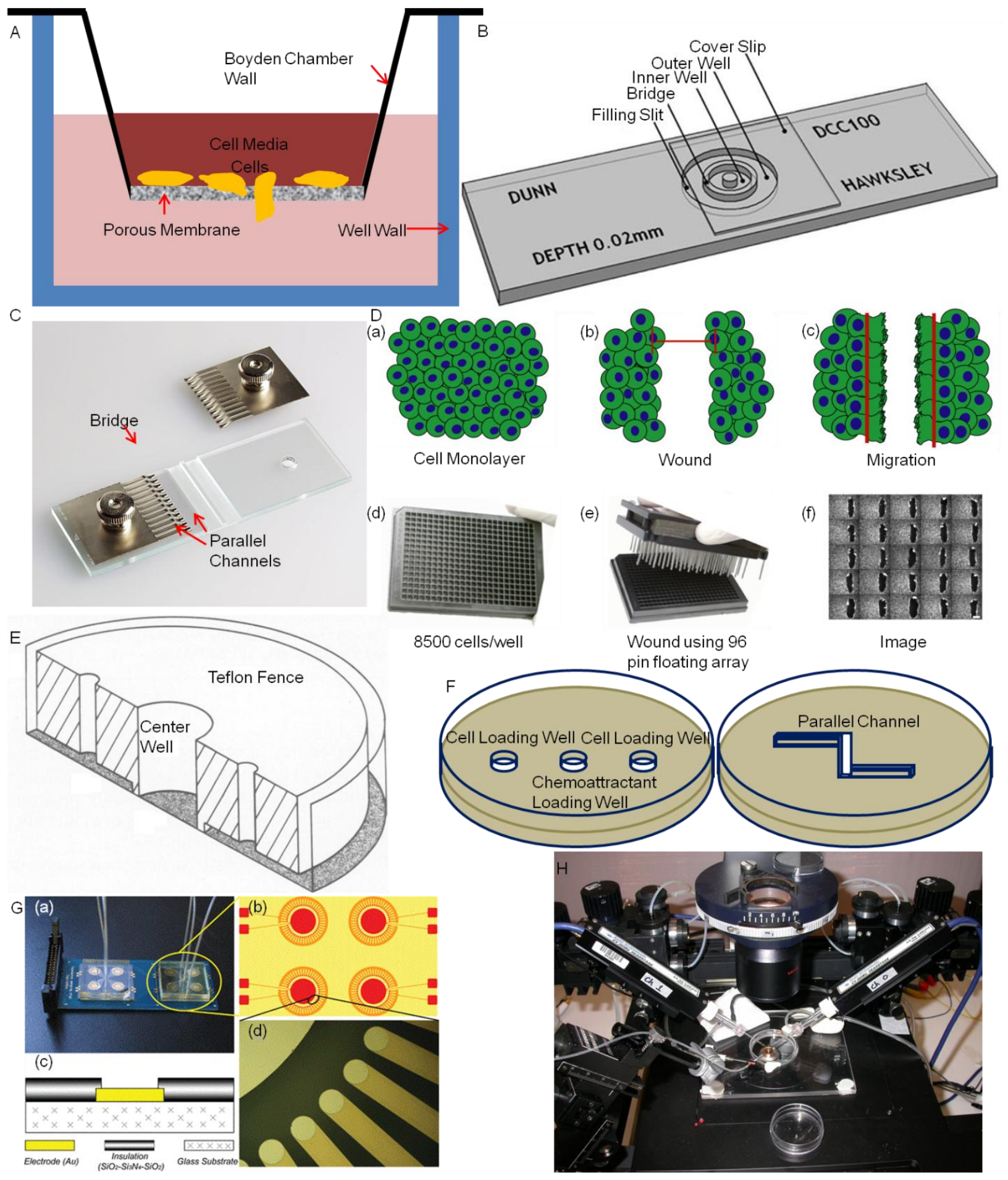

Figure 3. Conventional assays. (A) Schematic view of Boyden chamber. It consists of a chamber with the cell media, a porous membrane and a large chamber with chemoattractant. (B) Dunn chamber [19]. It consists of a glass cover slip and two concentric annular wells on a glass slide. (C) Zigmond chamber [20]. It consists of two parallel channels and a glass bridge that are etched into a glass slide. A cover slip is placed on top of the channels and bridge for cell seeding. (D) Schematic view of wound healing process and adaption to multiple well plates [23]. It involves 
the creation of a wound through a cell monolayer. The wound is healed by cell migration and proliferation. To get a high throughput result, this method is often integrated with multiple well plates. (a) Cell monolayer. (b) Creation of wound. (c) Cell migration to heal the wound. (d) 8500 well plate. (e) Producing wounds with consistent shape and position within each well with a 96 well pin array. (f) Images with 25 wells stained for filamentous actin. (E) Schematic drawing of Teflon fence used for cell migration studies [15]. Cells are seeded in the center well formed by

Teflon fence. The fence is removed when a cell monolayer is formed. Cells are cultured continuously for migration assessment. (F) Schematic view of agarose assay. Cells in small wells or parallel channels can migrate in or under the semi-solidified agarose layer towards the higher concentration of chemoattractant. (a) Agarose assay with small wells cut into agarose layer. (b) Agarose assay with connected parallel channels cut into agarose layer. (G) Microfluidic device integrated with cellular impedance sensing [21]. The substrate is electrode that carries weak alternating current. Cell attachment and migration can cause electric impedance change, which is recorded as a function of time. (a) Microfluidic device integrated with electrodes and circuits. (b) Schematic illustration of electrode array. (c) Cross-section view of the sensor chip. (d) A local enlarged photo of the electrode. (H) Micropipette-based assay [22]. Electrophysiology micropipettes mounted in a micro controller that is positioned close to cells in a culture dish. The micropipette is filled with chemoattractant and placed in the cell media. A precisely controlled gradient can be formed by pneumatically ejecting the chemoattractant or letting the chemoattractant passively diffuse from the micropipette tip to the cell media.

The Zigmond chamber is the first device that provides direct visualization of cell behavior within a chemoattractant gradient. As shown in Figure 3 (C), it consists of two parallel channels and a glass bridge. The parallel channels are etched into a glass slide, while the bridge is below the surface of the glass slide. There is a gap ( 3 to $10 \mu \mathrm{m})$ between the cover slip and the bridge, where cells seeded on the cover slip can migrate through the bridge when a gradient is established by filling one channel with chemoattractant media and the other channel with control media.

Wound assay involves the creation of a wound gap by scratching through a cell monolayer. The wound gap causes the disruption of cell-cell contacts and increases the concentrations of the growth factors at the wound margin. Cell monolayer will try to heal the wound by proliferation and migration, as shown in Figure 3 (D) [14]. The wound heals in a stereotyped fashion - cells polarize toward the wound, initiate protrusion, migrate, and close the wound [23]. By taking images with a constant time interval, cell migration and cell proliferation 
at different time can be observed and compared. Nowadays, the wound assay is often adapted to a multiple well plates to achieve a high throughput result. After seeding cells in a multiple well plates, characteristically sized wounds are created at each well by a pin array. Though wound assay should not be considered as a duplicate of cell migration in vivo, it is suitable for studying effects of ECM and other cells' migration in a simple and inexpensive way [24].

Teflon fence assay is the technology to confine cells in circular region within a Teflon fence, which is fitted in a culture dish. As shown in Figure 3 (E), cells of high density are plated into the center well. A central confluent monolayer is formed after a couple of hours (the specific time to form the monolayer depends on the cell type and the culture environment). Then the fence is removed and the dish is rinsed to remove any non-adherent cells. Cells in the dish are cultured continuously for the assessment of cell migration.

The agarose assay is a method to study directed cell migration to one or more chemoattractant sources. Small wells (or parallel channels) are cut into a layer of semi-solidified agarose on a substrate. Cells and chemoattractant are loaded into different wells or channels. Cells migrate towards the chemoattractant gradient in the semi-solidified layer or under the layer. Cell migration is then assessed by fixing and staining. Researchers are able to control positioning, timing and intensity of one or more chemoattractant signals with the agarose assay [25]. Figure 3 (F) shows a schematic view of the agarose assay.

The ECIS migration assay is a technique to quantitatively measure cell motion at nanometer level [17]. In this technique, substrates used for cell culture are electrodes carrying weak alternating current (AC) (usually in the frequency range from 1 to $40 \mathrm{kHz}$ ). A large change in the measured electrical impedance of the electrodes is observed when cells attach and spread 
on the electrodes. When the impedance is tracked as a function of time, the fluctuations are the direct measures of cell motion [17]. ECIS migration assay is often integrated with wound assay to achieve automatic migration monitoring and quantification. Figure $3(G)$ shows a microfluidic device integrated with cellular impedance sensing for cell migration study.

The micropipette-based assay involves a fine glass tip with an internal diameter of $1 \mu \mathrm{m}$ formed by heating and pulling axially a glass capillary. The micropipette is filled with the chemoattractant and the tip is positioned very close to cells. A radial gradient is formed at the micropipette tip by either pneumatically ejecting the media of chemoattractant that is controlled by a pneumatic pump. Alternatively, the media of chemoattractant can passively diffuse from the micropipette tip into the surrounding media. Figure $3(\mathrm{H})$ shows an electrophysiology micropipette mounted in a micro controller positioned close to cells in a culture dish.

Though these models have been widely adopted to study cell migration, they had their limitations. Cell migration in those models was confined in a two-dimensional (2D) substrate, which normally lacked the stable chemical gradient to induce directed cell migration, and mechanical simulation and interactions with other cells or ECM [26]. Most of these assays lack the ability of real-time monitoring of cell migration. Limited information about cell velocities and morphological changes during the migration can be extracted from these assays.

Their limitations can be overcome by microfluidic devices, which will be discussed in the next chapter. 


\section{Chapter 2. Microfluidic Gradient Device Based}

\section{Applications}

\subsection{Introduction to Microfluidics}

Microfluidics is the science and technology of systems that process or manipulate small

$\left(10^{-9}\right.$ to $10^{-18}$ Liters) amounts of fluids, using channels with dimensions of tens to hundreds of micrometers [27]. The advantages of microfluidics include small samples and reagents consumption, low power consumption, low cost, small dead volume, high throughput, parallel processing and short reaction time.

Emerged in the early 1980s, microfluidics has been used in the development of inkjet printheads, DNA chips, lab-on-a-chip technology, micro-propulsion and micro-thermal technologies. Key applications of microfluidics include continuous-flow microfluidics, dropletbased microfluidics, digital microfluidics, DNA chips (microarrays), molecular biology, evolutionary biology, microbial behavior, cellular biophysics, optics, acoustic droplet ejection and fuel cells [28].

\subsection{Features of Microfluidic Devices}

Laminar flow and large surface-area-to-volume ratio (SAV) are two important features of microfluidic devices.

Laminar flow occurs when a fluid flows in parallel layers without disruption between the layers, as shown in Figure 4 [29]. Flow patterns can be predicted with Reynolds Number $(R e)$, which is defined as the ratio of inertial forces to viscous forces, as shown in the following 
equation, where $\rho$ is the density of the fluid $\left(\mathrm{kg} / \mathrm{m}^{3}\right), v$ is the kinematic viscosity $\left(\mathrm{m}^{2} / \mathrm{s}\right), D$ is the hydraulic diameter $(\mathrm{m}), \mu$ is the dynamic viscosity of the fluid $(\mathrm{kg} /(\mathrm{m} \cdot \mathrm{s}))$.

$$
R_{e}=\frac{\rho v D}{\mu}
$$

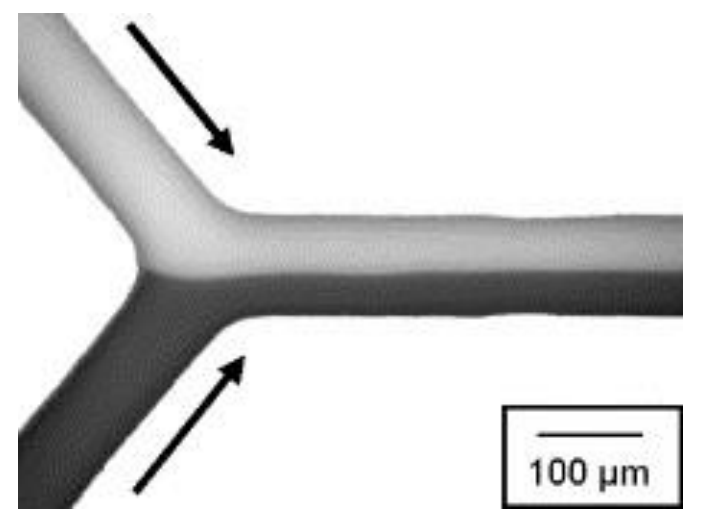

Figure 4. The optical micrograph that shows the laminar flow. Two different dyed aqueous streams flow in parallel without turbulent mixing [30].

The flow is laminar when $R e$ is smaller than 2300 , while the flow is turbulent when $R e$ is larger than 4000. Because of the micro-scaled channels and low flow rates, most microfluidic devices operate at the low $\operatorname{Re}[31]$, and flows in microfluidic devices are completely laminar. Thus microfluidic devices are capable of keeping multi-stream laminar flows separated for long travel distance and long time. Various microfluidic gradient generators have been designed based on the laminar flow feature. One example is shown in Figure 5. Each of the three flows in the inlet is separated into two branching channels and joined with another laminar flow to the next level. The difference among ratios of each flow at each branching channels becomes smaller and smaller as the flows go to next level. Finally a gradient is formed at the output channel where each tree branching channel contributes to a different percentage of the input fluids. 


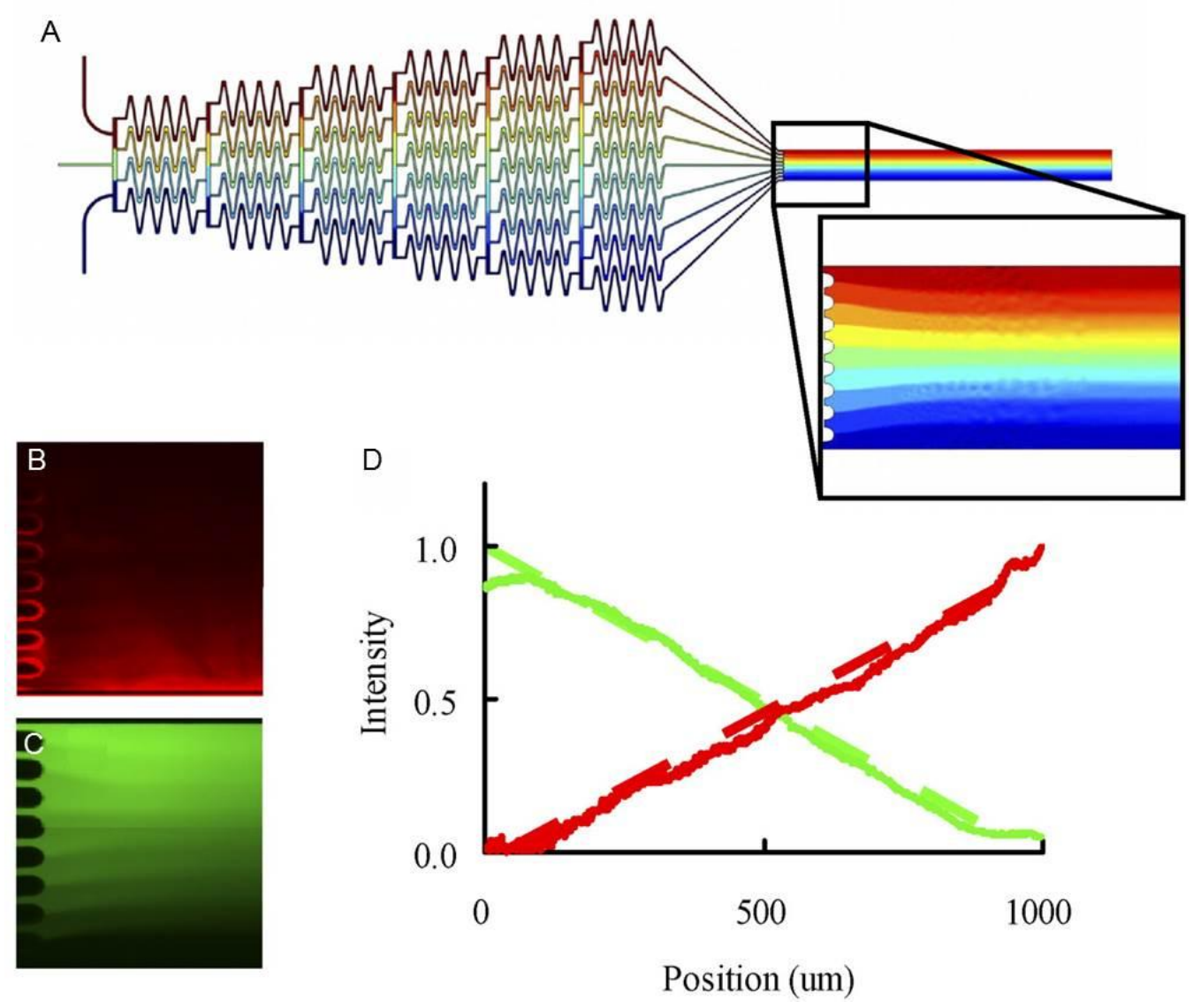

Figure 5. Perfusion based microfluidic gradient generator. (A) Design of the chamber, verified by COMSOL modeling. The chamber was used to make counter gradients of two chemokines. (B) Measurements of red fluorescent dyes in the channel. (C) Measurements of green fluorescent dyes in the channel. (D) Comparison between modeled (dashed line) and measured profiles [32].

$\mathrm{SAV}$ is an important factor for the mass transfer over reactive surfaces in microfluidic devices, which is central to explore and quantify biochemical reactions [33]. Compared to macroscale devices that have a relative small SAV, microfluidic devices have larger SAV by orders of magnitude, which make the surface phenomenon more dominant than volume factor. Large SAV has the benefits of heat/gas transfer, reducing lateral transfer and reaction time [34,35], cell attachment, growth, and proliferation. This makes capillary electrophoresis and high throughput immunoassays more efficient in microchannels. 


\subsection{Principles of Microfluidic Gradient Generators}

Various biochemical signals dissolved in or bound to the extracellular space are in the form of gradients [36]. The gradients can result in biological behaviors such as the directed cell migration. Because of its capabilities of manipulating soluble biochemical gradients and mimicking the cell microenvironment in vitro, microfluidic-based gradient devices have been proven effective in studying biological processes such as directed cell migration and geometric influence on cell survival [37].

Generally there are two types of microfluidic gradient devices according to the way of the gradient generation: perfusion based and diffusion based. The chemical gradients generated by perfusion-based devices utilize the properties of laminar flow, as shown previously in Figure 5. Because the structures of microfluidic devices are in the micrometer scale, fluids in microfluidic device are laminar flow, where streams of miscible fluids get mixed by diffusion across the interfaces without turbulent mixing [1]. Perfusion-based gradient generator has the advantages of generating precisely controlled stable gradients. However, the cells in such devices are exposed to a continuous shear flow. Shear stresses introduced by the flow can influence the cell migration and attachment $[38,39]$ and cause adverse effects. Gradients generated by diffusion based devices rely on the diffusive transport of signaling molecule across convection-free regions [40]. Shear stress is then avoided because no convection flow is involved in the establishment of the gradient, and the cells' migration will not be affected by shear stresses. The static gradient environment provided by diffusion based devices are suitable for many types of cells in which migration requires long period of time and cell adhesion is critical [41]. An example of diffusion based gradient generator is shown in Figure 6. Table 1 compares the properties of the perfusion based and diffusion based microfluidic gradient devices. 
A

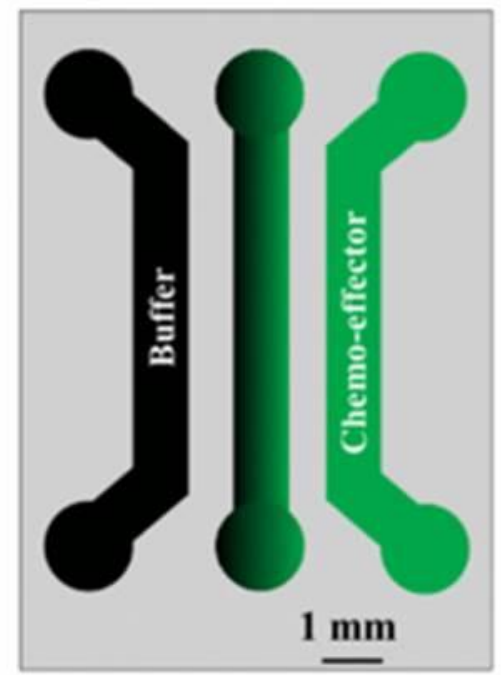

B

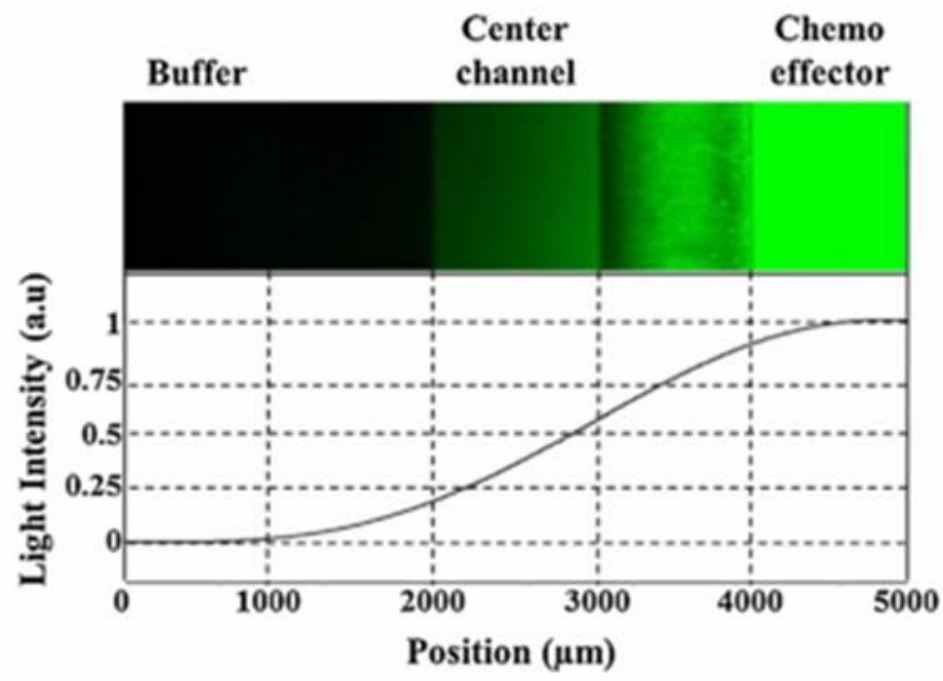

Figure 6. Schematic view of the diffusion based microfluidic gradient device and its chemical gradient profile. (A) A fluorescein solution with a known concentration was continuously flowed in the chemo-effector channel and similarly the buffer solution was continuously flowed in the buffer channel at a rate of $5 \mu \mathrm{Lmin}^{-1}$. (B) Fluorescent images of the center channel were obtained and analyzed [42].

Table 1. Comparison between perfusion based microfluidic devices and diffusion based microfluidic devices.

\begin{tabular}{|c|c|c|}
\hline Properties & Perfusion Based Devices & Diffusion Based Devices \\
\hline Gradient Establishment & Dynamic perfusion & Passive diffusion \\
\hline Shear Stress & Yes & No \\
\hline Gradient Duration & Long & Stable \\
\hline Gradient Stability & Stable & Yes \\
\hline Reproducible & Yes & \\
\hline
\end{tabular}

\subsection{Biological Applications of Microfluidic Gradient Devices}

Various platforms utilizing the microfluidic technologies have been developed to provide biological experiments with precisely controlled spatial and temporal gradients of biomolecules. 
The perfusion based microfluidic gradient generator shown in Figure 5 is first developed by Jeon et al [43]. By adjusting the flow rate and the concentrations of inlets solutions, different shapes of profiles are achieved as shown in Figure 7. Additionally, multiple parallelly aligned networks are developed to produce the saw tooth and the periodic gradient profiles [44].
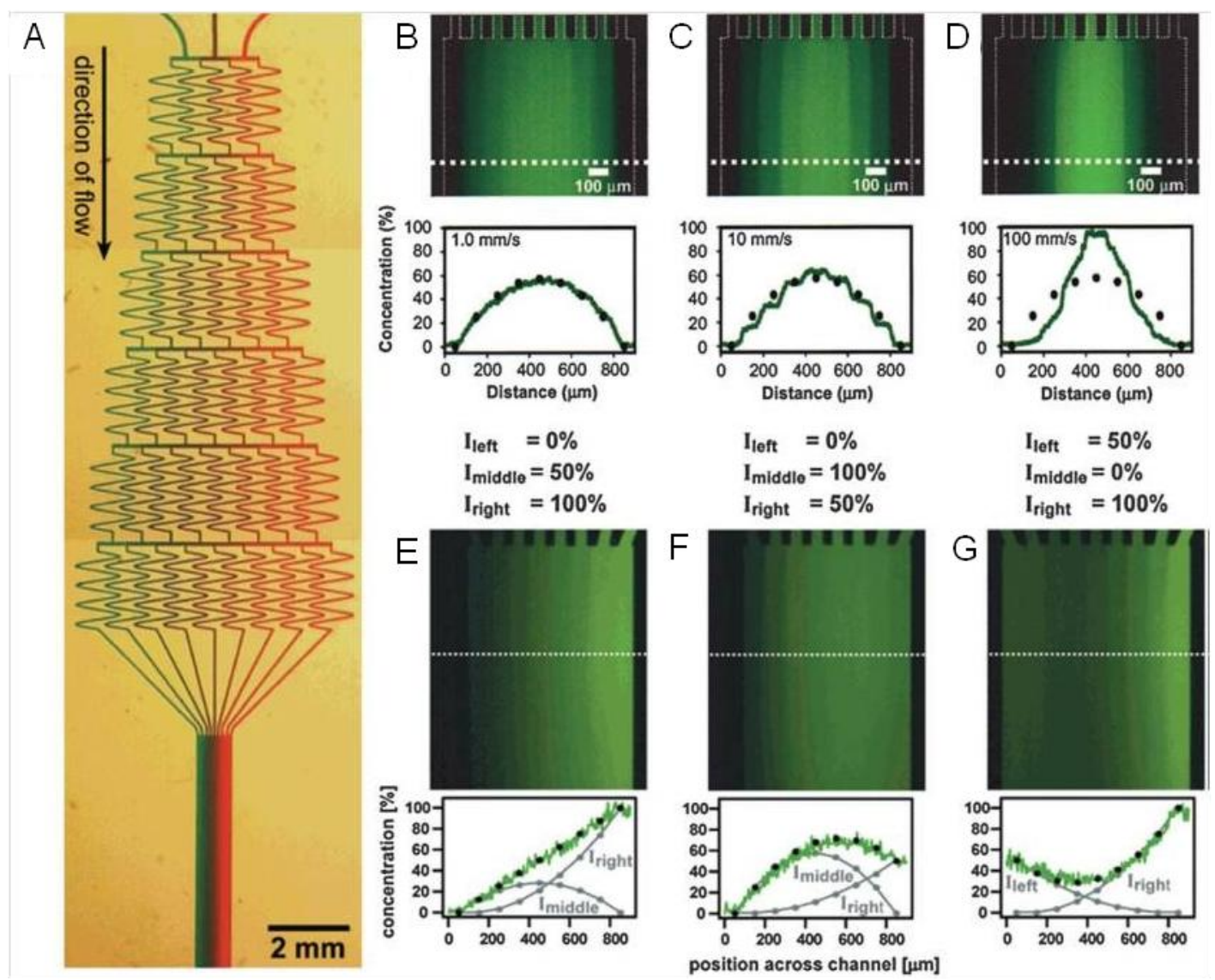

Figure 7. Perfusion based microfluidic device and gradient profiles [40]. (A) Photograph showing a premixing microchannel network generating gradients of green and red dyes. (B)-(D)

Gradients of Fluorescein isothiocyanate (FITC) observed at the outlet channel region at flow rates of $1 \mathrm{~mm} / \mathrm{s}, 10 \mathrm{~mm} / \mathrm{s}, 100 \mathrm{~mm} / \mathrm{s}$ respectively with dye delivered only to the center input channel. (E)-(G) Linear and parabolic gradients of FITC generated with different concentrations of three inlet solutions.

A universal gradient generator that can generate arbitrary monotonic gradients using flow dividers is developed by Irimia et al [45]. The flow dividers controlled splitting and mixing of flow streams by separating flows into defined volume ratios and controlling lateral transport of 
diffusing molecules, as shown in Figure 8. The position of the flow dividers can be determined by mathematical calculation to generate user-defined concentration profiles including power, exponential, error and cubic root functions [40].

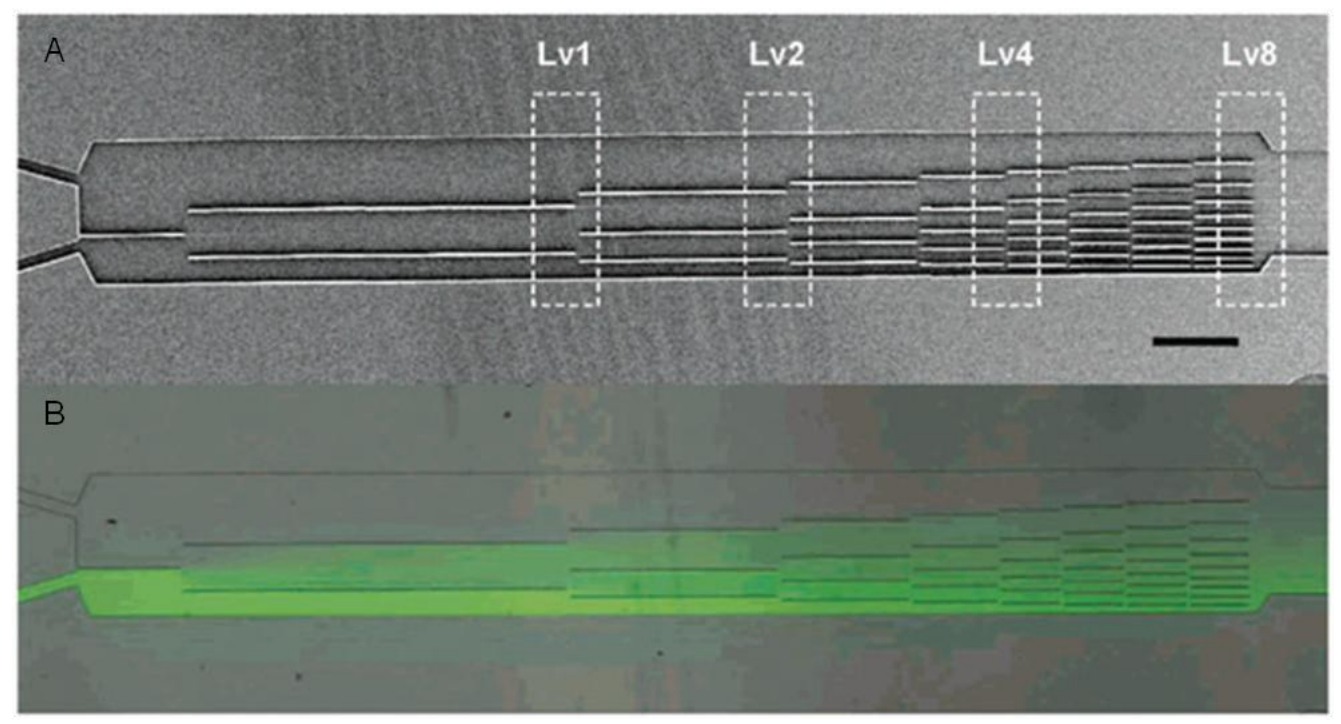

Figure 8. Universal gradient generator. (A) Scanning electron micrograph that showed 8 levels of flow dividers that controlled lateral transport of chemical species. (B) Fluorescence image that showed the resulting FITC distribution. Scale bar is $500 \mathrm{~mm}$.

An approach to switch gradient direction using multiple syringe pumps are developed by Liu et al [46]. As shown in Figure 9 (A), four tubing inputs were connected to syringes filled with the chemokine solution or the buffer solution alone. After filling the four segments of tubing with the solutions in the syringes quickly, one pump is kept running at $0.5 \mu 1 / \mathrm{min}$ to maintain a chemokine gradient that is high on the side of the channel of the top of Figure 9 (B). After 20 min running, the first pump is stopped and the second pump is running to generate a gradient with the high concentration on the side of the channel of the bottom of Figure 9 (C). This approach is used to quantify the chemotaxis gradient and the effects of a change in the direction of the gradient on the cell migration [46]. 
A design that generated stable gradients of complex and arbitrary profiles along flow free microfluidic channel is developed by $\mathrm{Wu}$ et al [47]. The device consists of a layer of porous hydrogel between two poly (dimethylsiloxane) (PDMS) layers, as shown in Figure 10. The top PDMS layer is embedded with two reservoirs for the chemoattractant solution and the buffer solution. A gradient is formed across the middle hydrogel layer by diffusion. The bottom PDMS layer is patterned with the user-defined microfluidic channels. The gradient profile of the chemoattractant in the device is determined by the shape of microfluidic channels.

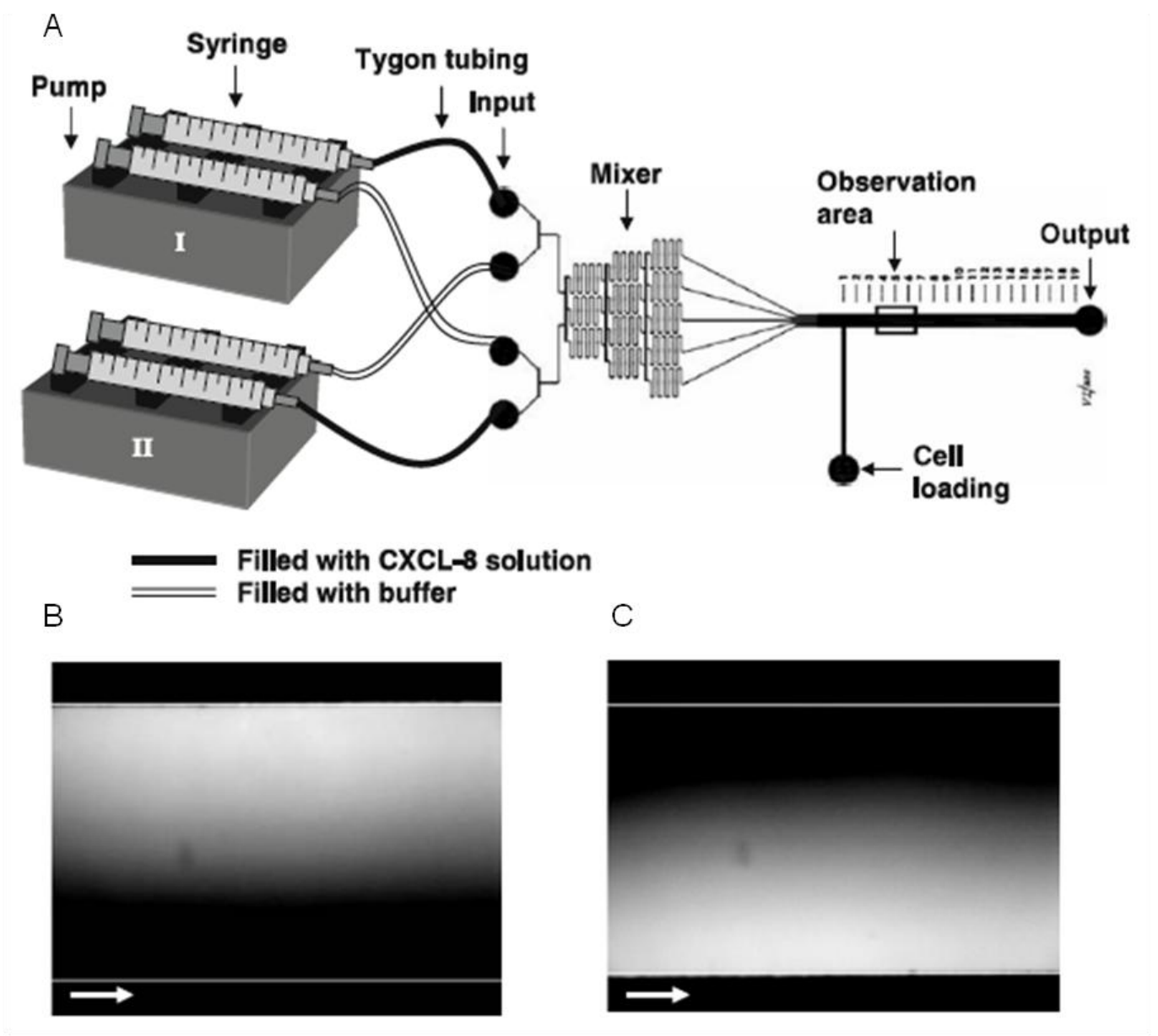

Figure 9. Perfusion based microfluidic gradient device that switches gradient direction using multiple syringe pumps [46]. (A) Schematic view of a microfabricated switched gradient device with dual two-syringe pumps. (B) Chemokine gradient formed by running Pump I. (C) Switched chemokine gradient formed by stopping Pump I and running Pump II. The white arrows in (B) and $(\mathrm{C})$ indicate the flow direction in the main channel. 


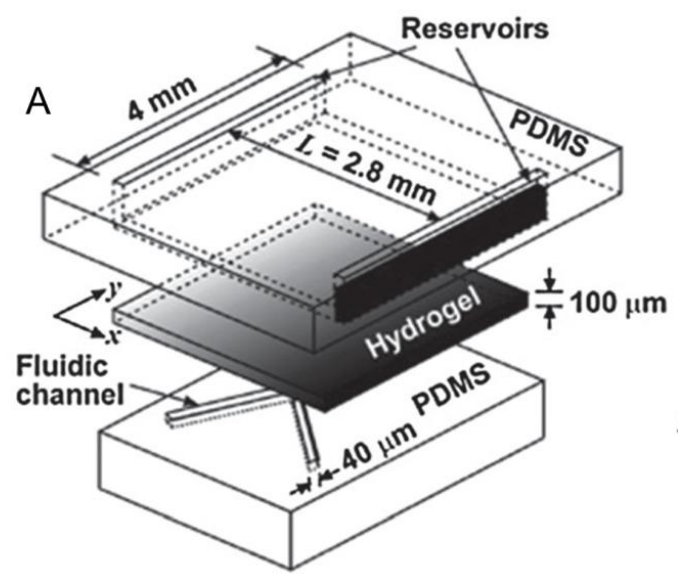

B $\quad$ C

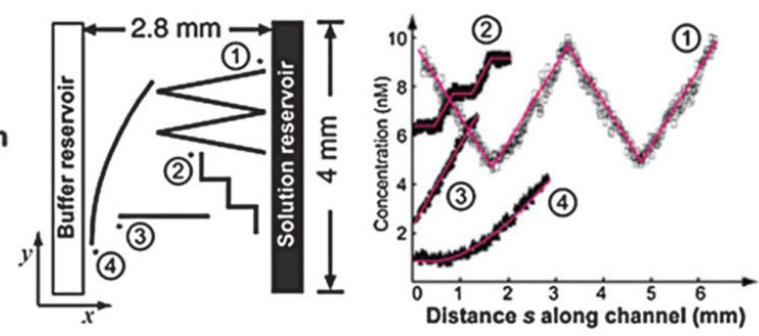

Figure 10. Gradient generator that uses hydrogel and microfluidic channels [40]. (A) Schematic diagram showing layers of gel and PDMS of the microfluidic device. (B) Various microfluidic channels patterned onto the bottom layer of the device. (C) Calculated (red lines) and empirical concentration profiles with various monotonic and complex shapes.

A microjets device that generates a dynamically controllable spatio-temporal concentration gradient is developed by Keenan et al [48]. As shown in Figure 11, this platform has an open reservoir that is positioned between a source manifold and a sink manifold. Each compartment is connected through an array of microchannels (microjet arrays). The release of chemicals into the gradient forming region (cell culture reservoir) is controlled by applying pressure to each manifold. Dynamic regulations such as shifting or steepening concentration gradients were achieved by adjusting the absolute and relative level of pressures [40].

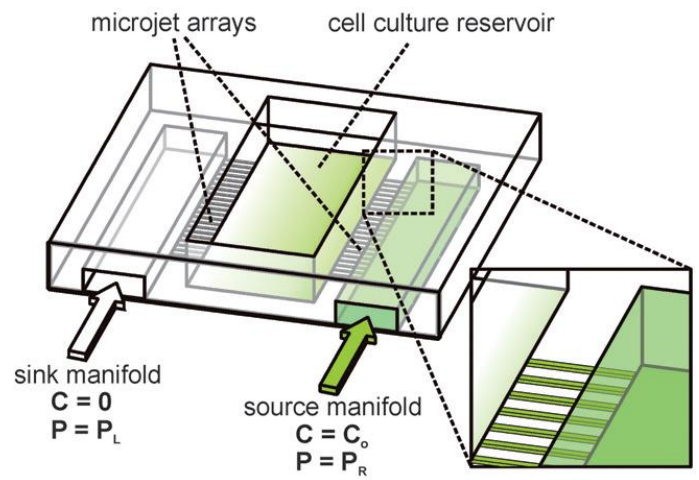

Figure 11. The schematic view of the device showing the open architecture of the cell culture/gradient chamber [48]. 

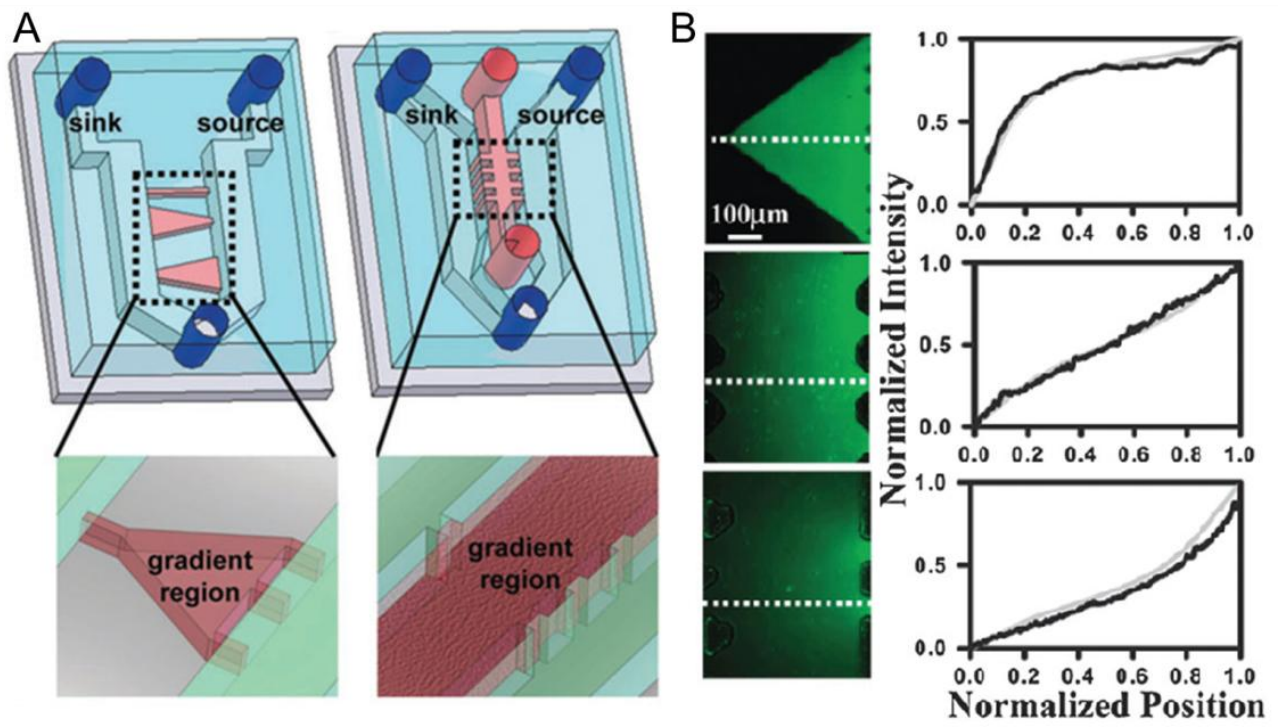

Figure 12. Ladder chamber devices and their gradient profiles [50]. (A) Ladder chamber devices with different microchannels. (B) Various gradient profiles are achieved by different microchannels.

Saadi et al develops a two-compartment diffusion ladder chamber that generates stable gradients across both 2D cell-culturing microchannels and 3D biological hydrogel [49]. This platform is further expanded by Mosadegh et al by accomplishing generation of various gradient profiles [50]. As shown in Figure 12 (A), this device consists of a source chamber and a sink chamber that are connected via an array of microchannels. Balanced microchannels produce a linear gradient profile, while unbalanced microchannels produce nonlinear gradient profile, as shown in Figure $12(\mathrm{~B})$.

\subsection{Advantages of Studying Cell Migration with Microfluidics}

In vitro assays, which have been used for studying cell migration, mainly focus on using conventional assays, including under-agarose assay, Boyden chambers, Dunn chamber, Zigmond chamber and micropipette-based assay. However, the conventional assays have limited capabilities of providing well-controlled chemical gradients or real-time monitoring cell migration. These disadvantages can be overcome by microfluidic devices [51]. Advances in 
microfluidic chip technologies have enabled a variety of insights into biomedical sciences, such as easily and tightly controlled biological conditions and dynamic fluidic environments, mimicking essential aspects of cellular microenvironment, great flexibility in generating stable and precisely controlled gradients, which will not have been possible with conventional macroscale techniques. Microfluidic gradient devices have been used to study cell migration recently [40,46]. Table 2 is a summary of the microfluidic gradient devices and conventional assays.

Table 2. Comparisons between microfluidic gradient devices and conventional assays for studying cell migration

\begin{tabular}{|c|c|c|}
\hline Properties & Microfluidic Gradient Devices & Conventional Assays \\
\hline Gradient control & Dynamic perfusion and static & Limited \\
\hline Control cell behavior & Yes and physiological relevant; & No / Limited physiological relevant; \\
individual cells; Multi-cell types & Large group of cells; single cell type \\
\hline Capture critical & Yeatures of & Very limited \\
microenvironments & and 3D invasion; repeatable & multiple parameters; repeatable \\
\hline Experimental results & Real-time monitoring 2D migration & Lack real-time observation; missing \\
\hline High throughput & Yow & No \\
\hline Cost & & High \\
\hline
\end{tabular}




\section{Chapter 3. Microfluidic Device Fabrication}

Photolithography is the dominant technology for microfabrication. It is a process to project the patterns of a photo mask or a chrome mask onto a photoresist thin film under the exposure of ultraviolet (UV) light. The excessive photoresist can be washed off by the photoresist developer to get the desired pattern transferred. It is capable of mass-producing patterned structures in photoresist thin films with feature sizes as small as $100 \mathrm{~nm}$ by using deep UV light and improved photoresists [52]. However, photolithography has its own limitations. It is an expensive and time-consuming process. It cannot be applied for microfabrication based on materials other than the photoresist, unless chromophore or photosensitizers are attached accordingly. It has little control over the chemistry on the surface, thus does not work well for 3D microstructures, structures on nonplanar surfaces or patterns of specific chemical functionalities on surfaces [52].

\subsection{Polymer Based Soft Lithography}

Polymer based soft lithography is a non-photolithographic set of microfabrication method that generates patterned microstructures on polymers using patterned elastomer, molds or masks. There are variety of polymers, including epoxy, polyurethane (PU), poly(methyl methacrylate) (PMMA), poly(acrylonitrile-butadiene-styrene) (ABS), cellulose acetate (CA), polystyrene (PS), polyethylene (PE), poly(vinyl chloride) (PVC) and PDMS. Various techniques have been developed for soft lithography, such as microcontact printing ( $\mu \mathrm{CP}$ ), replica molding (REM), microtransfer molding $(\mu \mathrm{TM})$, micromolding in capillaries (MIMIC), solvent-assisted micromolding (SAMIM), phase-shift photolithography, cast molding, embossing, and injection molding [52]. Compared to photolithography, soft lithography is easy to change, suitable for 
working with large or nonplanar surface and low cost. The polymer used in soft lithography is biocompatible and it has good chemical resistance and optical properties. In addition, because polymers have been widely used in biomedical and electronic research, soft lithography can be applied on applications in biotechnology and plastic electronics.
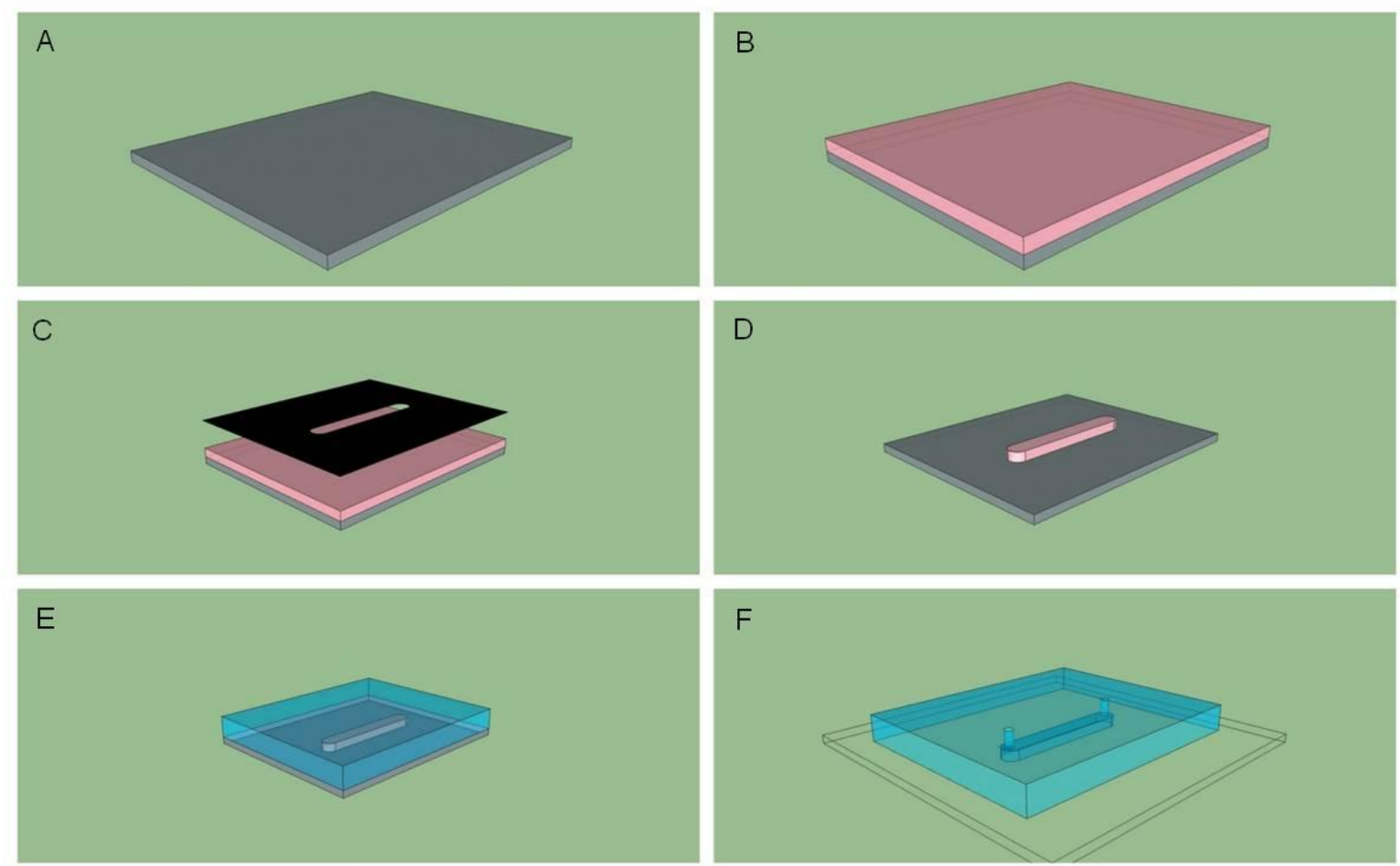

Figure 13. The fabrication processes for PDMS based microfluidic devices. Negative photoresist (SU-8) is used for the demonstration. (A) The wafer is cleaned with acetone, methanol and rinsed with DI water. (B) A layer of photoresist is spun-coated on the wafer. (C) A film mask was brought to an intimate contact to the photoresist layer, then, they are exposed to a UV light to transfer the pattern on the film mask to the photoresist layer. (D) Undesired photoresist is washed off by photoresist developer to get the transferred pattern on the wafer. (E) A layer of PDMS is poured on the wafer mold. The PDMS layer is cured in oven. (F) After punching holes, the cured PDMS slab is bonded onto a glass substrate with oxygen plasma.

Figure 13 shows the standard fabrication process of PDMS based microfluidic devices using soft lithography. The first step is to fabricate a master mold with standard photo lithography (Figure 13 (A) to (D)). Briefly, after cleaning the wafer with acetone, methanol and de-ionized (DI) water, a layer of photoresist is spun-coated on the wafer. The spinner used in this 
thesis is Laurel Technologies 400 Spinners, as shown in Figure 14. The thickness of the photoresist depends on the requirements of specific devices. By setting appropriate RPM, duration and acceleration speeds, different thicknesses can be achieved. The thickness of photoresist determines the height of the channel when making PDMS devices. A photo mask is brought to intimate contact with the photoresist on the wafer, which is then exposed to UV light. The UV light exposure system used in this thesis is OAI LS30 UV flood exposure system, as shown in Figure 15. For the negative photoresist, the area that is exposed under UV light stays on the wafer after the development. Finally, the wafer is hard baked to totally cure the photoresist.

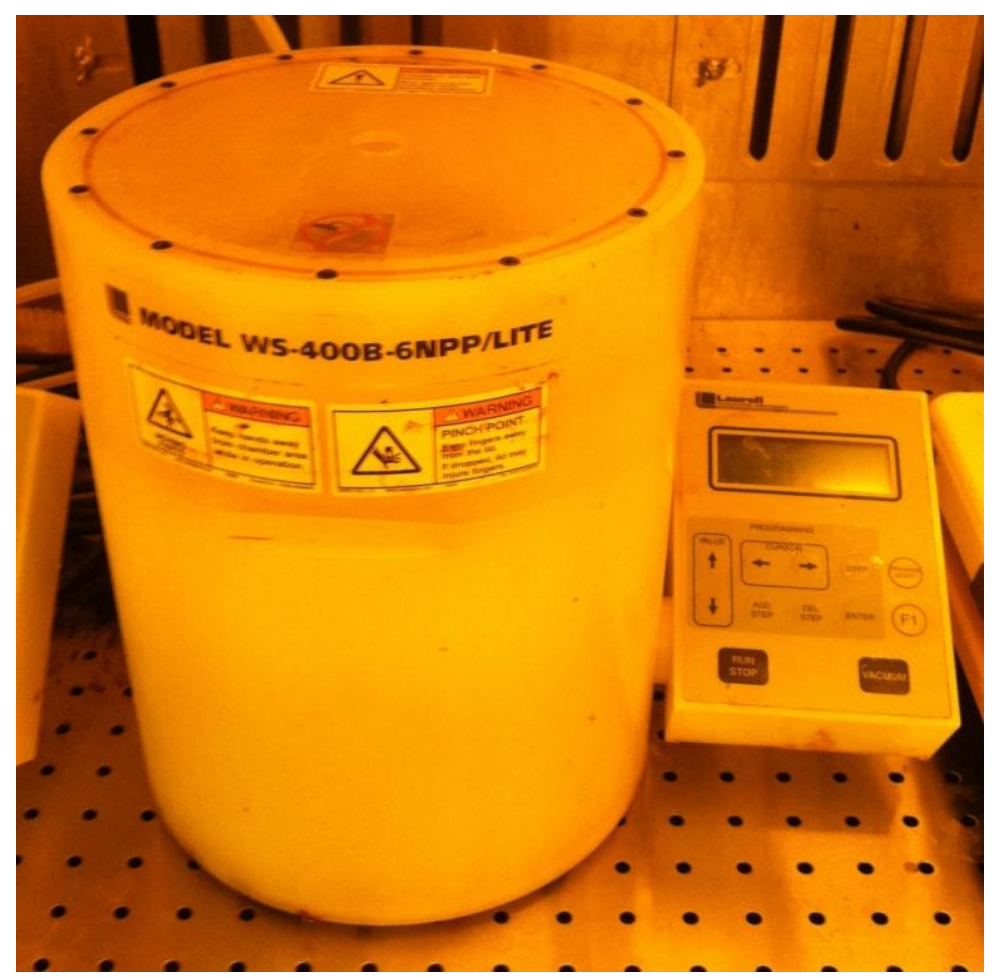

Figure 14. Laurel technologies 400 spinner. It supports substrates from $10 \mathrm{~mm}$ to 6 inches. The maximum speed is $8000 \mathrm{rpm}$. Multiple steps with different speed, acceleration and spinning time can be programmed, saved and retrieved. 


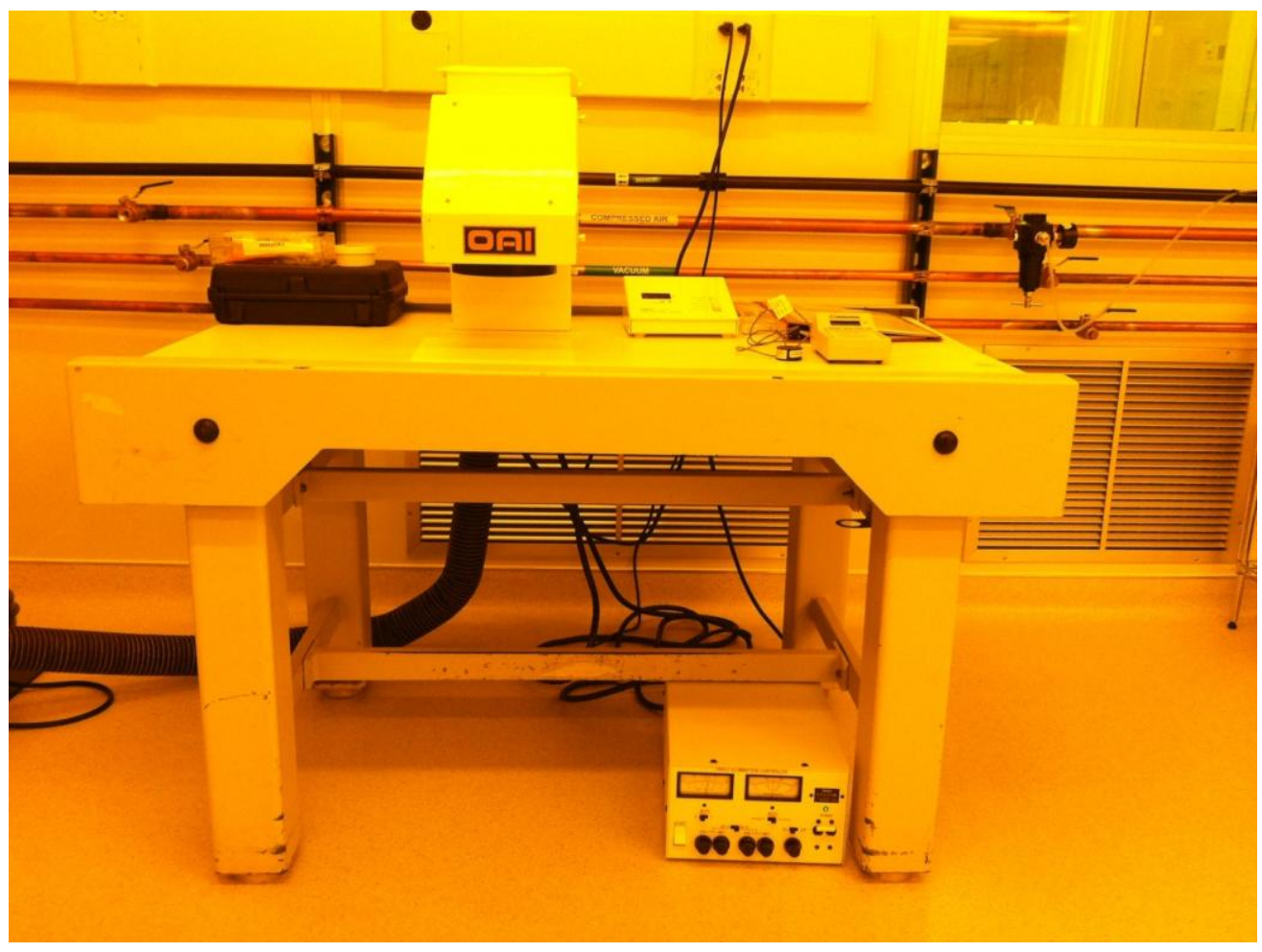

Figure 15. OAI LS30 UV Flood Exposure System. It provides a uniform beam of UV light (365 $\mathrm{nm}$ ) in a 5-inch diameter exposure area for photolithography processing. During exposure, the system was set to constant intensity. After exposure, it was set to constant power.

The next step of the fabrication is a PDMS replica molding process using soft lithography

(Figure $13(\mathrm{E})$ and $(\mathrm{F})$ ). The mixture of PDMS base solution and the curing agent (normally in a ratio of 10:1 by weight) is first casted onto the master mold, then degassed under vacuum and placed in an oven. When the PDMS mixture is cured, the PDMS slab is cut and peeled off from the master mold. In this way the pattern is transferred from the master mold to the PDMS slab. Then, the PDMS slab and a glass slide are treated with oxygen plasma (50 W, 100 mTorr) and brought together to form a permanent irreversible bonding.

\subsection{Chrome Mask Fabrication}

In order to achieve a good alignment, a chrome mask was fabricated in cleanroom to replace the film mask. The chrome mask was made from Telic chrome photomask blanks (Telic 
Company, Valencia, CA). It has a width of 4 inches, length of 4 inches and thickness of 0.06 inches. A layer with AZ $1500(530 \mathrm{~nm})$ was spun-coated on the thin chrome layer.

There were four patterns on each mask of the two photoresist layers. Four alignment markers were in the center of the four device patterns. An opening that surrounded the four alignment markers was added to the film mask for the second photoresist layer, as shown in Figure 16. The opening was necessary so that the alignment markers on the first layer could be seen during the alignment.
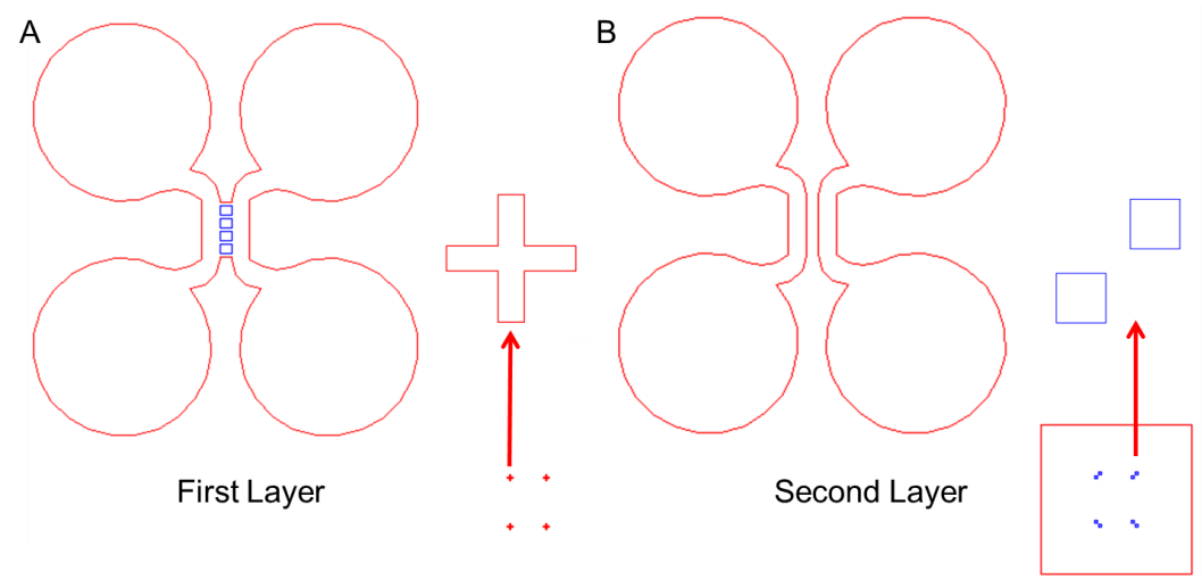

C

Figure 16. The film masks for the two layers wafer mold. For each film mask, only one pattern and four alignment markers were shown in this figure. (A) Patterns on the first layer of the film mask. (B) Patterns on the second layer of the film mask. The red square was the opening. (C) The alignment markers on the two films were precisely aligned.

The film mask was brought to an intimate contact to the chrome photomask blank. In order to transfer the patterns from the film mask to the photomask blank, they were exposed under the UV light with the flood exposure system for 1.5 seconds with a constant UV intensity of $20 \mathrm{~mW} / \mathrm{cm}^{2}$. Then the photomask blank was developed in AZ 300 MIF developer for 30 seconds and rinsed with the DI water. The features of the second layer and mask aligner were checked under a microscope. If the features were good, the photomask blank was submerged into 
Transene Chromium Etchants 1020 (Transene Company, Danvers, MA) for 3 minutes to etch off the exposed chrome layer. The photomask blank was rinsed with $20 \%$ sulfuric acid during the etching process. When the chrome layer was etched off, a glass layer would be seen at the exposed part of the photomask blank. All the chrome on the pattern must be etched off to produce a crystal clear pattern on the photomask. Any residual chrome could block the UV light during the exposure, resulting in an unexposed photoresist region.

\subsection{Mask Alignment}

For wafer molds with more than one layer of photoresist, a mask aligner is needed to have multiple layers accurately aligned. The mask aligner used in this thesis is Karl Suss MJB3 mask aligner, as shown in Figure 17.

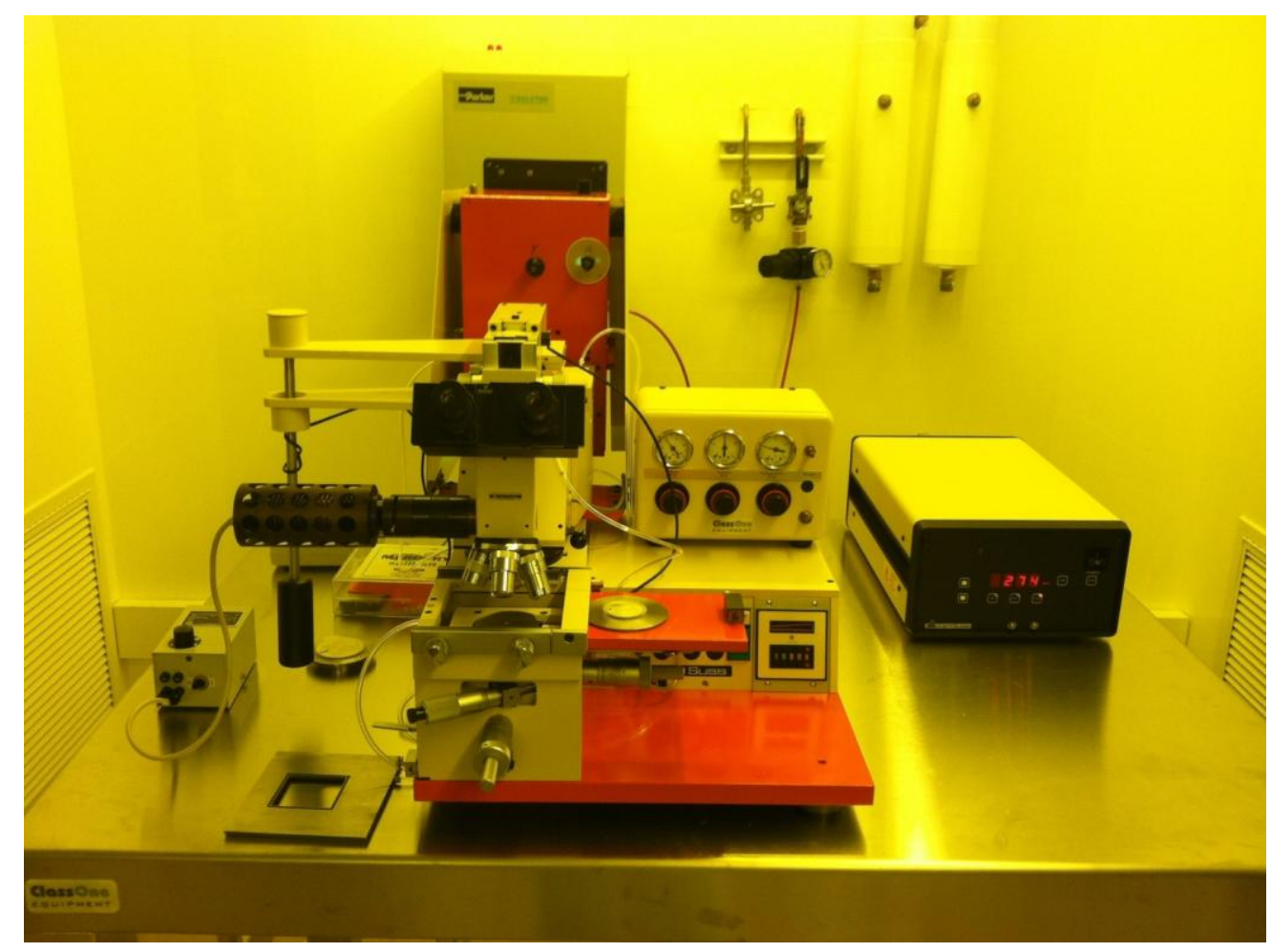

Figure 17. Karl Suss MJB3 mask aligner. It is used for patterning multiple layers of photosensitive polymer with UV light. 
The vacuum pump was turned on after the compressed air pressure of the two pressure gauges reached 70-80 psi and 40-60 psi, respectively. The vacuum was required for holding the sample and mask. When the display showed "rdy" (ready), the arc lamp was started and warmed up for 15 minutes. The mask aligner was powered on when the LED of the arc lamp was 275 Watts (power supply). When the nitrogen pressures of three gauges (exposure, parallelity and pressure/wafer) were 4 Bar, 2 Bar and 1 Bar, respectively, the mask aligner was ready to use. Finally the microscope was turned on for alignment.
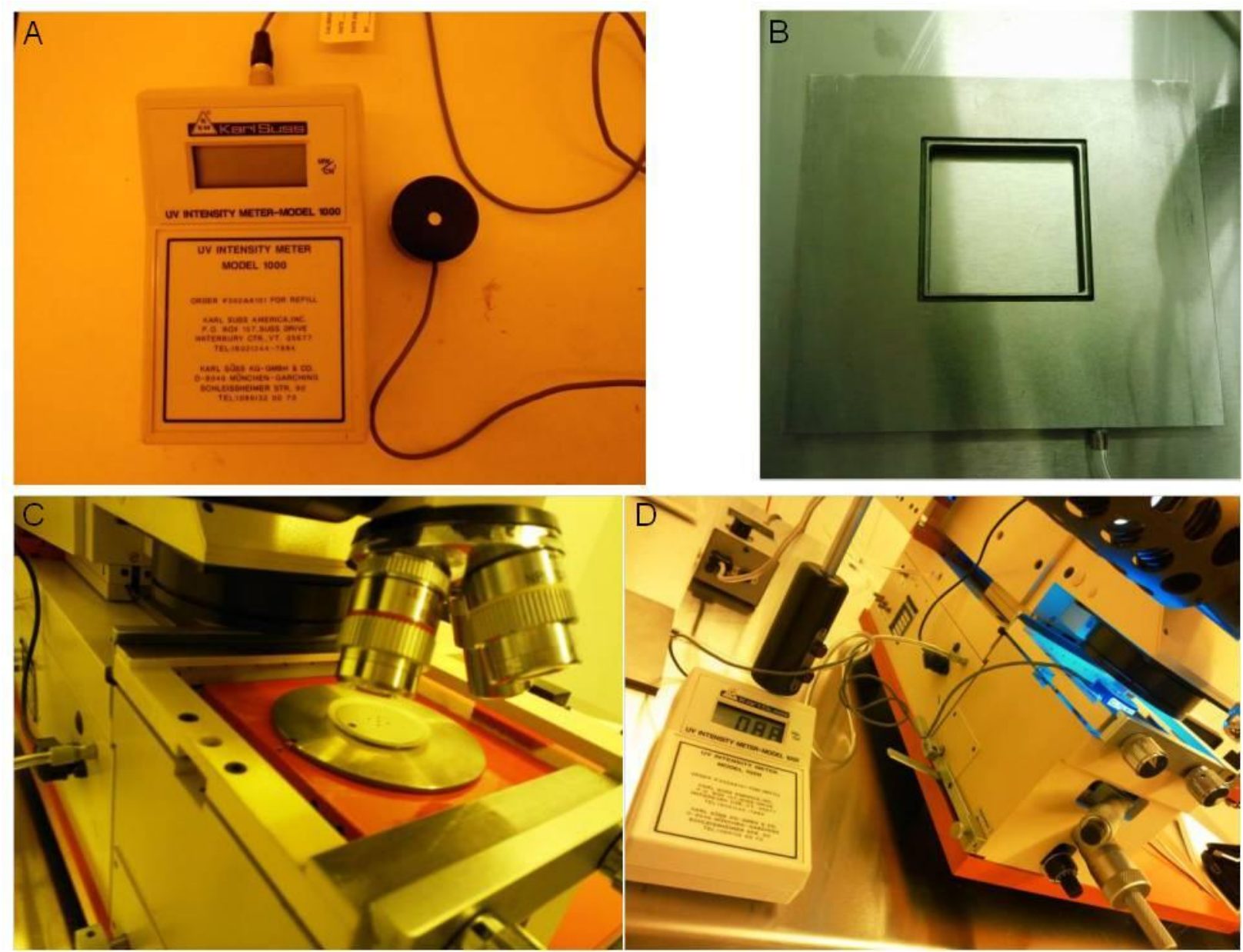

Figure 18. Intensity meter and holders [53]. (A) Karl Suss 1000 UV intensity meter and probe. (B) Mask holder. (C) Sample holder and mask holder grooves on mask aligner. (D) Put probe on sample holder and measure UV intensity. 
Before loading the sample into the sample holder for alignment and UV exposure, the UV intensity should be measured and recorded. The Karl Suss 1000 UV intensity meter (Figure 18 (A)) was turned on and the probe was placed on the sample holder (Figure 18 (C)) for intensity measurement (Figure 18 (D)). The exposure time was calculated based on the ratio of the desired exposure dosage and the UV intensity. The exposure dosage was provided by the manual of the photoresist (in this case, SU-8 2075) and depended on the thickness of the photoresist on the wafer. After mounting the photomask on the mask holder (Figure $18(\mathrm{~B})$ ), the mask holder was flipped over and inserted into the mask holder grooves on top of the sample holder. The wafer mold (with first layer of photoresist) was placed on sample holder. All vacuum holes should be covered to have the wafer mold placed on the holder tightly during the alignment and exposure. 


\section{Chapter 4. Chronic Toxicity of Carbon Nanotubes and}

\section{Cell Model}

\subsection{Why Study Pleural Mesothelial Cells}

The mesothelium is an extensive monolayer of mesothelial cells that lines the body's serous cavities and internal organs, such as lung, heart, abdomen and internal reproductive organs, as shown in Figure 19 [54]. The primary functions of mesothelial cells include enzymes regulation and production [55], antigen presentation [56], fluid and cell transportation [57], wound healing [58], coagulation and fibrinolysis [59], tumor cell adhesion and growth [60].

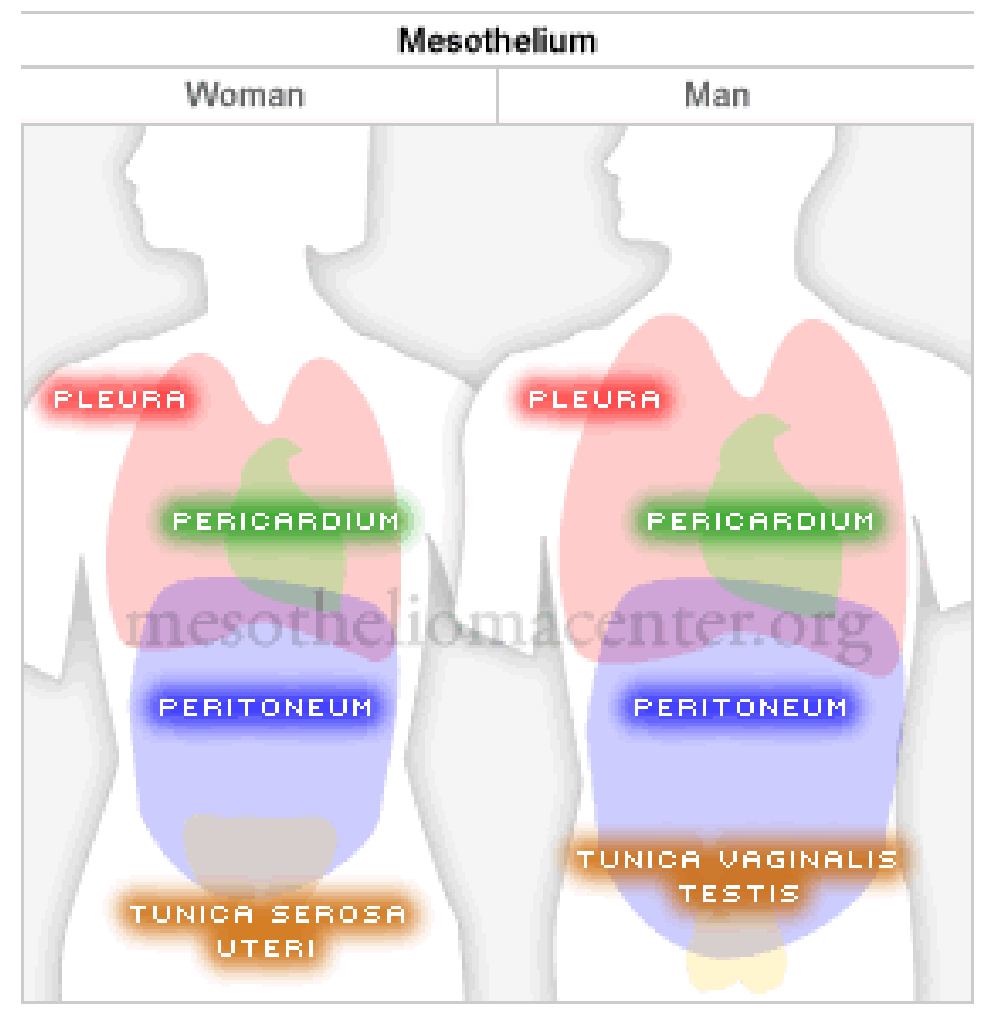

Figure 19. Types of Mesothelium [61]. Pleural mesothelioma (red area) surrounds lungs and lines chest cavity. Peritoneal mesothelioma (blue area) covers bulk of abdominal organs and provides support and allowing movement. Pericardial mesothelioma (green area) lines the heart. 
Testicular mesothelioma surrounds male internal reproductive organs, mesothelioma of uterine serosa covers female internal reproductive organs.

Malignant mesothelioma is a very aggressive tumor arises from mesothelial cells lining the pleural, peritoneal and pericardial cavities. It has very low survival rates and there is no effective therapy or consensus regarding treatment in spite of many years research [62]. Of all malignant mesothelioma cases, pleural mesothelioma is the most common cancer that accounts for about $70 \%$ of them [63]. Chronic exposure to asbestos is recognized as the major risk factor and leading cause of malignant pleural mesothelioma, especially through the occupational exposure to asbestos [64]. It is known that malignant pleural mesothelioma originates from mesothelial cells' aggressive spreading to the visceral pleural and beyond. Ultimately, mesothelial cells will invade into the adjoining chest wall, lung, diaphragm and mediastinal organs [62]. Because pleural mesothelial cells migration plays a crucial role in this process, it is important to study the migration of human pleural mesothelial cells.

\subsection{Potential Carcinogenicity of CNTs}

Carbon nanotubes are allotropes of carbon with cylindrical structure, as shown in Figure 20 (A) and (B). Both single-walled CNT (SWCNT) and multi-walled CNT (MWCNT) are macromolecules and featured with high tensile strengths, light weight, high aspect ratio and stable thermal and chemical properties [65]. Their significantly large length-to-diameter ratio makes them valuable for nanotechnology, electronics and optics. With extraordinary thermal conductivity and mechanical and electrical properties, CNTs have the potential to be widely used in drug delivery, high toughness material, solar cell, hydrogen storage, electrical circuits and cable [66]. 
Similar to asbestos, CNTs are high aspect ratio cylinders with diameters in the order of nanometers and lengths in the order of micrometers $[65,67]$ as shown in in Figure 20 (C) and (D). Additionally, the mode of exposure of CNTs is similar to asbestos fibers, which is very light and can become airborne and potentially reaches the lungs. This has raised a particular concern regarding to the potential carcinogenicity of CNTs, especially in the pleural spaces, which are key target tissues for asbestos-related diseases [68].

A
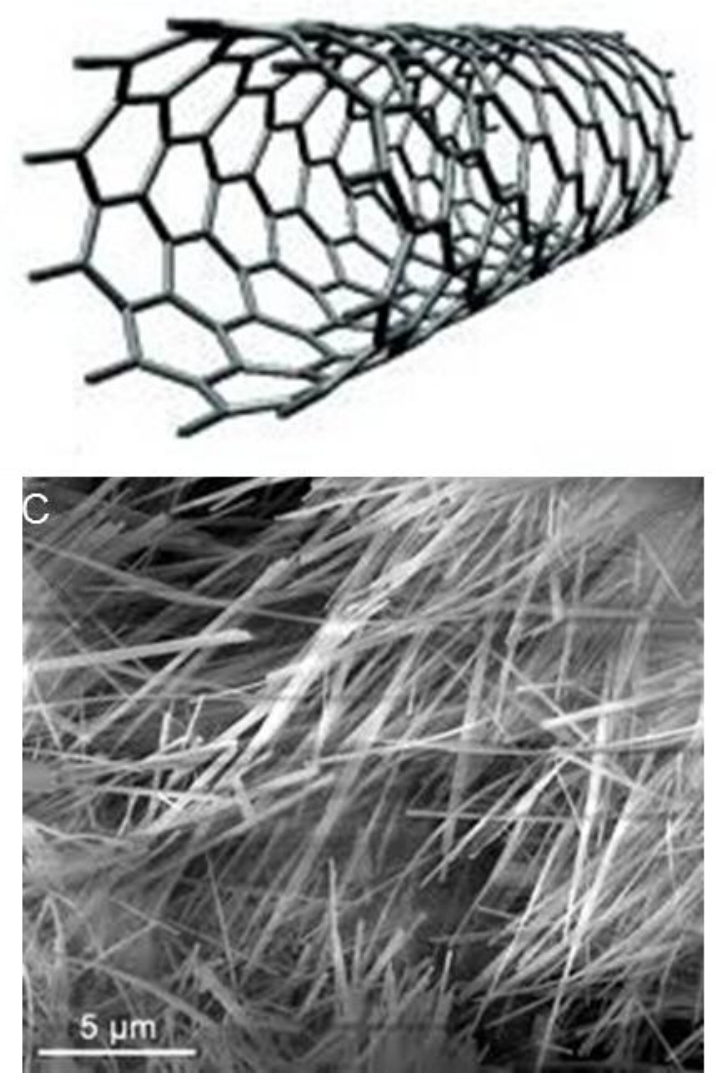

B

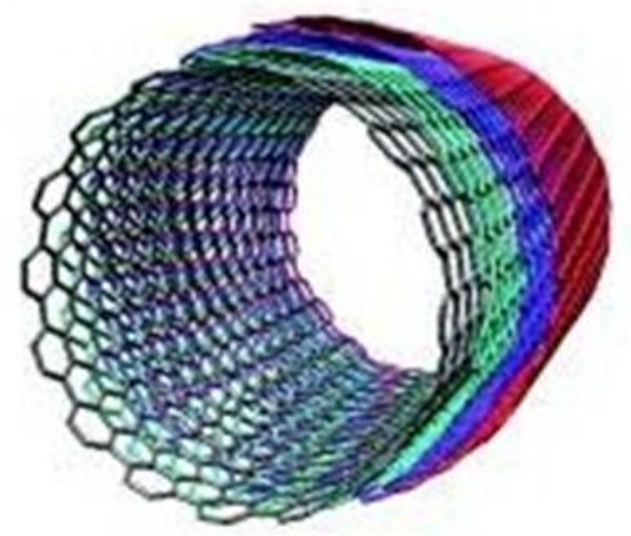

Figure 20. Carbon nanotube structures structure and scanning electron microscopy (SEM) images [65]. (A) Structure of SWCNT, (B) Structure of MWCNT. (C) SEM micrograph of a bundle of MWCNTs [69]. (D) SEM micrograph of synthetic tremolite asbestos [70].

Many in vivo studies have showed that CNTs are biopersistent and have low clearance rate. CNTs can cause inflammation, fibrosis, and granuloma formation $[71,72,73]$, and have the potential to further induce mesothelioma [74]. Previous work studied the effect of long-term 
exposure to high aspect ratio CNTs on the aggressive behaviors of human pleural mesothelial cells. Results indicated that SWCNTs and MWCNTs induced accelerated cell growth and invasiveness, which are key cancer phenotypes that may contribute to mesothelioma pathogenicity [68]. It is necessary to investigate the toxicity and carcinogenicity of CNTs thoroughly to determine their safety for long-term exposure.

\subsection{Studies on Mesothelial Cells Migration}

Conventional assays and in vivo animal studies have been used to study the migration of pleural mesothelial cells responding to the gradients of different chemical reagents. Nasreen et al. demonstrated that pleural mesothelial cells could respond with haptotactic migration to a gradient of transforming growth factor- $\beta$. The migration was performed in the polycarbonate transwell. But only the number of migrated cells was evaluated [75]. Zhong et al. explored the migration and proliferation of mesothelioma cells and how they were affected by matrix metalloproteinase (MMP)-2, membrane-type1-MMP (MT1-MMP) and tissue inhibitor of MMP (TIMP)-2. Again cell migration was evaluated by counting the number of migrated cells. No information of migration speeds or morphological changes was provided [76]. Zolak et al. showed that plural mesothelial cells were able to migrate into the lung and differentiate into myofibroblasts with mice recombinant for green fluorescent protein driven by Wilms tumor-1 promoter. The migration was shown by the abnormal presence of (Wilms tumor-1) WT-1+ cells within the parenchyma of an explanted lung from patient [77]. Nagai et al. showed that transformed mesothelial cells (MeT5A) migrated in various directions to a distant site. The migration velocities of most MeT5A cells were between 0.1 to $0.4 \mu \mathrm{m} / \mathrm{min}$. The velocity was calculated based on the original cell location from original position and its migrating time [78]. In terms of carcinogenicity of CNTs, Wang et al. showed that chronic exposure to SWCNT 
caused malignant transformation of human lung epithelial cells. The transformed cells exhibited an apoptosis resistant phenotype characteristic of cancer [79]. In summary, limited information about cells' velocities and cell morphological changes during their migration were provided in those studies, neither real-time monitoring of the cells were available.

In this thesis, a microfluidic device that generates a stable static gradient based on the molecule diffusion to study the migration of the chronic SWCNTs exposed human pleural mesothelial cells was presented. Different concentrations of FBS were used to establish the gradient and compared to study the migration velocities and the number of migrated pleural mesothelial cells. In addition, real-time imaging using the microfluidic device is able to provide detail information regarding to cells' morphological changes prior, during and after their migration. 


\section{Chapter 5. Microfluidic Device for Gradient}

\section{Generation and Cell Viability}

In this thesis work, a perfusion based microfluidic gradient device, a pseudo-perfusion based microfluidic gradient device and a static microfluidic gradient device were designed and fabricated to generate the gradient and facilitate cell loading. Different matrix coating materials (gelatin, collagen and fibronectin) and their concentrations were tried to facilitate cell attachment.

The perfusion based microfluidic gradient device had the shear stress issue. Cells were dead after being exposed to the continuous flow for a few hours. The pseudo-perfusion based microfluidic gradient device generated a linear gradient in a very narrow area, which was not suitable for studying cell migration. The static microfluidic gradient device was not capable of providing stable gradient. Cells in this device showed random movement during the experiment.

Finally a diffusion based microfluidic device with large reservoirs, chambers and migration channels was proven successful for pleural mesothelial cells migration study. Cells were healthy during the 24-hour experiment and directed migration was observed.

\subsection{Perfusion Based Microfulidic Gradient Device}

The perfusion based gradient device is shown in Figure 21. This device utilized "Christmas tree" gradient network to form a perfusion based gradient in the observation channel. Though excellent gradient can be generated, continuous shear stress introduced by perfusion flow made it unsuitable for studying the pleural mesothelial cell migration. As shown in Figure 22, most cells in this perfusion based gradient device failed to adhere to the substrate after 5 hours of initial attachment, while cells in another static gradient device remained healthy. In 
addition, cells were loaded into a relative large channel (observation area), which made it difficult to keep having similar number of cells at the interested region among different experiments.

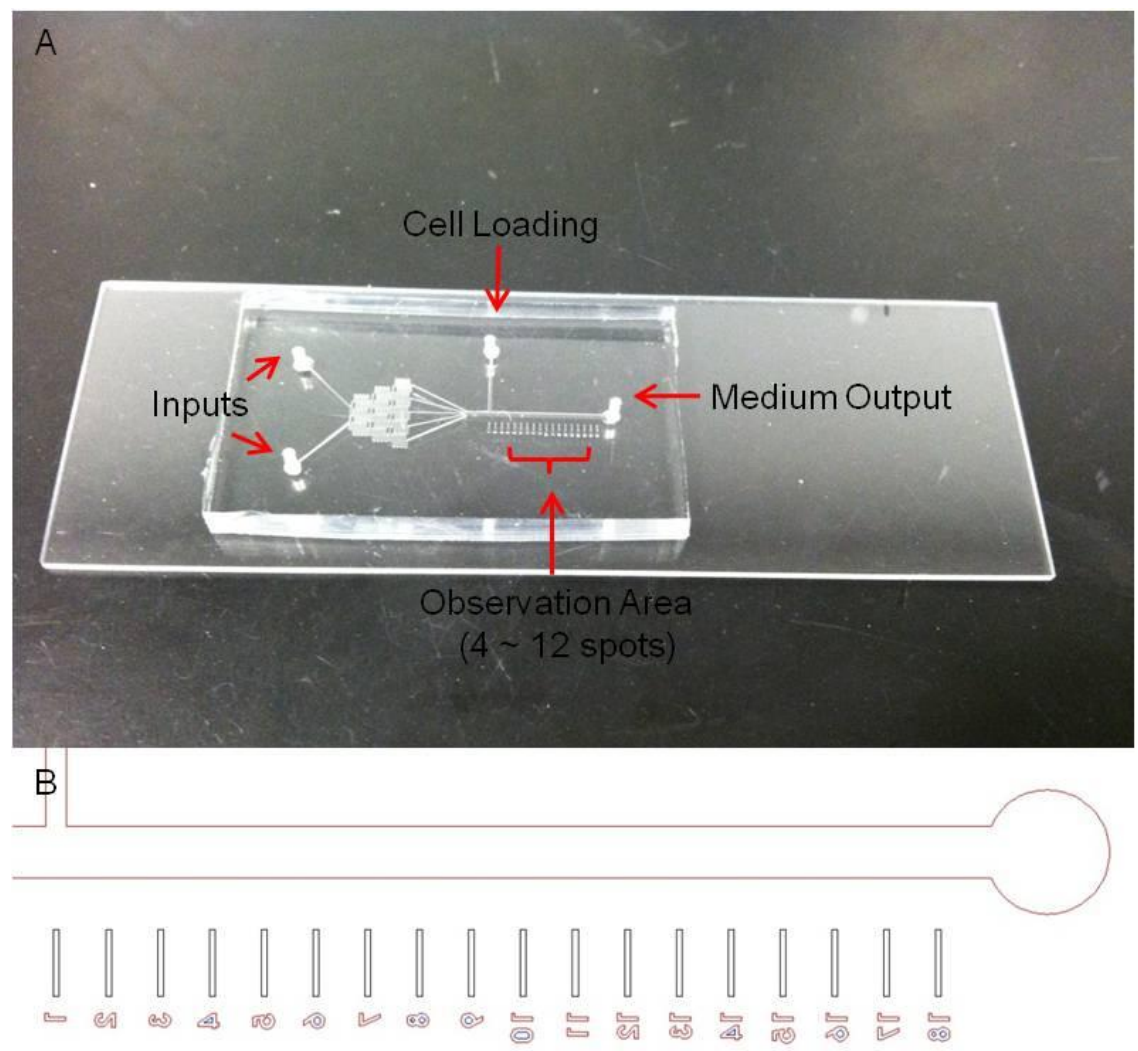

Figure 21. Perfusion based microfluidic gradient device. (A) Fabricated device. (B) Structure of observation area. Numbers along the observation channel help to mark multiple positions.
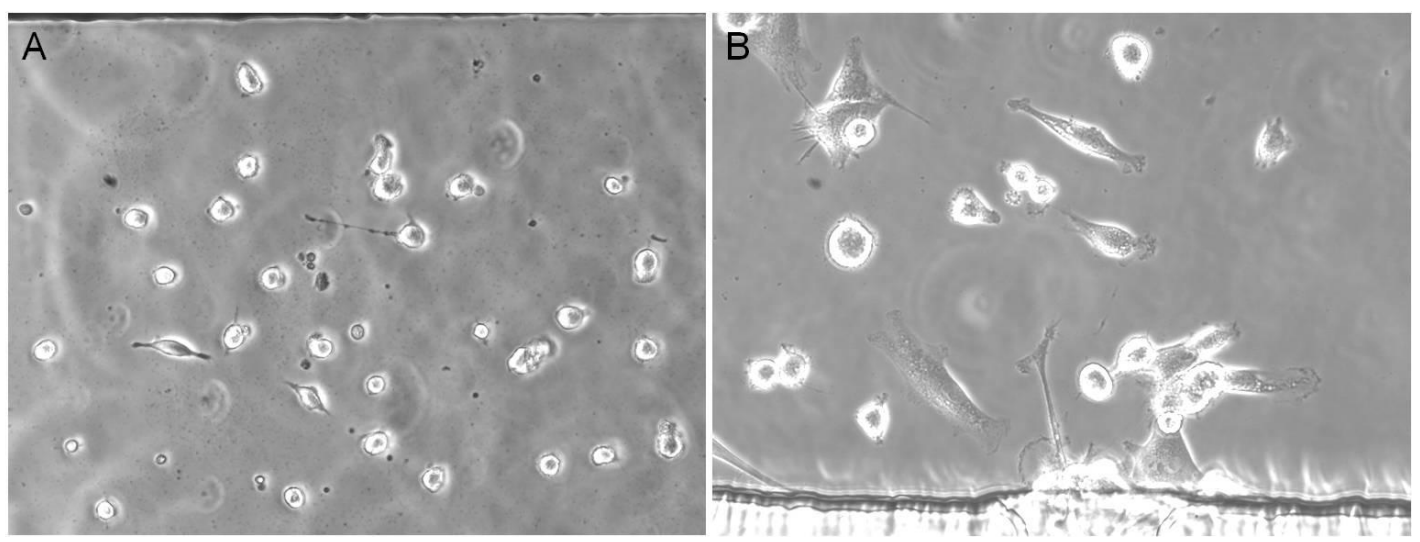

Figure 22. Comparison of cell adhesion at the 5th hour between the perfusion based microfluidic gradient device and static microfluidic gradient device. (A) Cells in the perfusion based gradient 
device at the $5^{\text {th }}$ hour. Most cells failed to adhere to the substrate because of the shear stress caused by the perfusion flow. (B) Cells in a static gradient device at the $5^{\text {th }}$ hour. All cells were alive and healthy. Some cells have turned into spindle-shape. The rest of cells turned into spindle-shape at the $6^{\text {th }}$ hour.

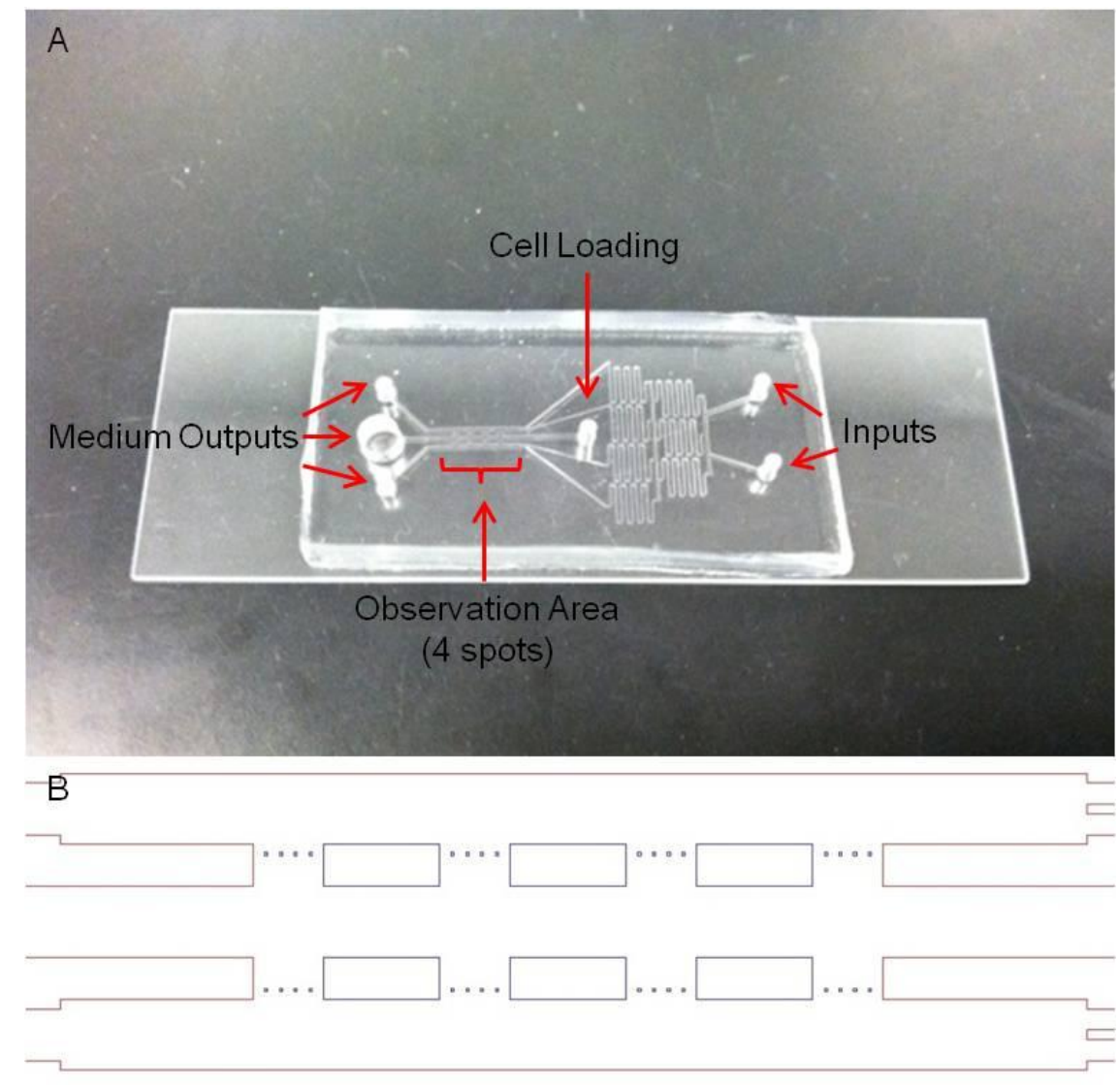

Figure 23. Pseudo-perfusion based microfluidic gradient device. (A) Fabricated device. (B) Structure of the observation area. Small barriers between the side channels and middle channels helped to confine cells in the middle channel.

\subsection{Pseudo-perfusion Based Microfluidic Gradient Device}

In order to overcome the shear stress effects on cells and generate a well-controlled stable good gradient, a pseudo-perfusion based microfluidic gradient device was designed and fabricated, as shown in Figure 23. First, all the channels were filled with sterilized DI water. Then one inlet was connected to a syringe pump for loading perfusion media with the chemoattractant, the other inlet was connected to another syringe pump for loading perfusion media without the chemoattractant. Perfusion flows from Christmas tree gradient network were 
guided to two side channels in the observation area, cells were loaded into the middle channel, as shown in Figure 23(B). Then a gradient perpendicular to the side channel was formed by diffusion. Cells in the middle channel were able to sense this gradient and migrate. However, the linear gradient (Figure 24) was formed within a narrow area for most of the time even though very low flow rate was used in various experiments to generate a perfusion based gradient at the two side channels. In order to reduce contaminations and media evaporation, PDMS plugs were inserted into the cell chamber reservoirs during experiment.
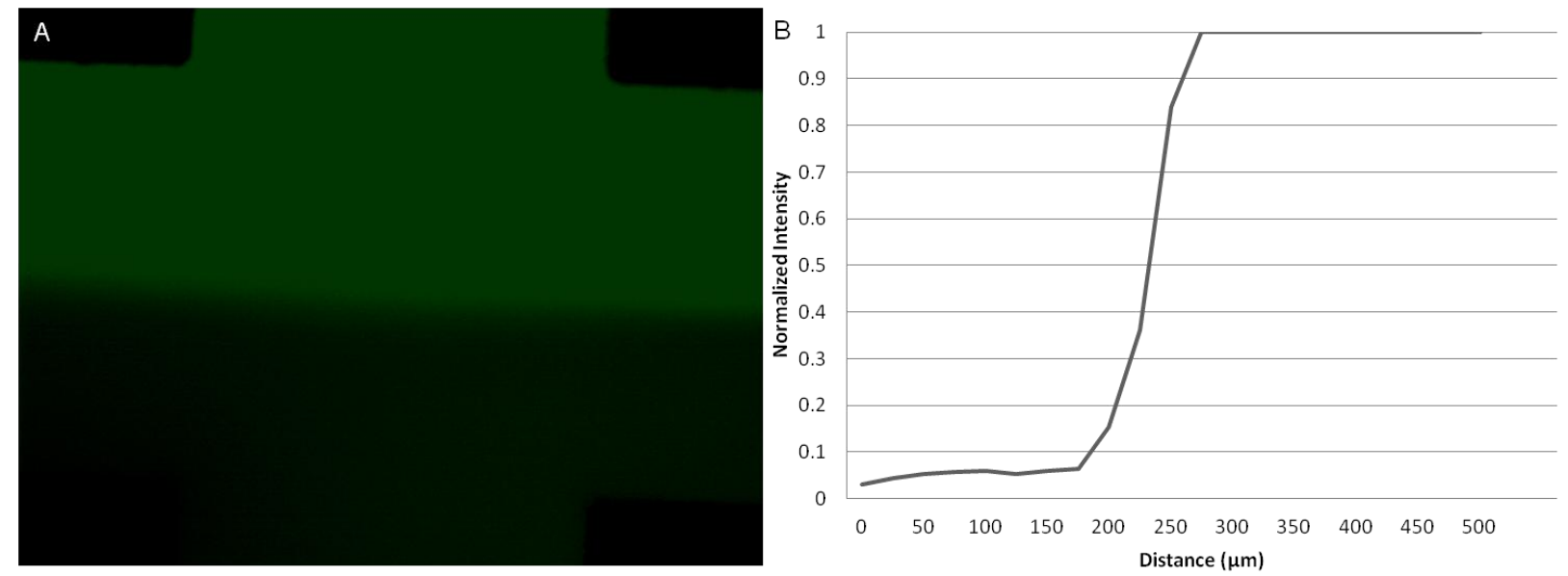

Figure 24. The gradient profile of the pseudo-perfusion based microfluidic gradient device. (A) Fluorescence image showing a stepped gradient. (B) The normalized intensity profile. This profile showed that a linear gradient with a narrow width (approximately $100 \mu \mathrm{m}$ ) was formed between the stepped gradient.

\subsection{Diffusion Based Microfluidic Gradient Device}

The diffusion based microfluidic gradient device was shown in Figure 25. It consisted of two chambers for the gradient generation, a middle horizontal channel for cell loading and four vertical migration channels. First, all the chambers and channels were filled with sterilized DI water. Then the media of chemoattractant was initially loaded into one chamber, the chemoattractant gradually diffused to the other chamber through the migration channels. In this 
way, the static gradient in the migration channels were formed. Overnight fluorescence imaging with FITC dextran showed that gradient generated this way was not stable (Figure 26), which resulted in random cell migration, as shown in Figure 27.

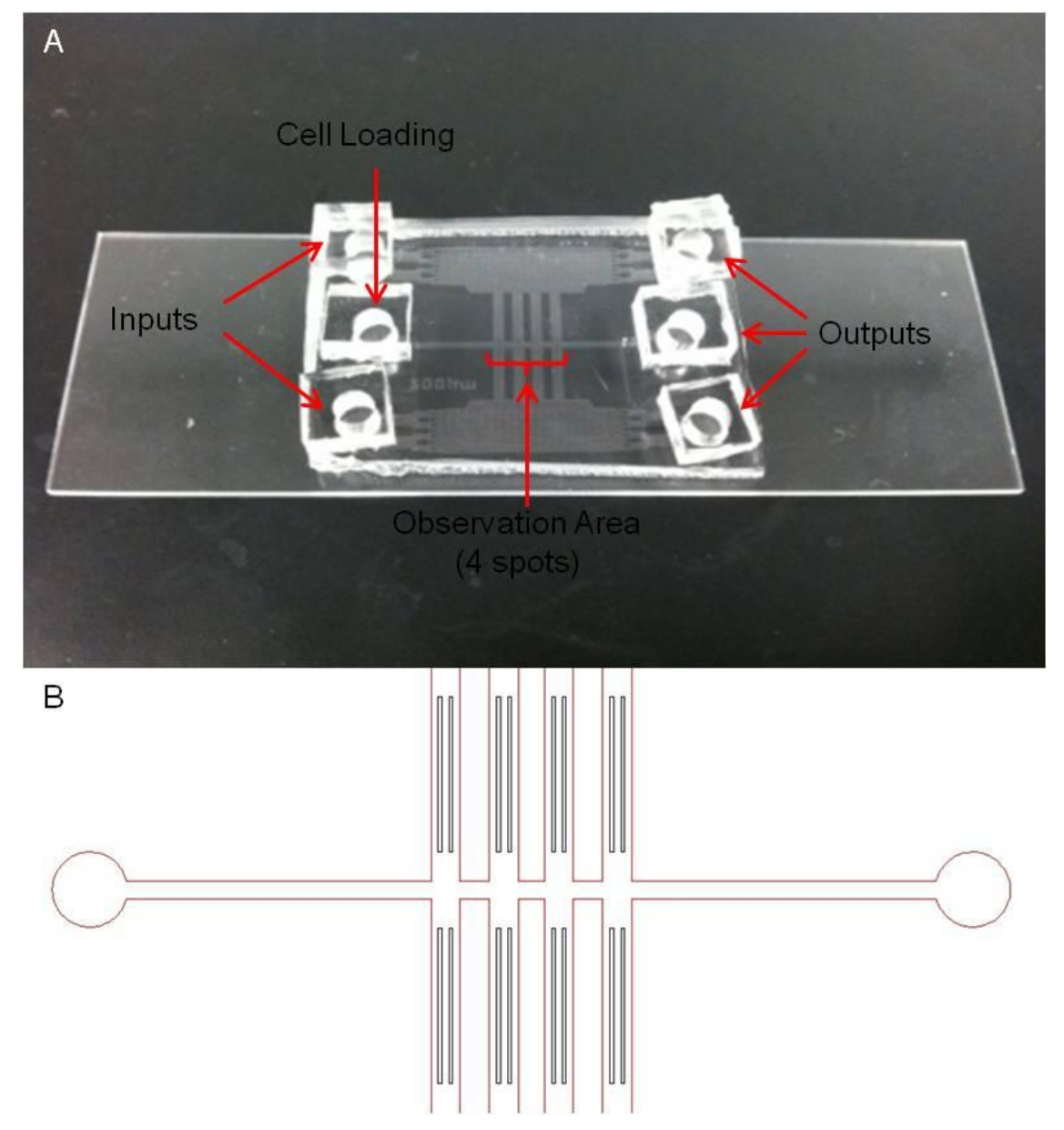

Figure 25. The static microfluidic gradient device. (A) Fabricated device. (B) Structure of the observation area. The rectangular barriers along the vertical migration channels confined cells in the horizontal middle channel for observation. 


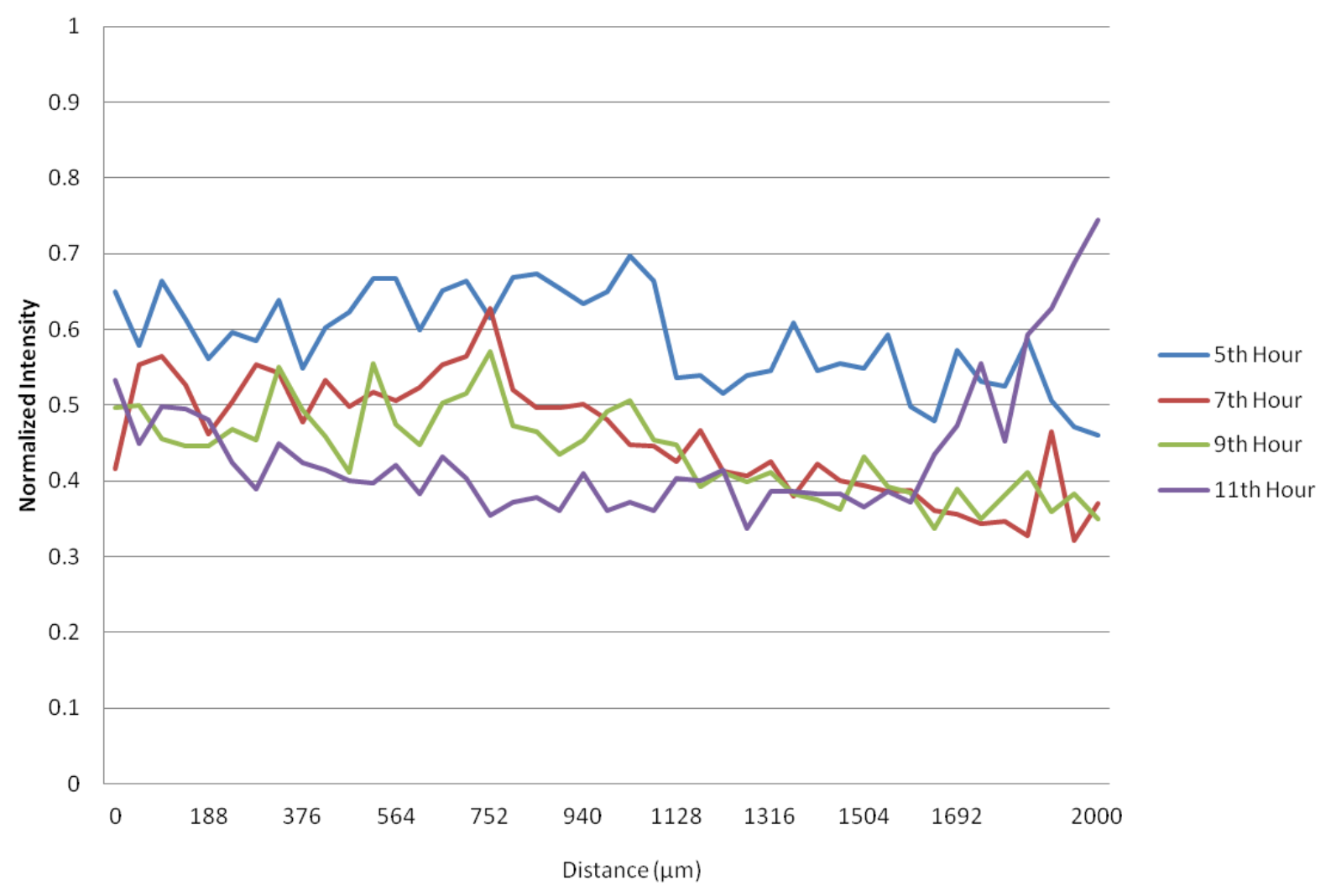

Figure 26. FITC intensity gradient profiles at different $5^{\text {th }}, 7^{\text {th }}, 9^{\text {th }}$ and $11^{\text {th }}$ hour. The profiles showed that the gradient was not stable.
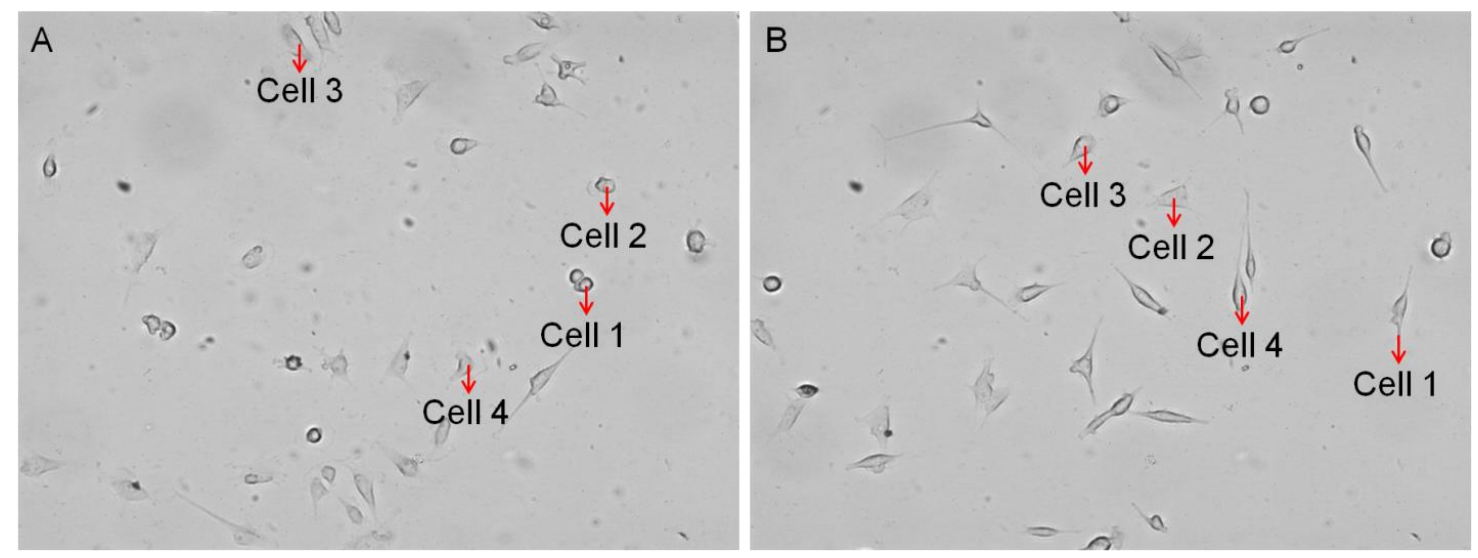

Figure 27. Cell distribution in the static gradient device at the $6^{\text {th }}$ (A) and $24^{\text {th }}$ (B) hour. Cells were alive and healthy during the experiment. However, random cell migration was observed because of the non-stable gradient. 


\subsection{Functional Device Design and Fabrication}

A review of unsuccessful devices showed that the following requirements must be met for a successful device to study pleural mesothelial cell migration:

1) No shear stress (gradient established mainly by diffusion);

2) Channels should be high enough to facilitate cell migration and hold enough media for long-term (24 hours) experiment and imaging;

3) An appropriate coating protein with an appropriate concentration on the glass substrate is required to facilitate cell attachment.
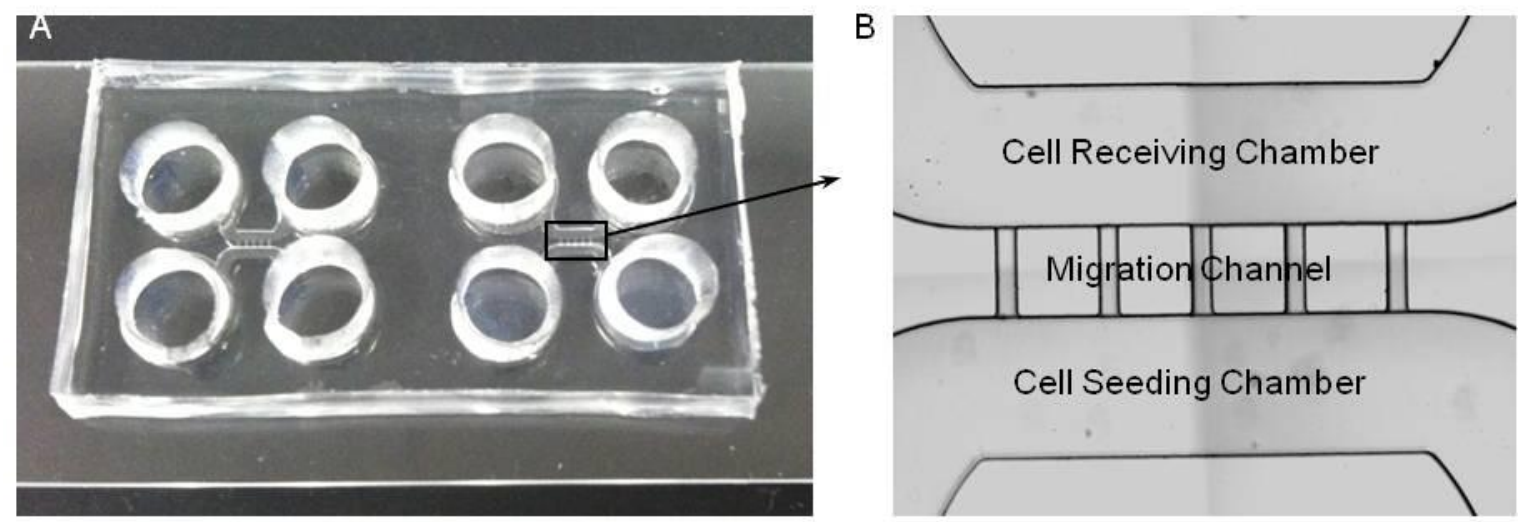

C

Cell Receiving Chamber

Media with FBS
Migration Channel

Cell Seeding Chamber

Media without FBS

Glass Slide

Figure 28. Microfluidic gradient device. (A) Two devices fabricated and bonded on one glass slide. One is for the control group test, the other is for the CNTs treated group of cells. (B) Image shows the cell receiving chamber, the migration channels, and the cell seeding chamber, respectively. (C) Schematic view of the cross section of the device shows different heights of the cell chambers and migration channels.

Based on those requirements, another microfluidic device was developed for the stable static gradient generation and live cell imaging. The device consisted of a cell seeding chamber, five migration channels and a cell receiving chamber as shown Figure 28 (A). Two devices were 
fabricated on a glass slide together. For each experiment with the same FBS concentration gradient, one device was used for observing SWCNTs treated cells, and another device was used for the control group, in which the cells were not treated with SWCNTs. Four reservoirs with a diameter of $6 \mathrm{~mm}$ were punched for cell and solution loading. The chambers had a width of 600 $\mu \mathrm{m}$ and a height of $160 \mu \mathrm{m}$. The migration channels had a dimension of $400 \mu \mathrm{m}$ in length, $80 \mu \mathrm{m}$ in width, and $16 \mu \mathrm{m}$ in height. The cell seeding/receiving chambers were much deeper than the cell migration channels for better control the gradient. The volume of each chamber was $0.52 \mu \mathrm{L}$ and the volume of each reservoir was $4.5 \mu \mathrm{L}$. The total volume of this device was approximately $19 \mu \mathrm{L}$, which was enough for a 24-hour experiment.

Standard photolithography and soft lithography were used for the master molds fabrication. PDMS soft lithography was used for device fabrication. The bottom migration channel was first fabricated using SU-8 2025 (MicroChem) to get shallow cell seeding and receiving chambers. The thickness of the bottom layer was $16 \mu \mathrm{m}$. SU-8 2075 (MicroChem) was then spun-coated over the bottom thin layer to form a second layer. After alignment, the top layer was exposed under the UV light, developed and hard baked. The heights of mold at the cell seeding and receiving regions were $160 \mu \mathrm{m}$. Silicone elastomer base (Slygard 184, Dow Chemical) was mixed with curing agent (Slygard 184, Dow Chemical) at a ratio of 10:1 and casted onto the master mold to obtain a $3 \mathrm{~mm}$ thick of PDMS layer. After curing the device in an oven at $60^{\circ} \mathrm{C}$ for three hours, the thick PDMS slab was cut and peeled off from the mold. Device reservoirs for cell and media loading were punched using a $6 \mathrm{~mm}$ diameter puncher. Two replicated PDMS devices and a glass slide were treated with oxygen plasma (50 W, 100 mTorr) for 20 seconds, and then they were brought together to form a permanent irreversible bonding. 
Before the cell experiment, the microfluidic devices were filled with DI water and UV sterilized for eight hours inside a biosafety hood.

\subsection{Gradient Characterization}

The concentration of the FBS gradient was visualized and quantified with FITC-albumin (Sigma-Aldrich, Saint Louis, MO). Similar to the experimental condition, 10\% FITC-albumin solution was loaded into the receiving reservoir to confirm and characterize the gradient generated in migration channels. Fluorescence images were taken every 15 minutes for 24 hours using an inverted microscope (Nikon Eclipse Ti, Japan). The fluorescence intensities in the region of the migration channels were recorded.

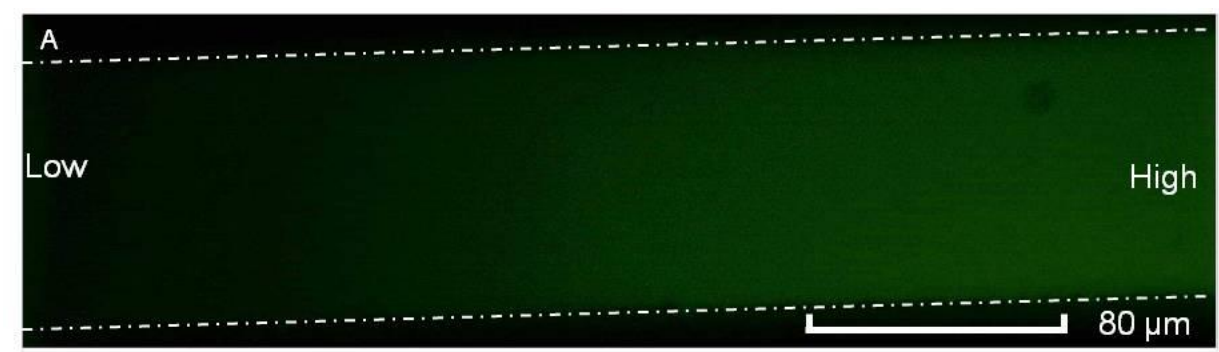

B

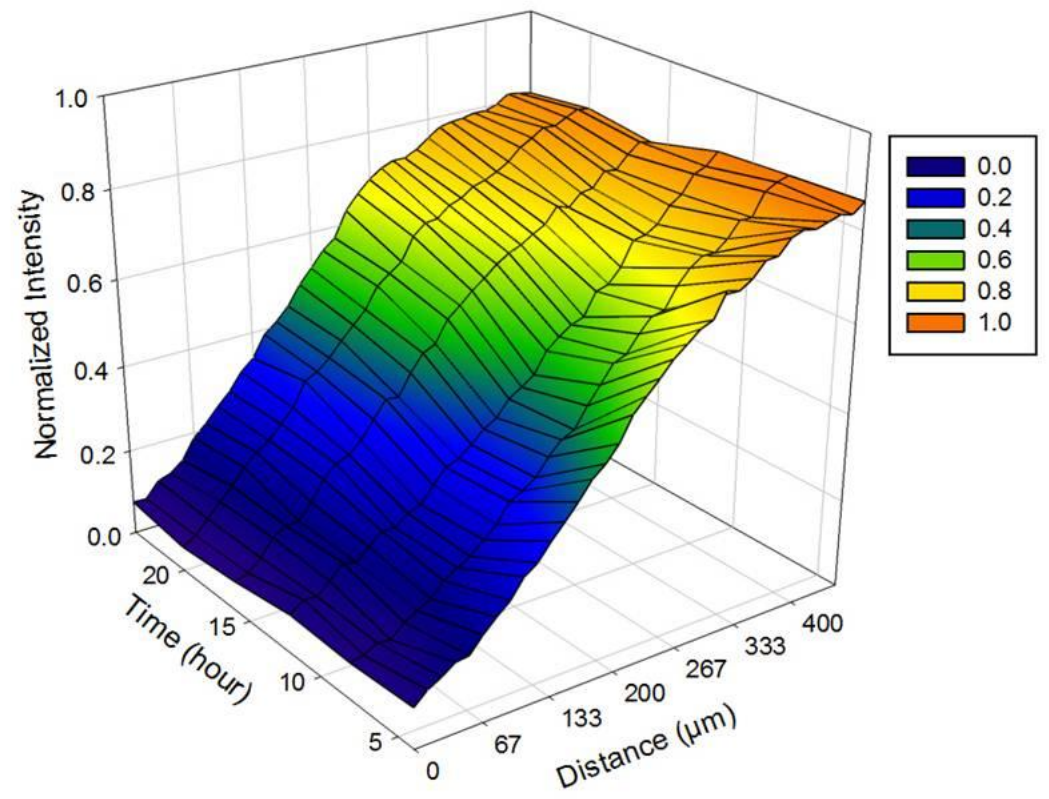

Figure 29. (A) Fluorescence image shows the gradient across one migration channel. Dashed white lines indicated the boundary of migration channel. Scale bar is $80 \mu \mathrm{m}$. (B) The time course 
of FITC-albumin gradient across the width of the channel. The normalized fluorescence intensities along the migration channel at different time were compared, showing a stable linear gradient through the migration channel.

As shown in the Figure 29, the gradient profile showed that a stable gradient was established after 4 hours and remained linear till the end of the experiment. Because of the reduced height in the migration channels, the fluidic resistance in these channels is high and further minimized the convective flow through the channels [4]. The gradient in the migration channels was generated mainly by diffusion [80]. 


\section{Chapter 6. Experiment Methods}

\subsection{Cell Culture and Chronic SWCNTs Exposure}

Human pleural mesothelial MeT5A cells were acquired from American Type Culture Collection (Manassas, VA) and maintained in M199 medium (Life Technologies, Grand Island, $\mathrm{NY}$ ) with 5\% FBS, $2 \mathrm{mM} \mathrm{L-glutamine,} 100 \mathrm{U} / \mathrm{mL}$ penicillin/streptomycin, $1 \mu \mathrm{g} / \mathrm{mL}$ EGF and 50 $\mu \mathrm{g} / \mathrm{mL}$ hydrocortisone. Cell cultures were performed in a humidified atmosphere of $5 \% \mathrm{CO}_{2}$ at $37^{\circ} \mathrm{C}$. SWCNTs, synthesized using high-pressure carbon monoxide disproportionate process (HiPCO), were obtained from Carbon Nanotechnology (CNI, Houston, TX). Elemental analysis of the supplied SWCNTs by nitric acid dissolution and inductively coupled plasma-atomic emission spectrometry (ICP-AES, NMAM \#7300) showed that SWCNTs were 99\% elemental carbon and contained less than $1 \% \mathrm{w} / \mathrm{w}$ of contaminants. Diameter and length distribution of dispersed SWCNT measured by field emission scanning electron microscopy (FESEM, model S4800; Hitachi, Tokyo, Japan) demonstrated $1.42 \mu \mathrm{m}$ mean length and $0.38 \mu \mathrm{m}$ mean width, respectively. Particles possessed surface areas between $400-1040 \mathrm{~m}^{2} / \mathrm{g}$.

The cells were continuously exposed to a sub-cytotoxic concentration $\left(0.02 \mu \mathrm{g} / \mathrm{cm}^{2}\right)$ of SWCNTs or vehicle for 4 months following the method previously described [81]. Briefly, 0.1 $\mathrm{mg} / \mathrm{mL}$ stocks of SWCNTs in phosphate buffer saline (PBS) containing $150 \mu \mathrm{g} / \mathrm{mL}$ Survanta ${ }^{\circledR}$ (Abbott Laboratories, Abbott Park, IL) were sonicated and diluted in media $(0.1 \mu \mathrm{g} / \mathrm{mL})$ prior to cell exposure. Cells were exposed to the dispersed particles every 3 days following a PBS wash and passaged once per week to initial seeding densities. 


\subsection{Long Term Imaging}

After sterilization, two microfluidic devices were coated with $50 \mu \mathrm{g} / \mathrm{mL}$ fibronectin for one hour at room temperature to enhance the cell attachment. After that, the fibronectin solution was replaced by serum free M199 medium and the devices were placed inside an incubator for warming up. Then, the chronic SWCNTs exposed human mesothelial cells $\left(1 \times 10^{6}\right.$ cells $\left./ \mathrm{mL}\right)$ were loaded into the seeding chamber in one device, and non-SWCNTs treated human mesothelial cells as control group were loaded into the other device. Both devices were kept in the incubator at $37{ }^{\circ} \mathrm{C}$ with $5 \% \mathrm{CO}_{2}$ for 2 hours for cell attachment. Finally, the devices were placed onto the microscope incubation stage for imaging.

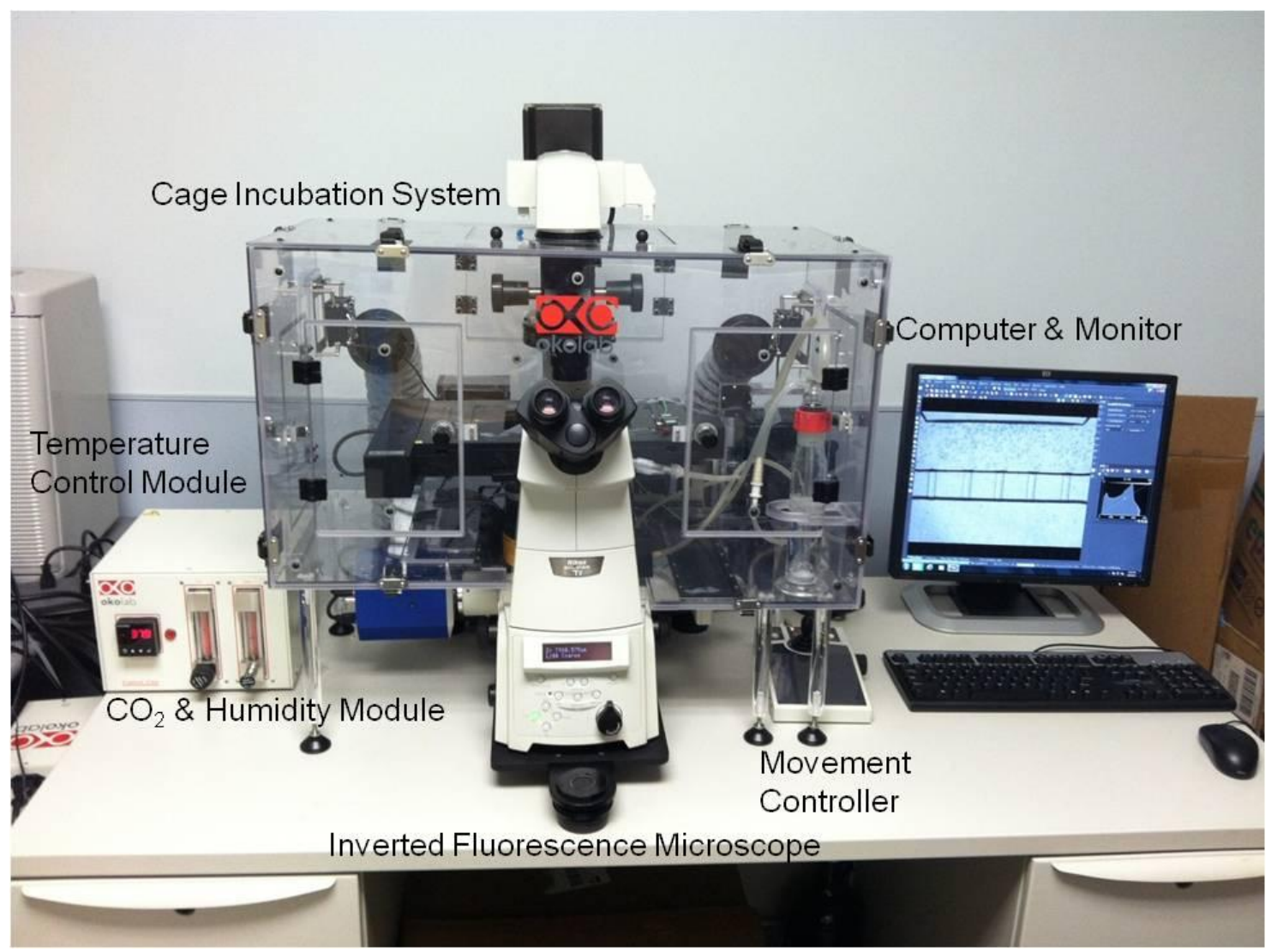

Figure 30. Real-time imaging system. Devices were placed on the stage in the cage incubation system. The movement of the stage was controlled by the controller equipped with the Nikon NIS Element software. Cells and device structures were shown and recorded in the monitor. 
A Nikon Eclipse Ti inverted fluorescence microscope (Japan) equipped with an OKOLab (Italy) Cage incubation system was used for the long-term and real-time imaging. The microscope is fully automated for imaging multiple positions in sequence and equipped with long working distance objectives and rapidly acquires high-resolution phase contrast and fluorescent real-time images. The cage incubator system includes an enclosure, a temperaturecontrol module, a $\mathrm{CO}_{2}$ and humidity modules, and a stage insert chamber. For each experiment, three positions, including one over the cell seeding chamber, one over the migration channel, and one over the cell receiving chamber, were imaged and tracked for each migration channel, and a total of 15 positions were recorded for each device. At each position, the bright field images were taken every 15 minutes for over 24 hours. The whole set up image is shown in Figure 30.

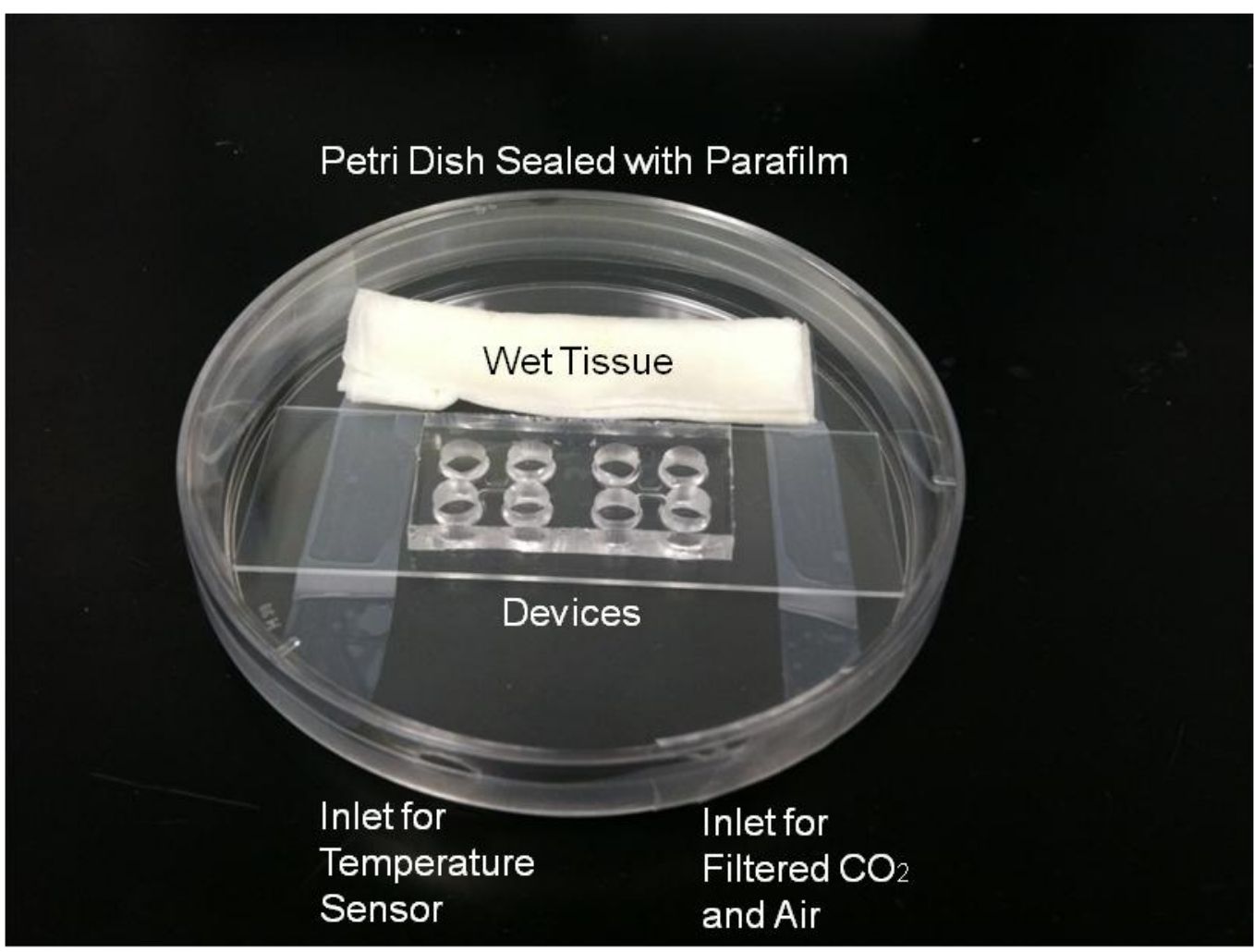

Figure 31. Devices in a sealed Petri dish. The Petri dish will be fixed on the stage for imaging.

Two devices bonded on one glass slide were put into a Petri dish and fixed with sterilized tape. A sterilized wet tissue was placed next to the devices to keep the environment inside the 
Petri dish humid. Two small holes were punched on the side wall of the Petri dish as inlets of the temperature sensor and source of filtered $\mathrm{CO}_{2}$ and air. Then the Petri dish was sealed with sterilized parafilm wrap (Parafilm, Neenah, WI), as shown in Figure 31. The Petri dish was placed on a holder in the stage of the cage incubator system and fixed with sterilized tape.

\subsection{Cell Movement Analysis}

ImageJ was used to track and analyze the cell movement. The MeT5A cells, which migrated the distance over two cell diameters (about $20 \mu \mathrm{m}$ ) from their original positions and kept moving along the gradient, were counted as exhibiting responses to the FBS gradient. The cells that remained within a $20 \mu \mathrm{m}$ radius of their original positions were excluded from the analysis, as were cells that stopped or detached from the substrate. For each cell that meets this requirement, the starting position, ending position, starting time and ending time were recorded. Cell displacement was the difference between the starting position and ending position. Cell migration velocity was calculated by dividing displacement by the time. Then the average velocity and standard error for all cells in one experiment were calculated.

For number of migrated cells, large images were taken before and after each experiment using image stitching technique supported by the Nikon NIS Element software. Basically, four images at 10X magnification at different positions were taken before (when cells were attached and media with $10 \%$ FBS was loaded into receiving chamber) and after each experiment (when the 24-hour experiment was ended). After image stitching, the large image covered the cell seeding chamber, cell receiving chamber and migration channels. The number of cells in the area of interests in the corresponding large images was counted. By finding the difference of cell numbers between prior-experiment and post-experiment images, the number of migrated cells were obtained for each experiment. 
The results for cell velocity and number of migrated cells were evaluated by the twotailed t-test and single factor analysis of variance (ANOVA). Each experiment was repeated for three times. 


\section{Chapter 7. Results and Discussion}

\subsection{Cell Morphological Changes}

Initially after the cells were loaded inside the devices, cells were kept in an incubator. It took $2 \sim 3$ hours for the cells to adhere on the fibronectin coated glass substrate. Most of the cells were flattened shape after adhesion as shown in Figure 32 (A) and (E). Prior to migration, elongated and spindle shaped cells were clearly observed as shown in Figure 32 (B) and (F). The result indicated that the cells needed to undergo morphological transition from the initial flattened shape in initial adhesion to spindle shape. The morphological transition was consistent with the conclusion of Lauffenburger [8] that cells must acquire spatial asymmetry by polarization prior to migration. This transition began at approximately 6 hours after the initial time point (Figure $32(\mathrm{~A})$ ). The morphological transition observed in our experiment was similar to the mesothelial cells' morphological change observed in vivo [78].

During the subsequent migration, the cells kept their elongated and spindle shapes and moved through the channels along the gradient direction (Figure $32(\mathrm{C})$ and $(\mathrm{G})$ ). Some cells showed considerably elongated shapes during their migration. After the cells migrated through the channel, the cells showed the random migration because of the uniform concentration of FBS in the receiving chamber. However, the cells (Figure 32 (D) and (H)) still kept their morphology similar to that shown in Figure 32 (B). Additionally, both the control cells and SWCNTs treated cells exhibited the similar migratory behaviors in their morphology as shown in Figure 32. 

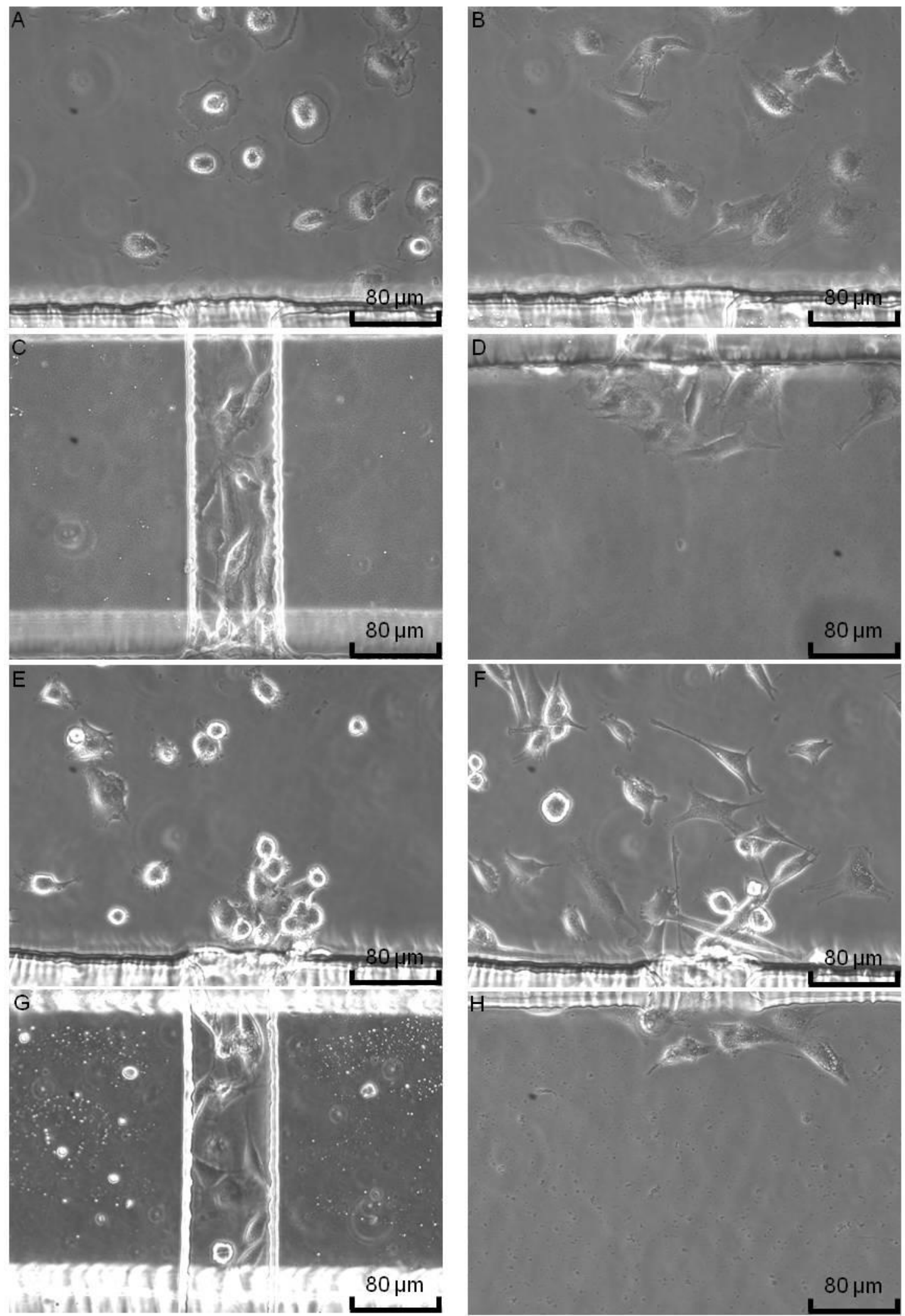

Figure 32. Cell morphologies at adhesion, prior to migration, during migration and after migration. A to D are control cells, E to H are SWCNTs treated cells. Most of the cells are 
flattened shape after adhesion, then they gradually turn to spindle shape prior to migration. (A) Control cell morphology after the initial adhesion. (B) Control cell morphology prior to their migration ( $\sim 6$ hours after adhesion). (C) Control cell morphology during migration. (D) Control cell morphology after migration. (E) SWCNTs treated cell morphology after initial adhesion. (F) SWCNTs treated cell morphology prior to migration. (G) SWCNTs treated cell during migration.

(H) SWCNTs treated cell after migration.

Conventional assays normally lack the ability to provide direct evidence to show the morphological changes during cell migration although it has been suggested that mesothelial cells need to undergo morphological transitions in response to inflammation or mesothelial injury $[82,83,84]$. Our microfluidic gradient device provides the technique and an experimental approach with direct observation of the dynamics of the morphological transition in mesothelial cell behavior as well as other types of cells.

\subsection{Migration Velocity}

Different concentrations of FBS, varying from $5 \%-20 \%$, were used to compare migratory behaviors between the SWCNTs treated and untreated MeT5A cells. FBS was used as the chemoattractant reagent because it contains a mixture of chemokines varying in size from $430 \mathrm{Da}$ to $13 \mathrm{kDa}$ and is widely used as the chemoattractant in Boyden chamber (Transwell cell migration assay) [85]. Previous work studied the effect of long-term exposure to high aspect ratio CNTs on the aggressive behaviors of human pleural mesothelial cells (MeT5A). Results indicated that SWCNTs induced accelerated cell growth and invasiveness [68].

As shown in Figure 33, cell velocities under different FBS concentration gradients for both control and treated cell groups were compared. In this thesis, the average velocity of MeT5A cells' movement without the FBS gradient (0\% FBS) was slower compared to the average velocity of the cells in the presence of the FBS gradient. With 5\% FBS concentration gradient, faster cell movement was observed but no significant different in velocities were found 
between control cells and SWCNTs treated cells (control 21.38 $\pm 1.24 \mu \mathrm{m} /$ hour, treated 22.22 $\pm 1.27 \mu \mathrm{m} /$ hour, $\mathrm{p}=0.64)$. Chronic SWCNTs exposed MeT5A cells demonstrated higher velocities under the 10\% FBS concentration compared to the control cells (control 9.74 \pm 1.66 $\mu \mathrm{m} /$ hour, treated $22.35 \pm 1.65 \mu \mathrm{m} /$ hour, $\mathrm{p}=0.04)$. At $15 \%$ and $20 \%$ FBS concentration gradients, the velocity of chronic SWCNTs exposed MeT5A cells movement was decreased compared to 5\% and 10\% FBS concentration gradients (5\%: $22.22 \pm 1.27 \mu \mathrm{m} /$ hour, $10 \%: 22.35 \pm 1.65 \mu \mathrm{m} /$ hour, 15\%: $19.89 \pm 1.20 \mu \mathrm{m} /$ hour, and $20 \%: 13.03 \pm 0.96 \mu \mathrm{m} / \mathrm{hour})$. Compared to other FBS concentration gradients, significantly slower movement of SWCNT-exposed cells under $20 \%$ FBS concentration was observed $\left(\mathrm{p}=2.88 \times 10^{-8}, 1.29 \times 10^{-6}, 1.12 \times 10^{-5}\right.$ when compared to $5 \%, 10 \%$ and 15\% FBS experiments, respectively). Additionally, chronic SWCNT-exposed cells demonstrated slower velocities than control cells under 15\% and 20\% FBS concentration gradients.

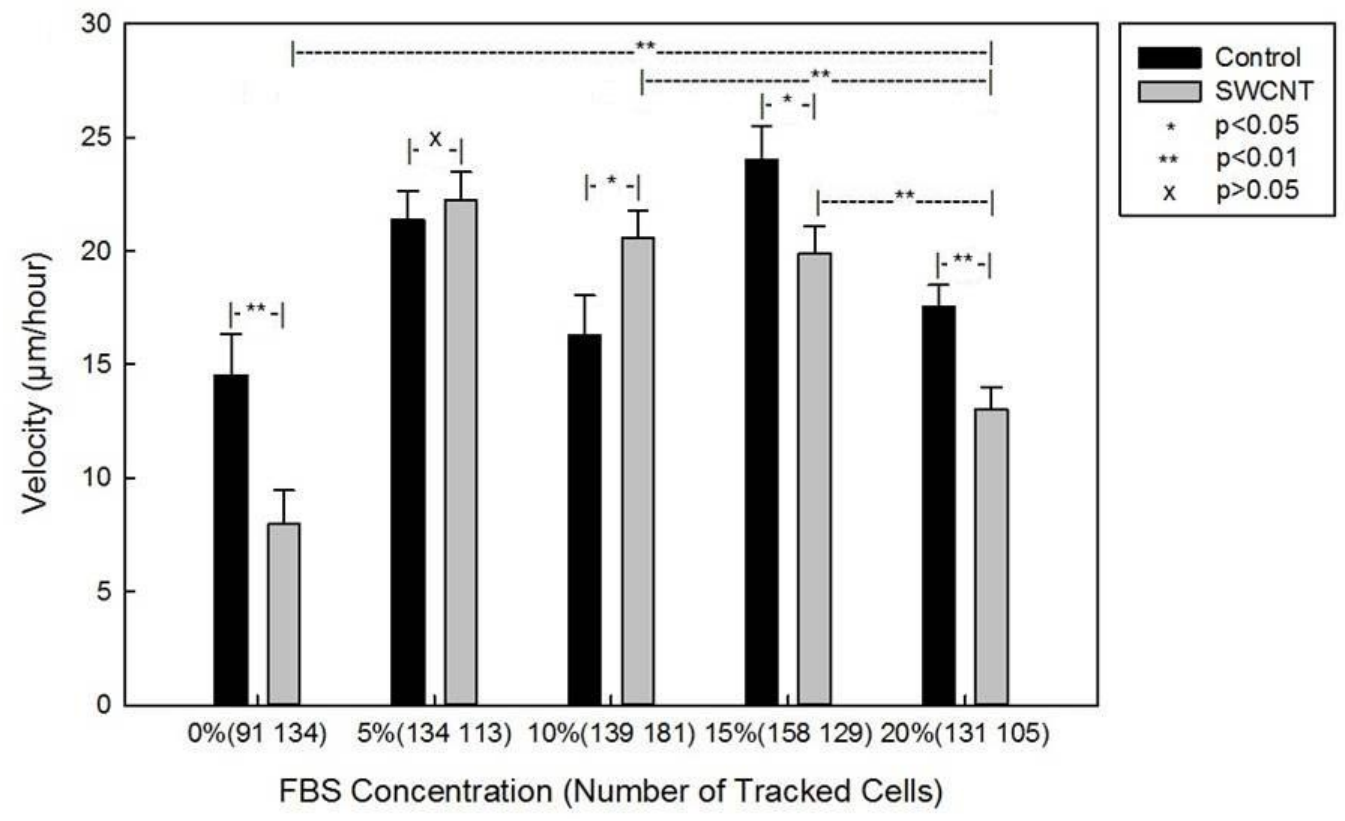

Figure 33. Average velocities of cell migration under different FBS concentration gradient for both control and treated cell groups with standard error bars. P values are marked between same group and different groups. 
The velocities observed in this thesis are consistent with the speed observed and reported in in vivo animal experiment previously, which stated that the velocities of most migrated mesothelial cells were between $6 \mu \mathrm{m} /$ hour to $24 \mu \mathrm{m} /$ hour with an average velocity of 14 $\mu \mathrm{m} /$ hour [78].

\subsection{Number of Migrated Cells}

Data for the number of migrated cells was extracted and compared for each FBS concentration. Four images covering the whole device were taken at the beginning and the end of each experiment, respectively. Then the four images were combined into one large image using image stitching technique supported by the Nikon NIS Element software, in which cell numbers and distribution could be clearly identified and counted. Number of migrated cells were analyzed and compared based on large images. Difference in cell distribution was clearly shown in Figure 34, where more cells were observed in the migration channels and the cell receiving chamber at the end of the experiment.

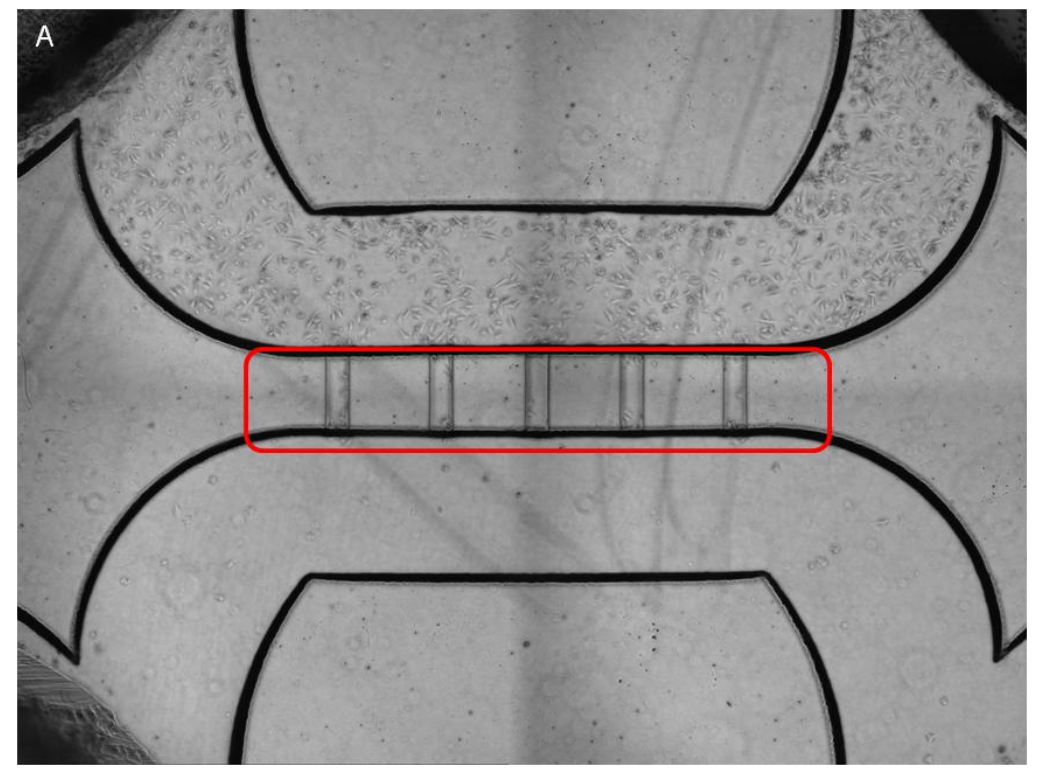




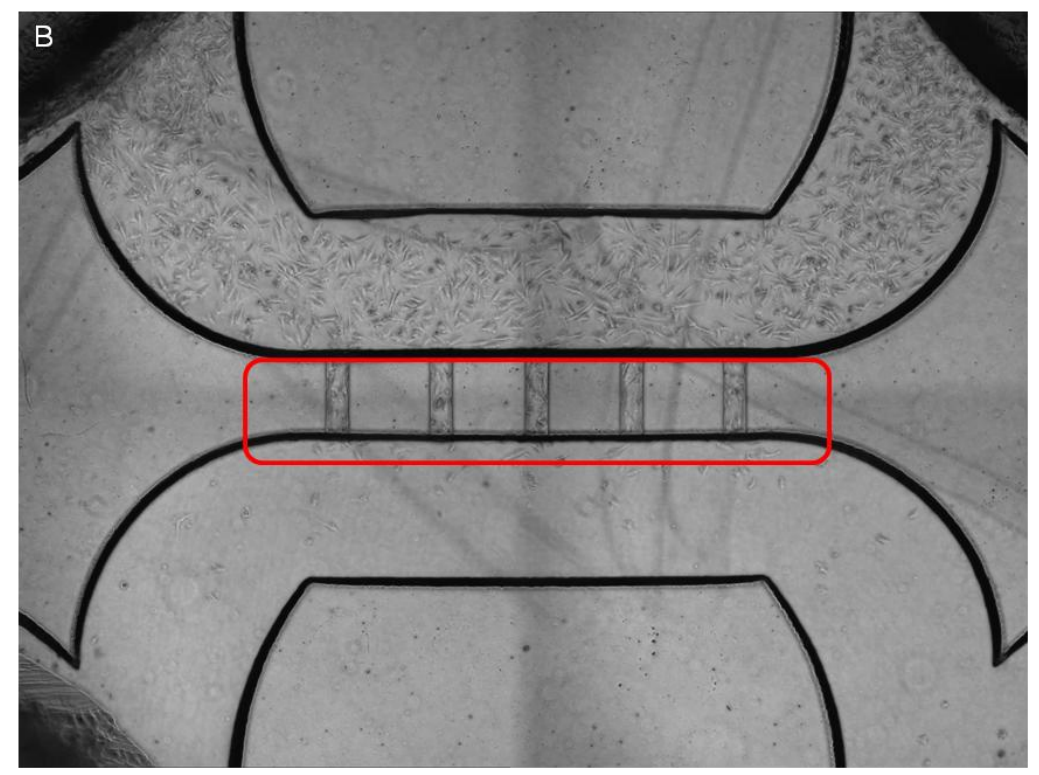

Figure 34. Large images showing cell distributions at the beginning and the end of the experiment. (A) At the beginning of the experiment, most cells were in the cell seeding chamber.

A small portion of cells were in the migration channels. (B) After 24 hours, more cells were observed in the migration channels. Some cells have migrated through the migration channels to the cell receiving chamber.

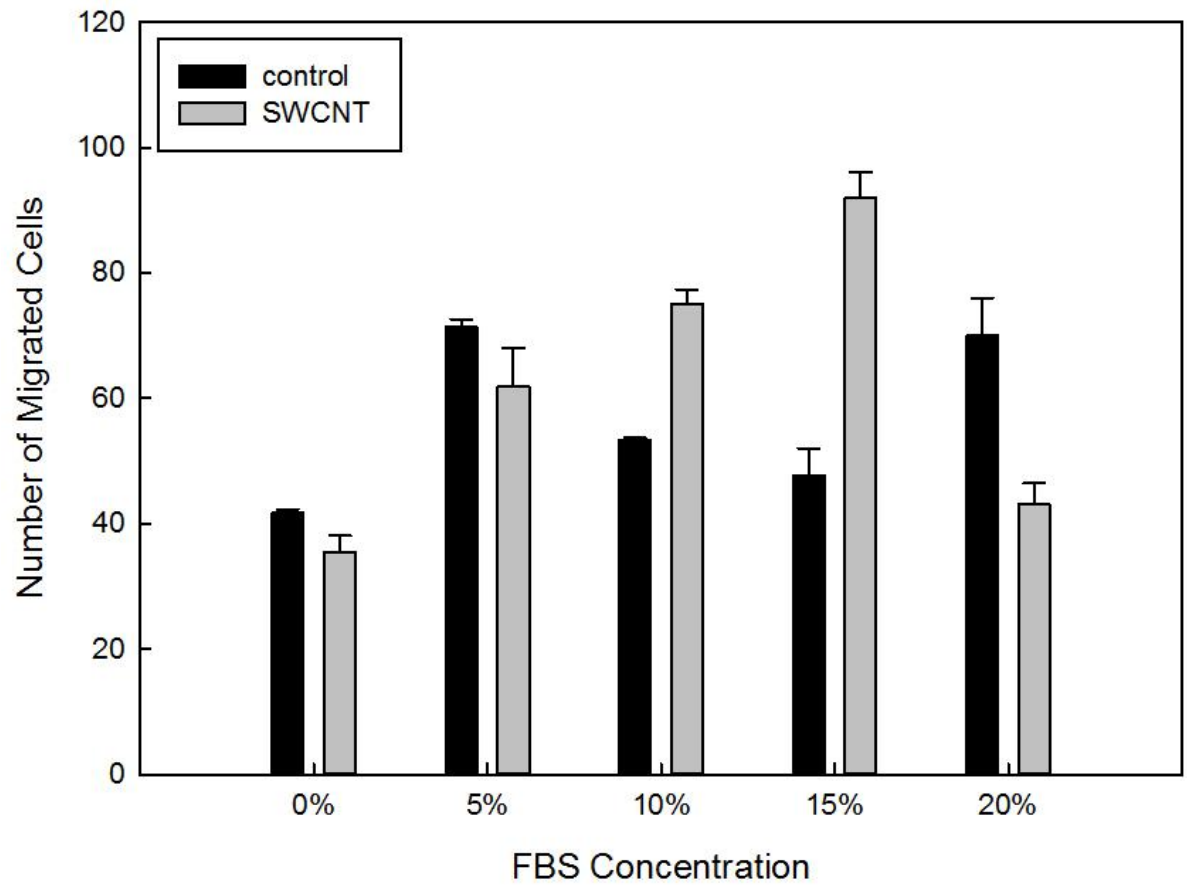

Figure 35. Average number of migrated cells under different FBS concentration gradients for both control and treated cell groups. 
Compared to the non-FBS condition, increased number of the migrated cells in the presence of FBS was observed in both SWCNT-exposed and control cells. For SWCNT-exposed cells, the number of migrated cells was increased with increasing FBS concentration of gradients. For control cells, the maximum number of migrated cells was observed in the experiment of 5\% FBS concentration gradient, and then the number of migration cells gradually decreased when FBS concentration of gradients at $10 \%$ and $15 \%$ (Figure 35). Compared between the SWCNTexposed cells and the control cells, no significant difference in the number of migrated cells were found in the experiment with 5\% FBS concentration of gradient (control: 71.33, SWCNT-treated: 62). More SWCNTs chronic exposed MeT5A cells migrated under the $10 \%$ and $15 \%$ FBS concentration of gradients, respectively (10\% FBS: control 53.33, SWCNTs-exposed 75; $15 \%$ FBS: control 47.67, SWCNTs-exposed: 92). 


\section{Chapter 8. Conclusions and Future Work}

\subsection{Conclusion}

Pleural mesothelial cells migration plays a crucial role in the process of malignant pleural mesothelioma, which is most common cancer of all malignant mesothelioma cases. High aspect ratio CNTs have the potential to contribute to mesothelioma pathogenicity. In this thesis, a microfluidic gradient device for studying the migration of mesothelial cells and the effects of chronic exposure to SWCNTs on their migration was designed and fabricated. Different concentrations of FBS $(5 \%, 10 \%, 15 \%$ and $20 \%)$ were tested as chemoattractant to evaluate the motility and morphology of pleural mesothelial cells. The average velocity of chronic SWCNTs exposed cells was faster with the presence of FBS compared to non-FBS ( $0 \%$ FBS). The velocity decreased as the FBS concentration increased from $5 \%$ to $20 \%$. The velocity for chronic SWCNTs treated cells was faster than control group cells with 5\% and 10\% FBS. It was slower at $15 \%$ and $20 \%$ FBS concentration gradients. Increased number of migrated cells in the presence of FBS was observed in both SWCNT treated and control cells compared to no FBS condition. For chronic SWCNT treated cells, the number of migrated cells was increased with increasing FBS concentration of gradients. For control cells, the maximum number of migrated cells was observed in the experiment of 5\% FBS concentration gradient. The number of migration cells decreased when FBS concentration of gradients at $10 \%$ and $15 \%$.

The results showed that chronic exposure of human pleural mesothelial cells to SWCNTs induced cell transformation with cancer-like properties such as rapid growth and increased cell migration with the presence of $10 \%$ FBS as the chemoattractant. 
The microfluidic approach demonstrated in this thesis is able to provide real-time observation of the dynamic behaviors of the pleural mesothelial cells in the responses to chemical gradients as well as quantify their migration velocities under different gradient conditions. Large reservoirs in the device were capable of providing enough media for long-term experiment and imaging. The device's simple structure was convenient for device fabrication and cell/media loading. The presented microfluidic gradient device will be applicable to study other types of adhesion cells in which gradient generated by non-shear flow condition may be more preferable.

\subsection{Future Work}

More experiments regarding cell migration velocity and number of migrated cells need to be done with the microfluidic device that can provide different gradient steepness. New patterns that can facilitate cell loading and cell attachment need to be designed and tested. Cell morphological changes regarding protrusive force and contractile force need to be further analyzed. 


\section{References}

${ }^{1}$ Nie, F. Q., Yamada, M., Kobayashi, J., Yamato, M., Kikuchi, A., \& Okano, T. (2007). On-chip cell migration assay using microfluidic channels. Biomaterials, 28(27), 4017-4022.

2 Mark, K., Schöber, S., \& Goodman, S. L. (1999). Integrins in cell migration. Integrin Protocols, 219-230. Humana Press.

${ }^{3}$ Cho, S. Y., \& Klemke, R. L. (2000). Extracellular-regulated kinase activation and CAS/Crk coupling regulate cell migration and suppress apoptosis during invasion of the extracellular matrix. The Journal of Cell Biology, 149(1), 223-236.

${ }^{4}$ Bozzuto, G., Ruggieri, P., \& Molinari, A. (2010). Molecular aspects of tumor cell migration and invasion. Annali Dell'Istituto Superiore Di SanitÃ, 46(1), 66-80.

${ }^{5}$ Ridley, A. J., Schwartz, M. A., Burridge, K., Firtel, R. A., Ginsberg, M. H., Borisy, G, Parsons, J. T. \& Horwitz, A. R. (2003). Cell migration: integrating signals from front to back. Science, 302(5651), 1704-1709.

6 Buddhini Samarasinghe, http://blogs.scientificamerican.com/guest-blog/2013/10/30/thehallmarks-of-cancer-6-tissue-invasion-and-metastasis/

${ }^{7}$ Alexandre Saez, http://commons.wikimedia.org/wiki/File:Four_steps_of_cell_migration.png

${ }^{8}$ Lauffenburger, D. A., \& Horwitz, A. F. (1996). Cell migration: a physically integrated molecular process. Cell, 84(3), 359-369.

${ }^{9}$ Mogilner, A., \& Oster, G. (2003). Force generation by actin polymerization II: the elastic ratchet and tethered filaments. Biophysical Journal, 84(3), 1591-1605.

${ }^{10}$ Fournier, M. F., Sauser, R., Ambrosi, D., Meister, J. J., \& Verkhovsky, A. B. (2010). Force transmission in migrating cells. The Journal of Cell Biology,188(2), 287-297.

11 Boyden, S. (1962). The chemotactic effect of mixtures of antibody and antigen on polymorphonuclear leucocytes. The Journal of Experimental Medicine,115(3), 453-466.

12 Zicha, D., Dunn, G. A., \& Brown, A. F. (1991). A new direct-viewing chemotaxis chamber. Journal of Cell Science, 99(4), 769-775.

${ }^{13}$ Zigmond, S. H. (1977). Ability of polymorphonuclear leukocytes to orient in gradients of chemotactic factors. The Journal of Cell Biology, 75(2), 606-616. 
${ }^{14}$ Zahm, J. M., Kaplan, H., Hérard, A. L., Doriot, F., Pierrot, D., Somelette, P., \& Puchelle, E. (1997). Cell migration and proliferation during the in vitro wound repair of the respiratory epithelium. Cell Motility and the Cytoskeleton, 37(1), 33-43.

${ }^{15}$ Pratt, B. M., Harris, A. S., Morrow, J. S., \& Madri, J. A. (1984). Mechanisms of cytoskeletal regulation. Modulation of aortic endothelial cell spectrin by the extracellular matrix. The American Journal of Pathology, 117(3), 349.

${ }^{16}$ Nelson, R. D., Quie, P. G., \& Simmons, R. L. (1975). Chemotaxis under agarose: a new and simple method for measuring chemotaxis and spontaneous migration of human polymorphonuclear leukocytes and monocytes. The Journal of Immunology, 115(6), 1650-1656.

17 Giaever, I., \& Keese, C. R. (1991). Micromotion of mammalian cells measured electrically. Proceedings of the National Academy of Sciences, 88(17), 7896-7900.

${ }^{18}$ Gundersen, R. W., \& Barrett, J. N. (1979). Neuronal chemotaxis: chick dorsal-root axons turn toward high concentrations of nerve growth factor. Science,206(4422), 1079-1080.

${ }^{19} \mathrm{http}: / / \mathrm{www}$. laboratoryresource.com/getitem.php?id=119

${ }^{20} \mathrm{http}$ //www.neuroprobe.com/product/neuro-probe-zigmond-chamber/

${ }^{21}$ Wang, L., Zhu, J., Deng, C., Xing, W. L., \& Cheng, J. (2008). An automatic and quantitative on-chip cell migration assay using self-assembled monolayers combined with real-time cellular impedance sensing. Lab on a Chip, 8(6), 872-878.

22 http://publish.uwo.ca/ bdonglin/research.html

${ }^{23}$ Yarrow, J. C., Perlman, Z. E., Westwood, N. J., \& Mitchison, T. J. (2004). A high-throughput cell migration assay using scratch wound healing, a comparison of image-based readout methods. BMC biotechnology, 4(1), 21-29.

${ }^{24}$ Rodriguez, L. G., Wu, X., \& Guan, J. L. (2005). Wound-healing assay. Cell Migration, 23-29. Humana Press.

${ }^{25}$ Heit, B., \& Kubes, P. (2003). Measuring chemotaxis and chemokinesis: the under-agarose cell migration assay. Science Signaling, 2003(170).

${ }^{26}$ Chung, S., Sudo, R., Vickerman, V., Zervantonakis, I. K., \& Kamm, R. D. (2010). Microfluidic platforms for studies of angiogenesis, cell migration, and cell-cell interactions. Annals of Biomedical Engineering, 38(3), 1164-1177. 
${ }^{27}$ Whitesides, G. M. (2006). The origins and the future of microfluidics. Nature,442(7101), 368373.

${ }^{28}$ http://en.wikipedia.org/wiki/Microfluidics

${ }^{29}$ Batchelor, G. K. (2000). An introduction to fluid dynamics. Cambridge university press.

${ }^{30}$ Choban, E. R., Markoski, L. J., Wieckowski, A., \& Kenis, P. J. (2004). Microfluidic fuel cell based on laminar flow. Journal of Power Sources, 128(1), 54-60.

31 Thorsen, T., Roberts, R. W., Arnold, F. H., \& Quake, S. R. (2001). Dynamic pattern formation in a vesicle-generating microfluidic device. Physical Review Letters, 86(18), 4163-4166.

${ }^{32}$ Ricart, B. G., John, B., Lee, D., Hunter, C. A., \& Hammer, D. A. (2011). Dendritic cells distinguish individual chemokine signals through CCR7 and CXCR4. The Journal of Immunology, 186(1), 53-61.

${ }^{33}$ Gervais, T., \& Jensen, K. F. (2006). Mass transport and surface reactions in microfluidic systems. Chemical Engineering Science, 61(4), 1102-1121.

${ }^{34}$ Hofmann, O., Voirin, G., Niedermann, P., \& Manz, A. (2002). Three-dimensional microfluidic confinement for efficient sample delivery to biosensor surfaces. Application to immunoassays on planar optical waveguides. Analytical Chemistry, 74(20), 5243-5250.

35 Erickson, D., Sinton, D., \& Li, D. (2003). Joule heating and heat transfer in poly (dimethylsiloxane) microfluidic systems. Lab on a Chip, 3(3), 141-149.

36 Gurdon, J. B., \& Bourillot, P. Y. (2001). Morphogen gradient interpretation. Nature, 413(6858), 797-803.

${ }^{37}$ Meyvantsson, I., \& Beebe, D. J. (2008). Cell culture models in microfluidic systems. Annu. Rev. Anal. Chem., 1, 423-449.

${ }^{38}$ Irimia, D., Liu, S. Y., Tharp, W. G., Samadani, A., Toner, M., \& Poznansky, M. C. (2006). Microfluidic system for measuring neutrophil migratory responses to fast switches of chemical gradients. Lab on a Chip, 6(2), 191-198.

${ }^{39}$ Walker, G. M., Sai, J., Richmond, A., Stremler, M., Chung, C. Y., \& Wikswo, J. P. (2005). Effects of flow and diffusion on chemotaxis studies in a microfabricated gradient generator. Lab on a Chip, 5(6), 611-618.

${ }^{40}$ Kim, S., Kim, H. J., \& Jeon, N. L. (2010). Biological applications of microfluidic gradient devices. Integrative Biology, 2(11-12), 584-603. 
${ }^{41}$ Abhyankar, V. V., Lokuta, M. A., Huttenlocher, A., \& Beebe, D. J. (2006). Characterization of a membrane-based gradient generator for use in cell-signaling studies. Lab on a Chip, 6(3), 389393.

${ }^{42}$ Traore, M. A., \& Behkam, B. (2013). A PEG-DA microfluidic device for chemotaxis studies. Journal of Micromechanics and Microengineering, 23(8).

${ }^{43}$ Jeon, N. L., Dertinger, S. K., Chiu, D. T., Choi, I. S., Stroock, A. D., \& Whitesides, G. M. (2000). Generation of solution and surface gradients using microfluidic systems. Langmuir, 16(22), 8311-8316.

${ }^{44}$ Dertinger, S. K., Chiu, D. T., Jeon, N. L., \& Whitesides, G. M. (2001). Generation of gradients having complex shapes using microfluidic networks. Analytical Chemistry, 73(6), 1240-1246.

${ }^{45}$ Irimia, D., Geba, D. A., \& Toner, M. (2006). Universal microfluidic gradient generator. Analytical Chemistry, 78(10), 3472-3477.

${ }^{46}$ Liu, Y., Sai, J., Richmond, A., \& Wikswo, J. P. (2008). Microfluidic switching system for analyzing chemotaxis responses of wortmannin-inhibited HL-60 cells. Biomedical Microdevices, 10(4), 499-507.

${ }^{47}$ Wu, H., Huang, B., \& Zare, R. N. (2006). Generation of complex, static solution gradients in microfluidic channels. Journal of the American Chemical Society, 128(13), 4194-4195.

${ }^{48}$ Keenan, T. M., Frevert, C. W., Wu, A., Wong, V., \& Folch, A. (2010). A new method for studying gradient-induced neutrophil desensitization based on an open microfluidic chamber. Lab on a Chip, 10(1), 116-122.

${ }^{49}$ Saadi, W., Rhee, S. W., Lin, F., Vahidi, B., Chung, B. G., \& Jeon, N. L. (2007). Generation of stable concentration gradients in $2 \mathrm{D}$ and $3 \mathrm{D}$ environments using a microfluidic ladder chamber. Biomedical Microdevices, 9(5), 627-635.

${ }^{50}$ Mosadegh, B., Huang, C., Park, J. W., Shin, H. S., Chung, B. G., Hwang, S. K., Lee, K. H., Kim, H. J., Brody, J., \& Jeon, N. L. (2007). Generation of stable complex gradients across twodimensional surfaces and three-dimensional gels. Langmuir, 23(22), 10910-10912.

${ }^{51}$ Frevert, C. W., Boggy, G., Keenan, T. M., \& Folch, A. (2006). Measurement of cell migration in response to an evolving radial chemokine gradient triggered by a microvalve. Lab on a Chip, 6(7), 849-856. 
52 Xia, Y., \& Whitesides, G. M. (1998). Soft lithography. Annual Review of Materials Science, 28(1), 153-184.

${ }^{53} \mathrm{http}: / /$ sharedresearchfacilities.wvu.edu/r/download/158738

${ }^{54}$ Mutsaers, S. E. (2002). Mesothelial cells: their structure, function and role in serosal repair. Respirology, 7(3), 171-191.

${ }^{55}$ Martin, J., Yung, S., Robson, R. L., Steadman, R., \& Davies, M. (2000). Production and regulation of matrix metalloproteinases and their inhibitors by human peritoneal mesothelial cells. Peritoneal Dialysis International, 20(5), 524-533.

${ }^{56}$ Valle, M. T., Degl'Innocenti, M. L., Bertelli, R., Facchetti, P., Perfumo, F., Fenoglio, D., Kunkl, A., Gusmano, R., \& Manca, F. (1995). Antigen-presenting function of human peritoneum mesothelial cells. Clinical \& Experimental Immunology, 101(1), 172-176.

${ }^{57}$ Yung, S., Li, F. K., \& Chan, T. M. (2006). Peritoneal mesothelial cell culture and biology. Peritoneal Dialysis International, 26(2), 162-173.

${ }^{58}$ Adam, H., Wojciech, D., Marzanna, O., Ewa, M., Ewa, D. K., \& Lech, C. (2010). Peritoneal cell response during adhesion formation. Journal of Investigative Surgery, 23(5), 267-272.

${ }^{59}$ Sitter, T., Spannagl, M., Schiffl, H., Held, E., Van Hinsbergh, V. W. M., \& Kooistra, T. (1995). Imbalance between intraperitoneal coagulation and fibrinolysis during peritonitis of CAPD patients: the role of mesothelial cells. Nephrology Dialysis Transplantation, 10(5), 677-683.

${ }^{60}$ Ren, J., Xiao, Y. J., Singh, L. S., Zhao, X., Zhao, Z., Feng, L., Rose, T.M., Prestwich, G.D., \& $\mathrm{Xu}$, Y. (2006). Lysophosphatidic acid is constitutively produced by human peritoneal mesothelial cells and enhances adhesion, migration, and invasion of ovarian cancer cells. Cancer Research, 66(6), 3006-3014.

${ }^{61} \mathrm{http}: / /$ www.mesotheliomacenter.org/about/mesothelioma.php

${ }^{62}$ Kaufman, A. J., \& Flores, R. M. (2011). Surgical treatment of malignant pleural mesothelioma. Current Treatment Options in Oncology, 12(2), 201-216.

${ }^{63}$ Bridda, A., Padoan, I., Mencarelli, R., \& Frego, M. (2007). Peritoneal mesothelioma: a review. Medscape General Medicine, 9(2), 32.

${ }^{64}$ Carbone, M., Kratzke, R. A., \& Testa, J. R. (2002). The pathogenesis of mesothelioma. Seminars in Oncology, 29(1), 2-17. 
${ }^{65}$ Foldvari, M., \& Bagonluri, M. (2008). Carbon nanotubes as functional excipients for nanomedicines: I. Pharmaceutical properties. Nanomedicine: Nanotechnology, Biology and Medicine, 4(3), 173-182.

${ }^{66} \mathrm{http}: / /$ en.wikipedia.org/wiki/Carbon_nanotube

${ }^{67}$ Shvedova, A. A., Kisin, E. R., Porter, D., Schulte, P., Kagan, V. E., Fadeel, B., \& Castranova, V. (2009). Mechanisms of pulmonary toxicity and medical applications of carbon nanotubes: two faces of Janus? Pharmacology \& Therapeutics, 121(2), 192-204.

${ }^{68}$ Lohcharoenkal, W., Wang, L., Stueckle, T. A., Dinu, C. Z., Castranova, V., Liu, Y., \& Rojanasakul, Y. (2013). Chronic Exposure to Carbon Nanotubes Induces Invasion of Human Mesothelial Cells through Matrix Metalloproteinase-2. ACS nano, 7(9), 7711-7723.

${ }^{69}$ Ferro, G., Tulliani, J. M., \& Musso, S. (2011). Carbon nanotubes cement composites. Frattura e Integrita Strutturale, 18, 34-44.

${ }^{70}$ Bloise, A., Fornero, E., Belluso, E., Barrese, E., \& Rinaudo, C. (2008). Synthesis and characterization of tremolite asbestos fibres. European Journal of Mineralogy, 20(6), 1027-1033 ${ }^{71}$ Chou, C. C., Hsiao, H. Y., Hong, Q. S., Chen, C. H., Peng, Y. W., Chen, H. W., \& Yang, P. C. (2008). Single-walled carbon nanotubes can induce pulmonary injury in mouse model. Nano Letters, 8(2), 437-445.

72 Lam, C. W., James, J. T., McCluskey, R., \& Hunter, R. L. (2004). Pulmonary toxicity of single-wall carbon nanotubes in mice 7 and 90 days after intratracheal instillation. Toxicological Sciences, 77(1), 126-134.

${ }^{73}$ Muller, J., Huaux, F., Moreau, N., Misson, P., Heilier, J. F., Delos, M., Arras, M., Fonseca, A., Nagy, J.B., \& Lison, D. (2005). Respiratory toxicity of multi-wall carbon nanotubes. Toxicology and Applied Pharmacology, 207(3), 221-231.

${ }^{74}$ Elgrabli, D., Floriani, M., Abella-Gallart, S., Meunier, L., Gamez, C., Delalain, P., Rogerieux, F., Boczkowski, Jorge., \& Lacroix, G. (2008). Biodistribution and clearance of instilled carbon nanotubes in rat lung. Part Fibre Toxicol, 5, 20-32.

${ }^{75}$ Nasreen, N., Mohammed, K. A., Mubarak, K. K., Baz, M. A., Akindipe, O. A., FernandezBussy, S., \& Antony, V. B. (2009). Pleural mesothelial cell transformation into myofibroblasts and haptotactic migration in response to TGF- $\beta 1$ in vitro. American Journal of Physiology-Lung Cellular and Molecular Physiology, 297(1), L115-L124. 
${ }^{76}$ Zhong, J., Cornelsen Gencay, M. M., Bubendorf, L., Burgess, J. K., Parson, H., Robinson, B. W., Tamm, M., Black, J.L., \& Roth, M. (2006). ERK1/2 and p38 MAP kinase control MMP-2, MT1-MMP, and TIMP action and affect cell migration: A comparison between mesothelioma and mesothelial cells. Journal of Cellular Physiology,207(2), 540-552.

${ }^{77}$ Zolak, J. S., Jagirdar, R., Surolia, R., Karki, S., Oliva, O., Hock, T., Guroji, P., Ding, Q., Liu, R.M., Bolisetty, S., Agarwal, A., Thannickal, V.J., \& Antony, V. B. (2013). Pleural mesothelial cell differentiation and invasion in fibrogenic lung injury. The American Journal of Pathology, 182(4), 1239-1247.

${ }^{78}$ Nagai, H., Chew, S. H., Okazaki, Y., Funahashi, S., Namba, T., Kato, T., Enomoto, A., Jiang, L., Akatsuka, S., \& Toyokuni, S. (2013). Metamorphosis of mesothelial cells with active horizontal motility in tissue culture. Scientific Reports, 3, 1144-1150.

79 Wang, L., Luanpitpong, S., Castranova, V., Tse, W., Lu, Y., Pongrakhananon, V., \& Rojanasakul, Y. (2011). Carbon nanotubes induce malignant transformation and tumorigenesis of human lung epithelial cells. Nano Letters, 11(7), 2796-2803.

${ }^{80}$ Ngalim, S. H., Magenau, A., Zhu, Y., Tønnesen, L., Fairjones, Z., Gooding, J. J., Böcking, T., \& Gaus, K. (2013). Creating Adhesive and Soluble Gradients for Imaging Cell Migration with Fluorescence Microscopy. Journal of Visualized Experiments, 74, e50310-e50310.

${ }^{81}$ Wang, L., Stueckle, T. A., Mishra, A., Derk, R., Meighan, T., Castranova, V., \& Rojanasakul, Y. (2014). Neoplastic-like transformation effect of single-walled and multi-walled carbon nanotubes compared to asbestos on human lung small airway epithelial cells. Nanotoxicology, 8(5), 485-507.

${ }^{82}$ Whitaker, D., \& Papadimitriou, J. (1985). Mesothelial healing: morphological and kinetic investigations. The Journal of Pathology, 145(2), 159-175.

${ }^{83}$ Mutsaers, S. E., Whitaker, D., \& Papadimitriou, J. M. (2002). Stimulation of mesothelial cell proliferation by exudate macrophages enhances serosal wound healing in a murine model. The American journal of Pathology, 160(2), 681-692.

${ }^{84}$ Fotev, Z., Whitaker, D., \& Papadimitriou, J. M. (1987). Role of macrophages in mesothelial healing. The Journal of Pathology, 151(3), 209-219. 
${ }^{85}$ Breckenridge, M. T., Egelhoff, T. T., \& Baskaran, H. (2010). A microfluidic imaging chamber for the direct observation of chemotactic transmigration. Biomedical Microdevices, 12(3), 543553. 